Portland State University

PDXScholar

$1-1-2011$

\title{
Growth and Optical Characterization of Zinc Oxide Nanowires for Anti-reflection Coatings for Solar Cells
}

Martha Coakley

Portland State University

Follow this and additional works at: https://pdxscholar.library.pdx.edu/open_access_etds

Let us know how access to this document benefits you.

\section{Recommended Citation}

Coakley, Martha, "Growth and Optical Characterization of Zinc Oxide Nanowires for Anti-reflection Coatings for Solar Cells" (2011). Dissertations and Theses. Paper 290.

https://doi.org/10.15760/etd.290

This Thesis is brought to you for free and open access. It has been accepted for inclusion in Dissertations and Theses by an authorized administrator of PDXScholar. Please contact us if we can make this document more accessible: pdxscholar@pdx.edu. 


\title{
Growth and Optical Characterization of Zinc Oxide Nanowires for Anti-Reflection Coatings for Solar Cells
}

\author{
by
}

Martha Coakley

A thesis submitted in partial fulfillment of the requirements for the degree of

Masters of Science

in

Physics

Thesis Committee:

Rolf Könenkamp, Chair

Andres La Rosa

Andrew Rice

Portland State University

2011 


\begin{abstract}
The optical properties of solar cells greatly affect their efficiencies. Decreasing the broadband and directional reflectance of solar cells increases the solar irradiance transmitted and absorbed by the cell, thereby increasing the production of electron-hole pairs. Traditional optical enhancements such as light trapping and anti-reflection coatings reduce the reflectance of silicon at an optimized wavelength and angle of incidence. They do not perform as well at high angles of incidence or over the broadband solar spectrum. Theoretical studies suggest that layers with a suitable gradient-index of refraction can create both a broadband and directional anti-reflective coating. Through their variations in height and tapered growth, Zinc oxide $(\mathrm{ZnO})$ nanowires can create a gradient index anti-reflection coating. $\mathrm{ZnO}$ is a wide-band gap semiconductor that is non-absorbing over most of the solar spectrum. With low cost, low temperature techniques, $\mathrm{ZnO}$ nanowires can be grown with a variety of morphologies.
\end{abstract}

$\mathrm{ZnO}$ nanowires were grown by aqueous chemical growth and by electrodeposition on silicon to create a gradient-index anti-reflective coating for solar cell applications. The nanowire arrays were characterized using SEM images, goniometer scattering measurements, and integrating sphere total reflectance measurements. $\mathrm{ZnO}$ nanowires grown by aqueous chemical growth on silicon had average diameters between $60 \mathrm{~nm}$ and $100 \mathrm{~nm}$ and average lengths between $800 \mathrm{~nm}$ and $1100 \mathrm{~nm}$. The nanowires had vertical alignment. They exhibited relatively small diffuse reflectivities and relatively large specular reflectivities. $\mathrm{ZnO}$ nanowires grown by electrodeposition had greater variances in length and diameter, with average diameters between $85 \mathrm{~nm}$ and $180 \mathrm{~nm}$ and average lengths between $500 \mathrm{~nm}$ and $1200 \mathrm{~nm}$. Electrodeposited $\mathrm{ZnO}$ nanowires were randomly 
arrayed and exhibited relatively large diffuse reflectivities and relatively small specular reflectivities. Total reflectance measurements showed that all nanowire arrays reduced the broadband reflectance of silicon. Smaller nanowire arrays outperformed the larger crystal growths. A five-fold decrease in the broadband reflectance of silicon was obtained from both vertical and randomly oriented nanowire arrays. The reflectances were constant for angles of incident below $35^{\circ}$. Measurements at angles of incidence greater than $35^{\circ}$ are required to determine whether $\mathrm{ZnO}$ nanowires can perform as directional anti-reflective coatings and whether the morphology of the nanowires affects the directional reflectances. 


\section{ACKNOWLEDGEMENTS}

- The Green Building Laboratory, Department of Engineering, Portland State University, for the use of the Lambda 950 UV/VIS/NIR spectrometer with integrating sphere. Thank you to Dr. David Sailor, Matt Grooves, and Seth Moody for their time and assistance.

- Pacific Northwest National Laboratory, Richland, Washington, for the use of the Fluorolog III spectrometer with integrating sphere. The research was performed at EMSL, a national scientific user facility sponsored by the Department of Energy's Office of Biological and Environmental Research. Thank you to Dr. Zheming Wang for his assistance.

- Athavan Nadarajah for taking all SEM images presented in this report.

\section{Appreciation and thanks to the following individuals:}

- Dr. Rolf Koenenkamp for his expertise, guidance, and advice in this research.

- Dr. Andres LaRosa and Dr. Andrew Rice for their time and participation as part of the thesis committee.

- Athavan Nadarajah for his assistance in experimental growths and for his thoughtful advice.

- Dr. Robert Word for his insights and suggestions.

- Dr. James A. Coakley, Jr. for extensive editing and advice. 


\section{TABLE OF CONTENTS}

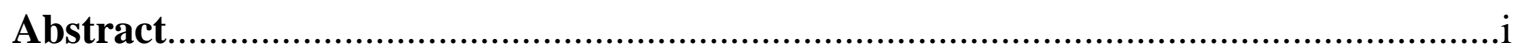

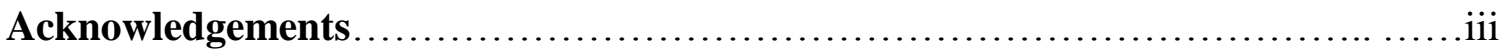

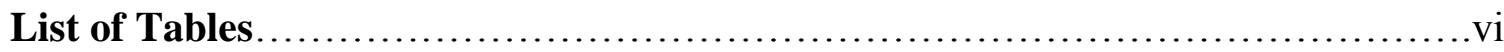

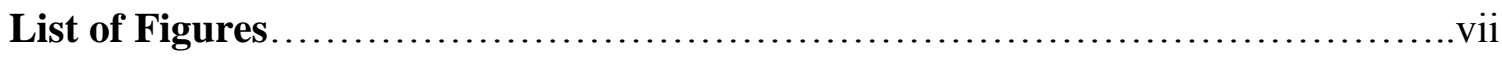

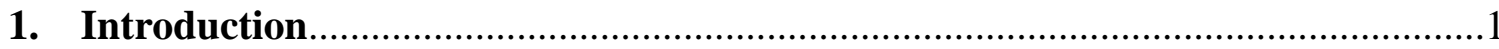

1.1 Optical enhancement for solar cells ........................................

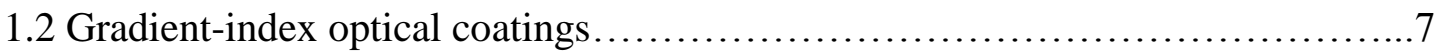

$1.3 \mathrm{ZnO}$ nanowires as anti-reflection coatings for solar cells....................... 9

1.4 Objectives of Research: Growth and characterization of $\mathrm{ZnO}$ nanowire arrays.. 11

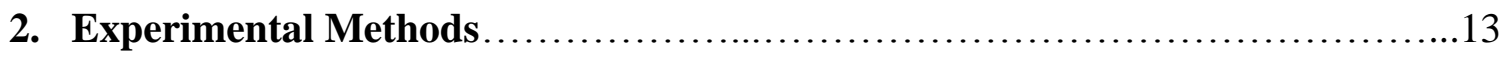

2.1 Growth of $\mathrm{ZnO}$ Nanowires.................................................

2.1.1 Aqueous Chemical Growth...........................................15

2.1.2 Electrodeposition................................................... 18

2.2 Optical Characterization of $\mathrm{ZnO}$ Nanowires................................21

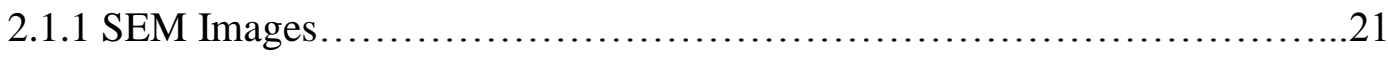

2.2.2 Goniometer.........................................................

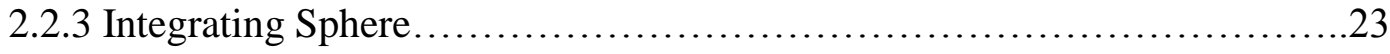

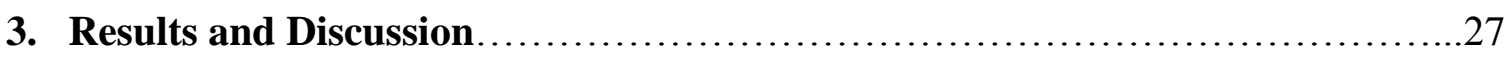

3.1 SEM images and Analysis of ZnO Nanowire Morphology......................27

3.1.1 Aqueous Chemical Growth........................................28

3.1.2 Electrodeposition................................................. 32 


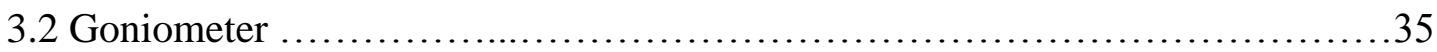

3.2.1 Introduction to Measurements..................................... 35

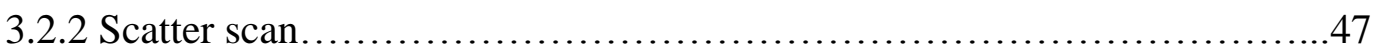

3.2.3 Angle Dependent Specular Reflectivity............................43

3.3 Integrating Sphere Measurements.....................................46

3.3.1 Introduction to Total Reflectance Measurements.......................47

3.3.2 Total Reflectance ..............................................55

3.3.3 Angular Dependent Reflectance....................................59

3.5 Theoretical Comparison................................................64

4. Summary of Results and Conclusions..................................68

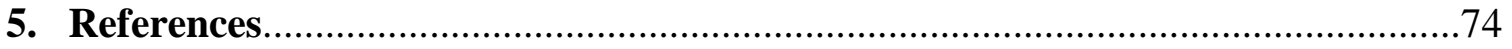

6. Appendices.......................................................... 78

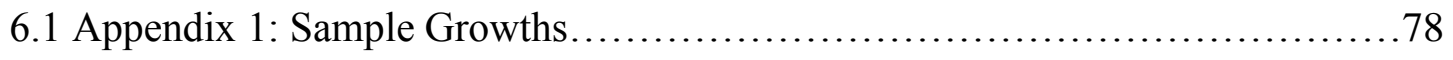

6.2 Appendix 2: Angle Dependent Reflectance Example.......................83

6.3 Appendix 3: Transfer Matrix Method MATLAB Code........................ 84 


\section{LIST OF TABLES}

Table 1. AR Coating Materials for Silicon: Single and Multilayer Coatings..............5

Table 2. Uniform ZnO Nanowires Grown on Silicon by ACG.......................30

Table 3. Electrodeposited ZnO Nanowires on ITO/Quartz ..........................32

Table 4. Electrodeposited $\mathrm{ZnO}$ Nanowires on ITO/Si at $-1.05 \mathrm{~V} \ldots \ldots \ldots \ldots \ldots \ldots . . . \ldots 34$

Table 5. Goniometer: Total Integrated Current and Reflectance......................42

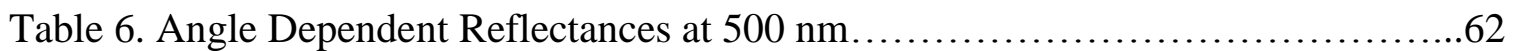

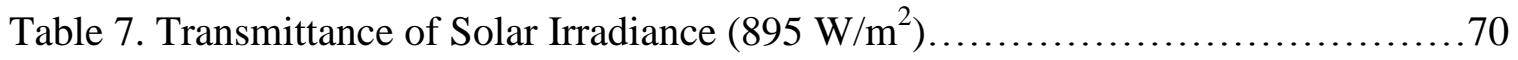




\section{LIST OF FIGURES}

Figure 1. Light trapping techniques for solar cells............................... 2

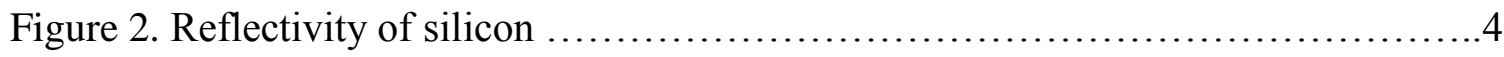

Figure 3. Boundary conditions for electromagnetic waves..........................4

Figure 4. Effectiveness of AR coatings on silicon...................................5

Figure 5. Gradient-index of refraction profile....................................... 8

Figure 6. Quintic profiles and corresponding broadband reflectivity...................9

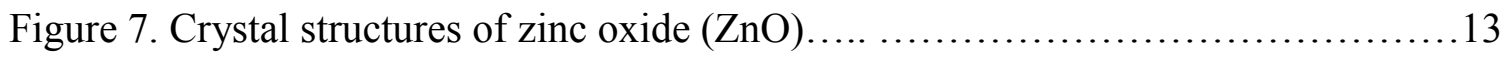

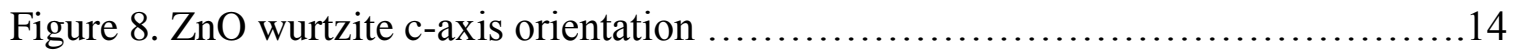

Figure 9. Experimental set-up for Aqueous Chemical Growth (ACG) .................17

Figure 10. Experimental set-up for electrodeposition of $\mathrm{ZnO}$ nanowires ...............19

Figure 11. Schematic of goniometer for reflectivity measurements....................22

Figure 12. Design of Lambda 950 UV/VIS/NIR $150 \mathrm{~mm}$ integrating sphere ............24

Figure 13. Fluorolog III 4 inch integrating sphere with sample holder .................25

Figure 14. SEM images of initial growth of $\mathrm{ZnO}$ nanowires grown by $\mathrm{ACG} \ldots \ldots \ldots \ldots \ldots . .28$

Figure 15. SEM images of zinc acetate seed layer sprays............................29

Figure 16. SEM images of vertical $\mathrm{ZnO}$ nanowires grown by ACG ..................29

Figure 17. Diameter, length and number density of $\mathrm{ZnO}$ nanowires grown by ACG... .31

Figure 18. SEM images of electrodeposited $\mathrm{ZnO}$ nanowires on ITO/silicon..............32

Figure 19. SEM images of sample I1, randomly oriented nanowires on ITO/silicon......33

Figure 20. SEM images of sample I3, large flower growth nanowires on ITO/silicon.....33

Figure 21. SEM images of sample I2, electrodeposited nanowires on $\mathrm{ZnO}$ on ITO/Si...34

Figure 22. Goniometer repeatability and variability scans of reflectivity $\ldots \ldots \ldots \ldots \ldots \ldots . \ldots 36$ 
Figure 23. Goniometer scatter scan for vertical $\mathrm{ZnO}$ nanowires grown by $\mathrm{ACG} . . . . . . .38$

Figure 24. Reflectivity repeatability measurements and spot variability.................38

Figure 25. Reflectivities of vertical $\mathrm{ZnO}$ nanowires compared to $\cos (\theta) \ldots \ldots \ldots \ldots \ldots . . . .39$

Figure 26. Reflecitivities of randomly oriented $\mathrm{ZnO}$ nanowires compared to $\cos (\theta) \ldots . .40$

Figure 27. Reflectivities of randomly oriented $\mathrm{ZnO}$ nanowire sample I1, I2 and A15...40

Figure 28. Geometry for goniometer integration................................41

Figure 29. Specular reflectivity of TE and TM waves for silicon, $n=3.95 \ldots \ldots \ldots \ldots .44$

Figure 30. Specular reflectivity of TE and TM waves for vertical sample A15 ........45

Figure 31. Specular reflectivity of TE and TM waves for electrodeposited samples.....46

Figure 32. Configuration for measurements on Lambda 950 integrating sphere ........48

Figure 33. Measured and theoretical reflectances of silicon and ITO/silicon............51

Figure 34. Reflectance of silicon, ITO silicon and sample A23 .....................51

Figure 35. Reflectance of silicon, ITO/silicon and sample A23 using sample holder......52

Figure 36. Reflectance comparison using modified sample holder..................53

Figure 37. Reflectance of white vinyl tape and use of tape in fitting parameters.........54

Figure 38. Reflectances of vertical $\mathrm{ZnO}$ nanowires grown in a $0.02 \mathrm{M}$ bath by ACG....55

Figure 39. SEM images of vertical nanowire samples A14, A15, and A16.............56

Figure 40. Reflectances of vertical nanowire variations, samples A20 and A22.........57

Figure 41. Reflectances of randomly arrayed $\mathrm{ZnO}$ nanowire samples I1, I2, and I3......58

Figure 42. Comparison of the lowest reflectances obtained for $\mathrm{ZnO}$ nanowires..........59

Figure 43. Internal configuration of Fluorolog III integrating sphere $\ldots \ldots \ldots \ldots \ldots \ldots \ldots . \ldots 0$

Figure 44. Angle dependent reflectance measurements of $\mathrm{ZnO}$ nanowires at $500 \mathrm{~nm} . . . .61$

Figure 45. Angle dependent reflectances for samples I2 and A19 .................62 
Figure 46. Analysis of SEM image for sample A14 to determine length variation ..... 63 Figure 47. Theoretical reflectances for 6- and 10-layer gradient-index profiles.........66 Figure 48. Reflectances of 10-layer gradient-index model with sample A15...........66 Figure 49. Spectral irradiance and relative reflectances of single layer AR coating

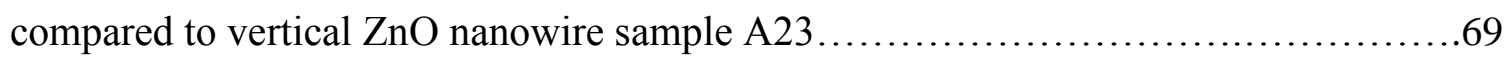

Figure 50. Ray tracing simulation of the absorptance and reflectance of silicon..........70 Figure 51. Reflectances of $\mathrm{ZnO}$ nanowires grown by Chen and Sun [24], and Lee et al. [25]. 


\section{Introduction}

Solar cells are at the forefront of alternative energy development. With a growth rate of close to $30 \%$, photovoltaic technology is considered one of the fastest growing fields, and in the face of fossil fuel shortages, the most viable future source of energy [1]. Solar cells generate energy when photons excite electron-hole pairs in a material. Electron-hole pairs are separated by a built in potential difference at a $p-n$ junction in a device, and are transported via electrical contacts to an external circuit.

Silicon, the most developed photovoltaic material, is reaching its theoretical limits for solar energy conversion. There is a focus on creating more efficient solar cells by creating multi-junction cells, using quantum-wells, and developing thin film cells that are less expensive and use fewer materials. A large element of solar cell improvement is creating cells that better exploit the solar spectrum. As photovoltaic technology enters its next generation of engineering and research, one important area of solar cell development is improving the optical properties of the cell.

The optical properties of a solar cell determine how much light enters the cell and thus, the quantity of light capable of generating an electron-hole pair. The sun movement and broadband solar spectrum provide a range of incident angles and wavelengths. Thus, improving optical properties optimizes the structure of the cell to admit light at a larger range of angles and energies.

The two conventional ways to improve the optical properties of solar cells are by light trapping and anti-reflection coatings. These methods increase the amount of light which enters a cell, but are limited in their ability to exploit the broadband spectrum or 
account for the movement of the sun. Using nanowires to create a gradient index antireflection coating will optimize the amount of solar radiation capable of entering a cell. A brief overview of light trapping techniques and anti-reflection coatings leads to the motivation for current research in the use of nanowires for anti-reflective coatings in solar cells.

\subsection{Optical enhancement for solar cells}

Silicon, the most developed photovoltaic material, has a relatively high reflectivity and poor absorption properties [2]. Light trapping structures and Antireflection (AR) coatings improve the efficiency of silicon solar cells by increasing the amount of light which enters and remains in the cell and thus able to generate an electronhole pair.

Light trapping structures are geometric structures such as pyramids or random Lambertian surfaces made on the silicon surface by etching or mechanical grooving. The randomization of light as it enters the solar cell causes it to be "trapped" by total internal reflection. Transmission into the cell is also enhanced by multiple reflections of light within the light trapping structure, shown in Figure 1a.

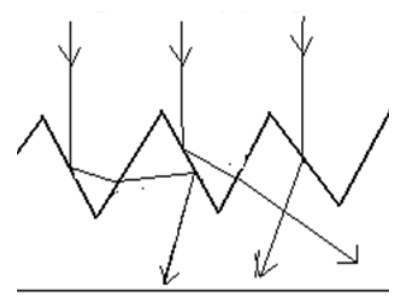

(a)

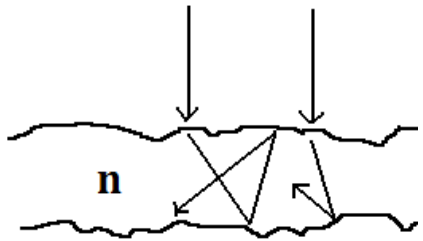

(b)

Figure 1. (a) Light trapping from multiple reflections of incoming light and total internal reflection. (b) Pathlength enhancement with a Lambertian surface. 
Lambertian surfaces, considered to be any non-periodic rough scattering surface, can theoretically enhance the path-length of light inside a material by $4 n^{2}$, where $n$ is the index of refraction of the material [3]. The path-length enhancement can be derived using geometric optics or statistical mechanics, and is modeled using computer ray-tracing programs [4]. For silicon, this leads to a path- length enhancement factor of 50. The absorption enhancement as a function of the wavelength, $a_{I}(\lambda)$, can calculated as:

$$
a_{I}(\lambda)=\frac{a(\lambda)}{a(\lambda)+\frac{1}{4 n^{2} W}}
$$

The absorption increases as a function of the width of the cell, $W$ [3]. The dependence of the absorption on the path-length enhancement factor and the width has enabled solar cells to use a thinner silicon substrate with light trapping structures and maintain solar cell efficiency. Experimentally, light trapping structures have improved the efficiency of solar cells by up to $4 \%[4,5]$.

The second optical enhancement technique for solar cells is anti-reflection (AR) coatings, which are based on the principle of interference between incident and reflected light. Matching boundary conditions for electromagnetic radiation at the interface of two dissimilar media will lead to Fresnel equations [6-8], which can be solved for the reflected and transmitted light at an interface. For TE (s-polarized) and TM (p-polarized) polarized light the reflectance of silicon varies as a function of angle (Figure 2). 


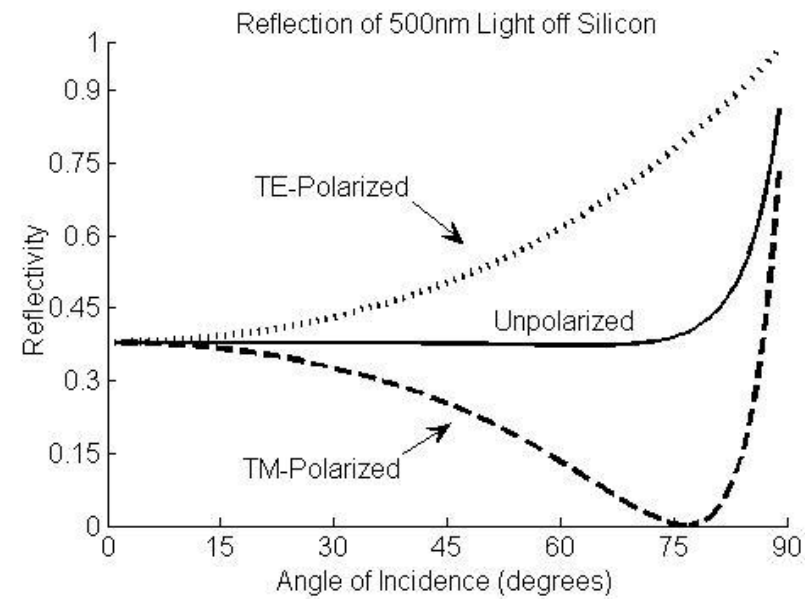

Figure 2. Reflectivity of silicon as a function of angle according to Fresnel equations.

When a thin AR layer is placed on the silicon surface, the Fresnel equations can be applied to both surfaces to solve for the total reflectance. The width of the thin layer will correspond to a phase change between the reflected waves from each surface. If the two reflections are out of phase then destructive interference will occur at the first interface and all incident energy is transmitted.

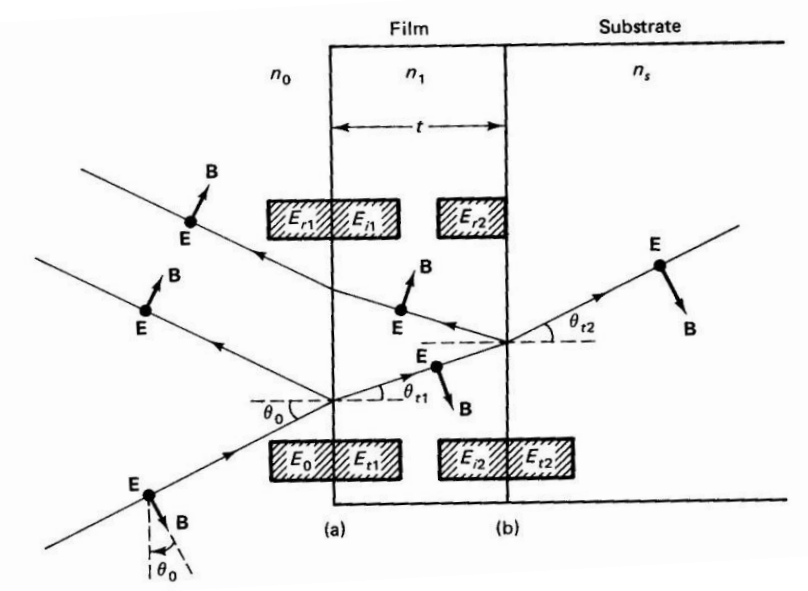

Figure 3. Matching of boundary conditions leads the energy of reflected and transmitted waves [8]. 
Single layer AR coatings are made a quarter-wavelength optical thickness to create a half-wavelength path difference between the reflections of normal incident light, creating the destructive interference. For a quarter-wavelength coating and normal incident light, the reflectance from a single layer coating can be simplified to be: $R=\frac{\left(n_{0} n_{S}-n_{1}^{2}\right)^{2}}{\left(n_{0} n_{S}+n_{1}^{2}\right)^{2}}$, where $n_{o}, n_{1}$, and $n_{s}$ represent the refractive indices for the incident media, thin layer coating and substrate, respectively. There will be zero reflection when: $n_{0} n_{s}=n_{1}^{2}$ or $n_{1}=\sqrt{n_{0} n_{s}}$. For $500 \mathrm{~nm}$ light, the optimized index of refraction for an AR coating for silicon would be $n_{1}=2.07$. Table 1 lists indices of refraction for materials commonly used as AR coatings.

\begin{tabular}{|l|c|l|l|l|l|l|}
\hline \multicolumn{7}{|c|}{ Table 1. AR Coating Materials for Silicon: Single and Multilayer Coatings } \\
\hline Typical AR coating material & $\mathrm{ZnS}$ & $\mathrm{TiO}_{2}$ & $\mathrm{Ta}_{2} \mathrm{O}_{5}$ & $\mathrm{SiO}_{2}$ & $\mathrm{MgF}_{2}$ & $\mathrm{ITO}$ \\
\hline Index of refraction & 2.5 & $2.3-2.7$ & 2.2 & 1.5 & 1.38 & 2.0 \\
\hline
\end{tabular}

Common single layer AR coatings for silicon solar cells are titanium dioxide and indium-tin oxide, which have indices of refraction between 2 and 3. For multi-layer AR coatings, the reflection from thin film coatings can be calculated using the transfer matrix methods for electromagnetic waves [8]. Multilayer coatings perform better than single layers because of the interference between layers, as shown in Figure 4. 


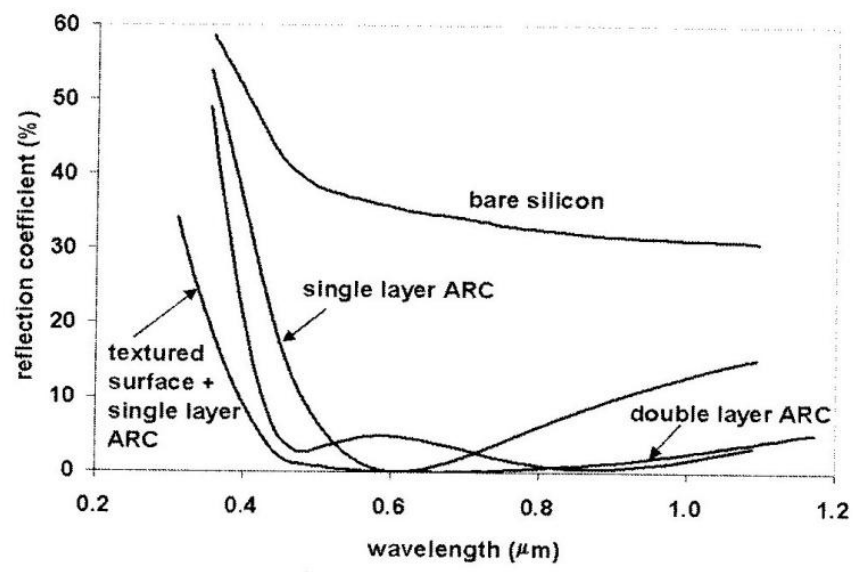

Figure 4. Effectiveness of different AR coatings (ARCs) on silicon. [9]

A combination of these two optical enhancement techniques, light trapping and AR coatings, is used for solar cells. A typical silicon solar cell may have pyramidal front and back surfaces with a quarter-wavelength AR coating. However, both optical enhancement methods have drawbacks. Light trapping structures are made by mechanical grooving or chemical etching of the solar cell surface. Mechanical grooving can be expensive and time intensive, and etching with substances such as hydrofluoric acid (50\%): nitric acid (65\%): acetic acid (96\%) leads to toxic chemical by-products [5]. Single layer AR coatings fail to exploit all wavelengths and all angles of the incident sunlight. On the other hand, improving AR coatings by adding multiple layers increases manufacturing costs.

Improving the optical properties of solar cells will increase their efficiency, but at the same time, the fundamental structure of solar cells is changing. Current solar cells such as thin films, p-i-n junction cells, organic solar cells, and multi-junction devices are made from an array of materials such as InP, GaAs, and CdTe. Nanostructured materials represent a promising area for solar cell development. The use of nanostructures in solar 
devices could mean using fewer materials, creating more versatile structures such as flexible solar devices, and exceeding the efficiency of traditional "bulk" cells. Improving the optical properties of solar cells should parallel the evolution of their structure. Nanostructures could be used to create gradient index AR coatings that could be applied to a variety of solar cell structures.

\subsection{Gradient index optical coatings}

A novel way to create an omni-directional and broadband AR coating is to make a gradient index of refraction coating using multiple thin layers or nanoporous media. Gradient index of refraction materials have been used since the 1850 s, to correct aberration in lenses and create light propagation in fiber optic cables [10]. Gradient index optics takes advantage of the gradual curvature of light as it passes through a material. The effect was observed by Lord Rayleigh, who solved for a gradient between two media after observing that the reflection due to a gradual change in media must be less than that of an abrupt change [11]. The atmosphere is often cited as a gradient index media, where light bends due to the change in air density.

A gradient index of refraction can be modeled using the transfer matrix method for multi-layer films [6-8, Appendix 3]. Splitting the gradient layer into slabs parallel to the surface, an effective index of refraction can be found for each layer using Effective Media Approximation (EMA) [12]. Using the index of refraction for each of these layers, the reflection for each thin layer surface can be calculated. It is necessary to solve Maxwell's equations since the dimensions of the structures are much less than the wavelength of light, and render geometric approximations inappropriate. 
In the 1980s it was found that a quintic gradient index profile could reduce reflection from a surface better than a linear gradient coating [13]. The quintic profile is given by:

$$
n_{Q}(z)=n_{\max }-\left(n_{\max }-n_{\min }\right)\left[10\left(\frac{Z}{d}\right)^{3}-15\left(\frac{Z}{d}\right)^{4}+6\left(\frac{Z}{d}\right)^{5}\right]
$$

where $n_{\max }$ is the maximum index of refraction, $n_{\min }$ is the minimum (incident) index of refraction, $d$ is the thickness of the layer, and $z$ the depth into the layer. The profile represents a continuously varying media. The composite coating is referred to as an inhomogeneous layer (Figure 5).

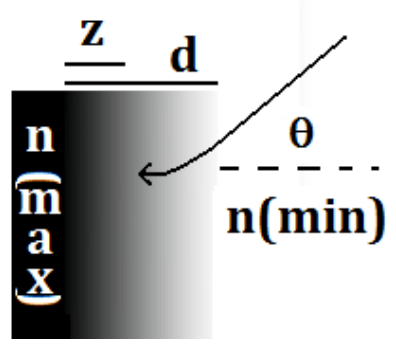

(a)

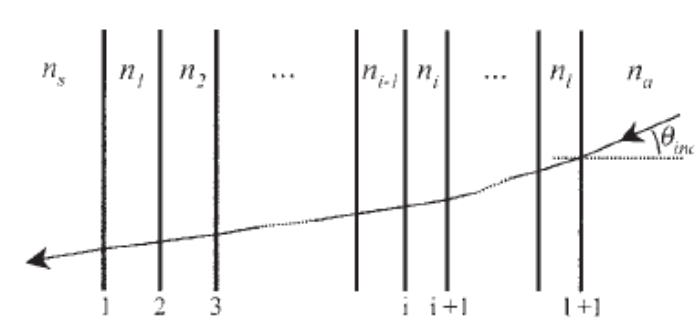

(b)

Figure 5. (a) Gradient index profile, labeled according to a quintic profile. (b) Splitting of a gradient index profile into thin layers to apply the transfer matrix method for thin films [14].

Modifications of the quintic profile have been made to take into account grazing angles of incidence [14], which may also be improved by exponential and Gaussian index profiles [15]. These profiles perform better at large angles of incidence by minimizing the change in angle as light propagates through each layer. However, they require thicker layers and may not perform as well for normal incident light. Figure 6. shows a quintic profile for silicon, which corresponds to a broadband reflectance under $1 \%$. The profile was optimized for an index of refraction $n=4.2$. However, as the wavelength changes, 
the index of profile will also change, altering the quintic shape. This effect, however, will be small.

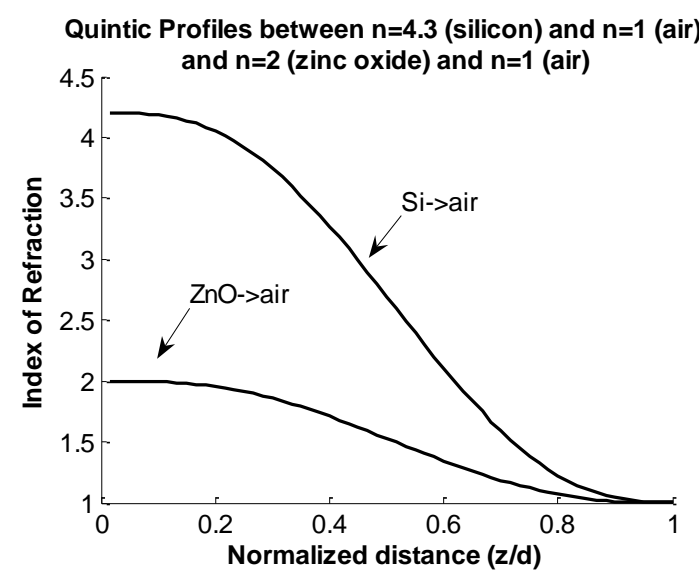

(a)

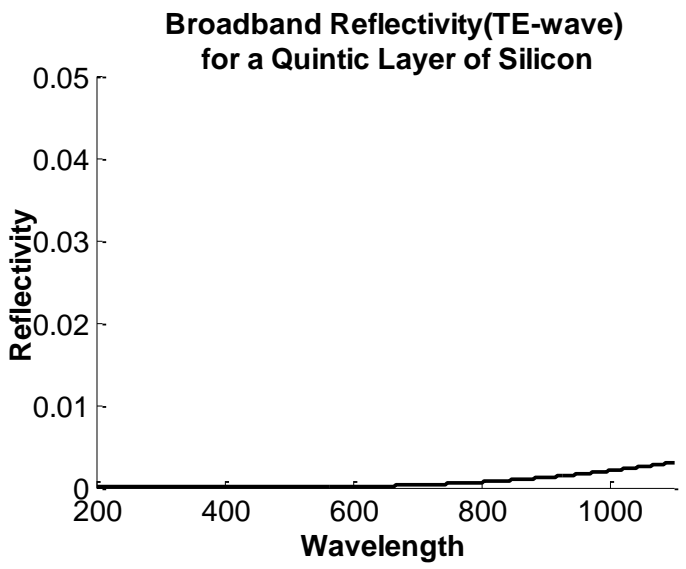

(b)

Figure 6. (a) Quintic profiles for silicon ( $\mathrm{Si})$ to air and zinc oxide $(\mathrm{ZnO})$ to air interfaces (b) Reflectivity for a TE wave calculated for a $1.2 \mu \mathrm{m}$ Si to air quintic interface using a transfer matrix method written for MATLAB, with a minimum of 15 layers per $\lambda / 4$ optical thickness. It does not account for the shift in the profile due to the wavelength dependent index of refraction.

The manufacturing of gradient index anti-reflection layers remains difficult. One approach to such thin film layers is to coat them intermittently, using porous media to achieve a range of indices of refraction. Thin layer gradient index layers have been achieved using laser assisted evaporation and sputtering, but they require deposition techniques which can be expensive and time intensive to achieve ideal layers $[16,17]$. Nanowires represent a way to create gradient index layers efficiently and inexpensively.

\subsection{ZnO Nanowires as anti-reflection coatings for solar cells}

Nanowires have been presented as a novel way to create a gradient index of refraction between two media. They can be grown with different orientations using a variety of techniques. Vertically orientated nanowires can create a graded index of 
refraction either by tapering into a conical shape or by random height variations. Nanowires used as gradient-index AR coatings are different than the previously discussed quarter-wavelength optical coating and geometric light trapping techniques. Gradientindex nanowire layers are inhomogeneous and structures are smaller than the wavelength of incident light. To be effective, according to theoretical models, the nanowires should have a diameter much less than the wavelength of light, and have a minimum vertical length equivalent to at least $\lambda / 2$ in optical thickness [16]. A variety of nanowires, nanorods, and other sub-wavelength structures have been grown using materials such as $\mathrm{GaN}, \mathrm{GaP}, \mathrm{Si}$ and $\mathrm{ZnO}$. Nanowires are grown using a variety of methods such as epitaxial beam deposition, chemical vapor deposition, electron beam lithography, and etching [18-21]. The use of nanowires as part of the electronic structure of solar cells is widespread, and they have been shown to improve the optical and absorptive properties of the cells $[22,23]$. Nonetheless, due to the large extent of this topic, research will be limited to the use of dielectrics as non-absorptive AR coatings.

Zinc oxide nanowires have been grown for anti-reflection coating for solar cells $[24,25]$. The advantage of $\mathrm{ZnO}$ nanowires is that they can be grown using a variety of low temperature deposition techniques from inexpensive, non-toxic materials. The large band-gap of $\mathrm{ZnO}$ makes them a transparent, non-absorbing layer. Chen and Sun [24] have shown that $\mathrm{ZnO}$ nanorods grown using an aqueous chemical growth technique are capable of 10 percentage point reduction in the broadband reflection by a silicon device and a $2.4 \%$ improvement in its efficiency. Lee, et al. [25], explored the optical properties 
of the nanowires resulting from tapering during the growth process and have achieved broadband reflectance by nanowires on silicon below $10 \%$.

Vertical nanowire arrays can be simply modeled using Bruggemann's Effective Media Approximation (EMA) [19,22]. A vertical layer with random height variations or tapering can be split into thin horizontal slabs. Each slab has an effective index of refraction, $n_{\text {eff, }}$, according to a volume fill factor. For a $\mathrm{ZnO}$ layer in ambient air, the EMA is: $\boldsymbol{f}_{Z n o} \frac{\boldsymbol{n}_{Z n O}^{2}-n_{e f f}^{2}}{n_{Z n O}^{2}+2 n_{e f f}^{2}}+\left(1-f_{Z n O}\right) \frac{n_{a i r}^{2}-n_{e f f}^{2}}{n_{a i r}^{2}+2 n_{e f f}^{2}}=\mathbf{0}$, where $f_{Z n O}$ represents the percent volume filled with ZnO. Bruggemann's EMA is only valid for sub-wavelength structures and is contingent on the geometry of such structures [27].

\subsection{Objectives of Research: Growth and characterization of $\mathrm{ZnO}$ nanowire arrays}

$\mathrm{ZnO}$ nanowire arrays show promise as anti-reflection coatings for solar cells and can be deposited over large surface areas. The nanowires can be grown with a variety of methods with varying morphologies, diameters, lengths and densities. Unfortunately, there has been little experimental research into the effect of these morphologies on antireflection properties. Previous research has focused solely on the broadband properties of vertical $\mathrm{ZnO}$ arrays. It is unclear whether vertical $\mathrm{ZnO}$ nanowire arrays will perform better at different angles of incidence than a random $\mathrm{ZnO}$ nanowire orientation. The objective of this research is to investigate the effect of morphology on the anti-reflective properties of $\mathrm{ZnO}$ nanowire arrays. 
Using two different chemical solution growth techniques, electrodeposition and aqueous chemical growth, $\mathrm{ZnO}$ nanowire arrays were grown on silicon. These growth methods are low cost, low temperature chemical solution techniques. The goal was to create such arrays without caustic chemicals and to use methods that can be scaled up to large surface areas. Nanowires were deposited on silicon so that relative reflectance comparisons could be made to a polished silicon substrate surface. Morphologies were characterized using scanning electron microscopy (SEM). Scattering and total reflectance measurements were taken using a goniometer and an integrating sphere.

Theory suggests that as nanowire arrays approach a quintic gradient index profile with respect to incident light, their performance as an AR coating improves. Although tapering the nanowires with chemicals is difficult, selective growth of nanowires that fit the desired profile may be possible. For this reason, growth methods were orientated toward creating longer, thinner wires, with larger height variations [15]. Comparisons of the different characteristic parameters of the wires with respect to the reduction in reflection by a silicon substrate may lead to an improved understanding of the way that light is scattered by the nanowires, and whether theoretical models can accurately reflect nanowire morphology. 


\section{Experimental Methods}

\subsection{Growth of ZnO Nanowires}

$\mathrm{ZnO}$ is a II-VI semiconductor, with a direct band-gap of $3.37 \mathrm{eV}$. $\mathrm{ZnO}$

nanostructures are widely used in LEDs for their UV luminescence and in gas sensors and solar cells for their electron transport properties. Zinc oxide can be grown either as a hexagonal wurtzite crystal, cubic zincblende or cubic rock salt, as illustrated in Figure 7. A zincblende crystal, however, is only a stable when grown on other cubic lattices and rock salt is rare and must be grown under high pressure [28].

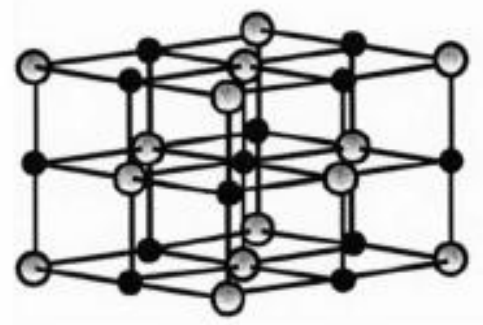

(a)

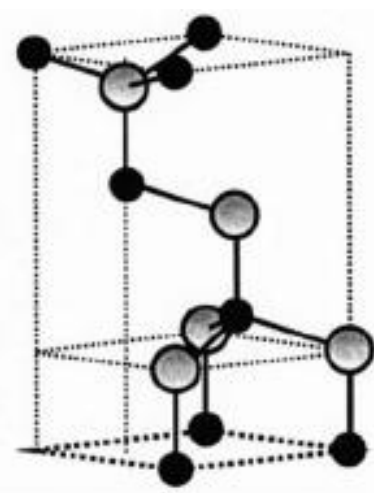

(b)

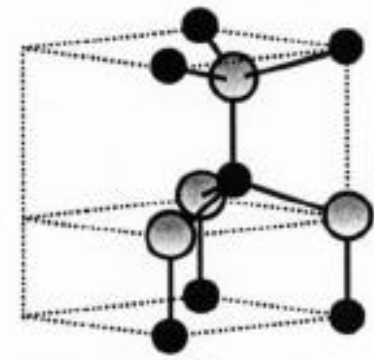

(c)

Figure 7. (a) Rock salt (b) Zincblende and (c) Hexagonal wurtzite structure for ZnO. [29]

Under ambient conditions, $\mathrm{ZnO}$ has a wurtzite crystal structure also called zincite.

The zinc is tetrahedrally bonded to four oxygen atoms. Although a tetrahedral bond usually would be considered covalent $s p^{3}$, the bond is considered highly ionic due to the different electronegativities of the zinc and oxygen atoms. The lattice parameters of the crystal are $a=3.2495 \AA$ and $c=5.2069 \AA$, where $a$ extends in the basal plane, and $c$ extends in the vertical plane. Alternating layers of $\mathrm{Zn}-\mathrm{O}$ make up the crystalline structure. The c/a ratio varies from 1.593 to 1.6035 , which is close to that of an ideal hexagonal 
structure $(\mathrm{c} / \mathrm{a}=1.63)$ [28-30]. Owing to the polar-face of the [001] plane, which is perpendicular to the c-axis as seen in Figure $8 \mathrm{a}, \mathrm{ZnO}$ nanowires grow preferentially along the c-axis [31].

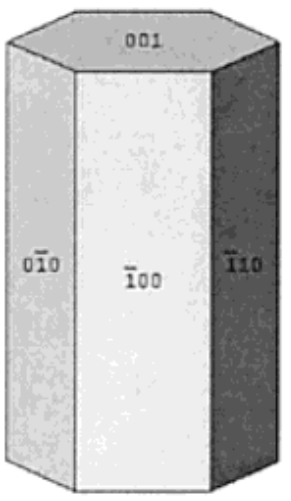

(a)

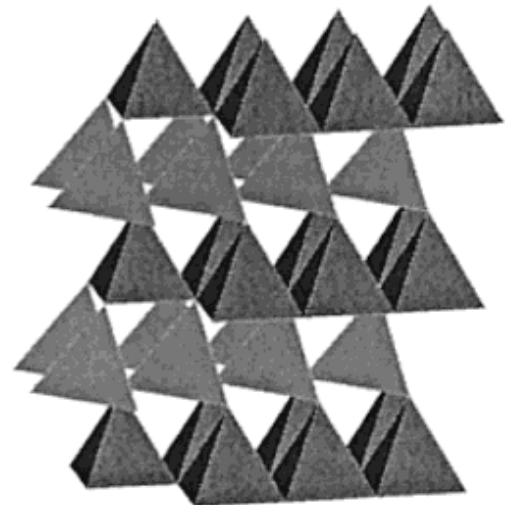

(b)

Figure 8. (a) Hexagonal faces of wurtzite $\mathrm{ZnO}$ with c-axis [001] orientated growth and (b) Zincite crystal structure [31].

$\mathrm{ZnO}$ structures can be grown by a variety of deposition techniques, with diameters ranging from $50 \mathrm{~nm}$ to $200 \mathrm{~nm}$ and lengths exceeding $10 \mu \mathrm{m}$. Epitaxial deposition by vapor deposition techniques such as metal-organic chemical vapor deposition (MOCVD), pulse laser deposition (PLD) and vapor-liquid-solid (VLS) growth are often employed in research and industry $[31,32]$. Although they allow for easy doping and control of growth parameters, these methods typically require vacuum systems and temperatures exceeding $800{ }^{\circ} \mathrm{C}$. Two chemical solution techniques for growing $\mathrm{ZnO}$ nanostructures at low temperature have been developed: aqueous chemical growth and electrochemical deposition or simply referred to as electrodeposition. The advantage of using two different growth techniques is obtaining nanowires with different morphologies. Electrodeposited $\mathrm{ZnO}$ nanowires tend to have random orientation, whereas $\mathrm{ZnO}$ nanowires grown by aqueous chemical growth exhibit vertical orientation 


\subsubsection{Aqueous Chemical Growth}

Aqueous chemical growth (ACG) of $\mathrm{ZnO}$ nanowires was developed by Vayssierres and Kleis [31] and is a thermal decomposition method. The method consists of equal molar mixtures of two chemicals, zinc nitrate hexahydrate $\left(\mathrm{Zn}\left(\mathrm{NO}_{3}\right)_{2} \cdot 6 \mathrm{H} 2 \mathrm{O}\right)$ and hexamethylenetetramine, also called hexamine or methenamine $\left(\mathrm{C}_{6} \mathrm{H}_{12} \mathrm{~N}_{4}\right)$, in deionized water. Both substances are stable, low cost, and pose minimal health risks. The aqueous bath is heated to $90{ }^{\circ} \mathrm{C}$ for a time span on the order of hours. SEM images and $\mathrm{x}$ ray diffraction show $\mathrm{ZnO}$ wurtzite crystal presence with c-axis oriented growth [31]. The chemical reaction taking place is documented as:

$$
\begin{aligned}
& \mathrm{C}_{6} \mathrm{H}_{12} \mathrm{~N}_{4}+6 \mathrm{H}_{2} \mathrm{O} \rightarrow 4 \mathrm{NH}_{3}+6 \mathrm{HCHO} \\
& \mathrm{NH}_{3}+\mathrm{H}_{2} \mathrm{O} \leftrightarrow \mathrm{NH}_{4}^{+}+\mathrm{OH}^{-} \\
& \mathrm{Zn}^{2+}+2 \mathrm{OH}^{-} \leftrightarrow \mathrm{Zn}(\mathrm{OH})_{2} \\
& \mathrm{Zn}(\mathrm{OH})_{2} \rightarrow \mathrm{ZnO}+\mathrm{H}_{2} \mathrm{O}
\end{aligned}
$$

In general, nitrate salts provide $\mathrm{Zn}^{2+}$ ions, and water provides $\mathrm{O}^{2-}$ ions. The exact role of the methenamine is not understood, only that the methenamine hydrolyzes slowly which controls the precipitation rate of the $\mathrm{Zn}^{2+}$ ions [33].

The concentrations of the bath, temperature of growth, $\mathrm{pH}$ of the solution, and time of deposition all affect the $\mathrm{ZnO}$ nanostructure morphology. For nanowire or nanorod growth, typical concentrations range from $0.001 \mathrm{M}$ to $0.1 \mathrm{M}$, leading to control of wire diameter from $40 \mathrm{~nm}$ to $300 \mathrm{~nm}$ [32]. Height and diameter variations are also affected by temperature and $\mathrm{pH}$. Decreasing temperature from $95{ }^{\circ} \mathrm{C}$ to $90{ }^{\circ} \mathrm{C}$ decreases the evaporation of ammonia from the solution, leading to larger nanowire diameters. 
Experiments have also been performed directly manipulating the $\mathrm{pH}$, where wires become flower like structures at a pH of 12 [35]. A pH of 6 to 7 is the optimum growth environment for $\mathrm{ZnO}$ nanowires. Growth time is proportional to both the diameter and vertical length of the nanowires. Samples can be placed in a new chemical bath to sustain growth rates $[36,37]$.

The ACG method is dependent on the polarity of the $\mathrm{ZnO}$ crystalline structure which allows for self-alignment in the hexagonal shape. Seeding the substrate prior to ACG with a planar $\mathrm{ZnO}$ layer has been found to produce dense, vertical nanowire growth. Depositing zinc acetate dihydrate dissolved in ethanol by spin coating [38] or spray pyrolysis [39] at low temperature creates a planar layer of $\mathrm{ZnO}$.

Experimentally, the following methods were used to grow $\mathrm{ZnO}$ nanowires. An n-type (Sb doped) silicon substrate approximately $25 \mathrm{~mm}$ x $15 \mathrm{~mm}$ in dimension was used. Prior to growth the silicon was cleaned by sonication for 10 minutes in methanol, 10 minutes in acetone, and then rinsed with de-ionized water.

Before the growth of nanowires by ACG, a seed layer was deposited using the spray pyrolysis of 0.1 M zinc acetate dihydrate (99.99\% purity, Sigma Aldrich) dissolved in ethanol, with $2 \%$ acetic acid and $4 \%$ deionized water by volume. The substrate was placed on a hot plate heated to $280{ }^{\circ} \mathrm{C}$. Using an airbrush, layers were sprayed on the substrate every thirty seconds. The numbers of layers ranged from 10 to 40 , with 40 layers yielding a uniform $\mathrm{ZnO}$ film. After spraying, the substrate was annealed at $380{ }^{\circ} \mathrm{C}$ for 20 minutes to guarantee the complete evaporation of ethanol. 
Chemical bath growth was performed using $0.02 \mathrm{M}$ zinc nitrate hexahydrate (99\% purity, Sigma Aldrich) and 0.02 M methenamine (99.5\% purity, Sigma Aldrich). The compounds were dissolved in de-ionized water and sonicated for 15 minutes to break up large crystals. A few samples were made using slightly lower and higher concentrations to study the effects on morphology. A set-up of the ACG growth is shown in Figure 9.

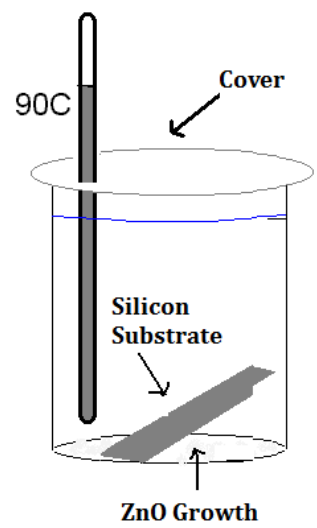

Figure 9. Growth of $\mathrm{ZnO}$ nanowires by Aqueous Chemical Growth (ACG) in a $0.02 \mathrm{M}$ bath. The substrate with the pre-growth layer was placed face down in $40 \mathrm{ml}$ of the ACG solution and heated to $85{ }^{\circ} \mathrm{C}-95{ }^{\circ} \mathrm{C}$. Owing to the variability of the hot plate and the small volume of solution, maintaining a constant temperature at all times was difficult, The temperature could, however, be kept within the $85{ }^{\circ} \mathrm{C}-95^{\circ} \mathrm{C}$ range. The substrate sits at a tilted angle, with the seed layer facing the bottom. $\mathrm{ZnO}$ nanowire growth occurs on the bottom-facing surface. Mixing the solution was found to cause the deposition of large crystals on the sample. Placing samples face down in a stationary solution helped keep large crystals from falling onto the nanowires.

The bath was covered with aluminum foil to avoid excess evaporation. Evaporation would lead to a low $\mathrm{pH}$, too low to support the desired nanowire growth. To counter the evaporation over time and replenish reactants, small amounts of the $0.02 \mathrm{M}$ 
solution were periodically added to maintain a constant volume. Growth time ranged from 3 hours to 5 hours, but was typically 4 hours for most samples. Following deposition the substrate was rinsed with de-ionized water and dried with nitrogen gas.

For two samples grown by ACG, a titanium dioxide $\left(\mathrm{TiO}_{2}\right)$ layer was spin-coated prior to the deposition of a seeding layer. $\mathrm{TiO}_{2}$ has a higher index of refraction than $\mathrm{ZnO}$ and may create a step-layer between the $\mathrm{ZnO}$ and $\mathrm{Si}$, leading to an improved $\mathrm{AR}$ coating. First, titanium (IV) isopropoxide was diluted to $10 \%$ by volume in isopropanol. The titanium solution was uniformly coated on a Si substrate by applying a spin-coating for 30 seconds at a spin-rate of 2500 RPM. The substrate was heated to $100{ }^{\circ} \mathrm{C}$ for 5 minutes to allow for slow evaporation of the isopropanol, and then annealed at $380{ }^{\circ} \mathrm{C}$ for 1 hour. Appendix 1 presents a complete table describing the particular growth conditions of each ACG $\mathrm{ZnO}$ nanowire sample. The results section discusses the resulting nanowires morphology and optical characteristics.

\subsubsection{Electrodeposition}

Electrodeposition of $\mathrm{ZnO}$ nanowires was performed following the method of Peulon and Lincot [41]. Electrodeposition is a method where a potential difference is created between a reference electrode, a positive anode, and negative cathode. The potential difference helps dissociate ions for a chemical reaction. By creating a potential difference in an aqueous chemical solution of $\mathrm{ZnCl}_{2}$, bubbled with oxygen, $\mathrm{ZnO}$ crystals can form on a conductive substrate attached to the cathode. The following chemical reactions are known to take place: 
(1) $\mathrm{O}_{2}+2 \mathrm{H}_{2} \mathrm{O}+4 \mathrm{e}^{-} \rightarrow 4 \mathrm{OH}^{-}$

(2) $\mathrm{ZnCl}_{2} \rightarrow \mathrm{Zn}^{2+}+2 \mathrm{Cl}^{-}$

(3) $\mathrm{Zn}^{2+}+\frac{1}{2} \mathrm{O}_{2}+2 \mathrm{e}^{-} \rightarrow \mathrm{ZnO}$

$-0.93 \mathrm{~V} / \mathrm{NHE}$

Reaction (3) takes place at the negatively charged cathode, where positive zinc ions

combine with oxygen and hydroxide complexes and form nanowires. Potassium chloride $(\mathrm{KCl})$ is added to the solution to improve the conductivity. Morphology of the nanowires is highly dependent on the solution $\mathrm{pH}$, temperature, and the potential difference. Figure 10 depicts the set-up for the elecrodeposition of $\mathrm{ZnO}$ nanowires.

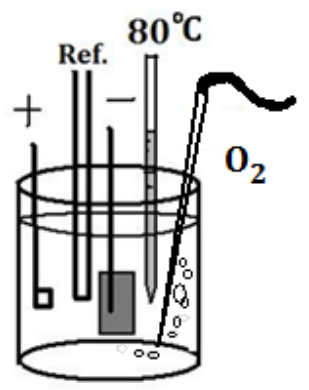

Figure 10. Schematic of electrodeposition of $\mathrm{ZnO}$ nanowires. A conductive substrate is attached to a negative cathode, where $\mathrm{Zn}^{2+}$ react with $\mathrm{O}_{2}$.

In order for electrodeposition to work, the substrate must have a conductive layer to connect to the cathode. Unfortunately, the rapid formation of an oxide layer on the silicon surface impairs the electrodeposition of $\mathrm{ZnO}$ nanowires directly on silicon. As a result, the experimental growth of $\mathrm{ZnO}$ nanowires by electrodeposition was performed on silicon coated with ITO (Sn-doped indium oxide). ITO is a transparent conductive oxide layer with a large band-gap and is often used as an AR coating. 
Growth conditions for $\mathrm{ZnO}$ nanowires were first found on ITO covered quartz glass, with the coating layer approximately $20 \mathrm{~nm}$ and a sheet resistance of $100 \Omega /$ square. After determining conditions favorable to nanowire growth, $\mathrm{ZnO}$ nanowires were grown on ITO covered n-type ( $\mathrm{Sb}$ doped) silicon substrates. The ITO had a sheet resistance of $100 \Omega /$ square, with a transmittance ranging from $85 \%$ at $400 \mathrm{~nm}$ to $95 \%$ at $900 \mathrm{~nm}$. Prior to deposition, the ITO/Si substrate was sonicated for 10 minutes each in methanol and acetone. The substrate was then rinsed with de-ionized water. For a few samples a pregrowth layer of planar $\mathrm{ZnO}$ layers was deposited using the spray pyrolysis of zinc acetate dihydrate, as outlined in ACG section. As a seeding layer was not necessary for growth of $\mathrm{ZnO}$ nanowires, electrodeposition was also carried out without this layer present. Electrodeposition was performed using an EG\&G Instrument from Princeton Applied Research Potentiostat/Galvanostat Model 283. The reference electrode was a $\mathrm{Ag} / \mathrm{AgCl}$ electrode $(0.2 \mathrm{~V} / \mathrm{NHE})$, while the cathode and anode were platinum wires. The platinum wires were cleaned with $0.1 \mathrm{M} \mathrm{HNO}_{3}$ prior to use. The ITO/Si substrate was attached to the cathode. Using the potentiostat method, the cathode was kept at $-1.05 \mathrm{~V}$ relative to the reference electrode. The deposition solution was $0.3 \mathrm{mM} \mathrm{ZnCl} 2(99.9 \%$ purity, Sigma Aldrich) and $0.1 \mathrm{M} \mathrm{KCl} \mathrm{(99.9 \%} \mathrm{purity,} \mathrm{Sigma} \mathrm{Aldrich)} \mathrm{in} \mathrm{deionized} \mathrm{water.}$ The solution was bubbled with $\mathrm{O}_{2}$ at a constant rate while being magnetically stirred. The solution was heated to $80{ }^{\circ} \mathrm{C}$ for a growth time of 1 hour. Following deposition the sample was rinsed with deionized water and dried with nitrogen gas. The results section discusses the properties of the nanowires grown by electrodeposition. Appendix 1 presents a table listing samples grown by electrodeposition and growth parameters. 


\subsection{Optical Characterization of $\mathrm{ZnO}$ Nanowires}

\subsubsection{SEM Images}

A Scanning Electron Microscope (SEM) was used to characterize the morphology of $\mathrm{ZnO}$ nanowire arrays and seeding layers. The SEM images were useful in developing growth techniques, and in associating the scattering and reflectances of the wires with wire morphology. Images were made using a FEI Sirion XL30 SEM, which is capable of resolutions down to $1.5 \mathrm{~nm}$. Images were usually made with a $20 \mathrm{kV}$ electron beam at $30^{\circ}$ to $45^{\circ}$ incidence.

\subsubsection{Goniometer}

A goniometer with a photodiode was used to measure the angular dependent scattering by $\mathrm{ZnO}$ nanowire array samples. A goniometer can measure both the specular and diffuse reflectivity of samples. In the goniometer set-up, a laser was used to illuminate the sample and the light reflected by the sample was measured with a photodiode that rotated around the perimeter in the horizontal plane. The top-view graphic of the goniometer is shown in Figure 11. The entire system was kept under a black box to eliminate stray room-light. A 532nm, $1.8 \mathrm{~mW}$ diode laser with a collimated beam was used. The laser was chopped by a small fan at a frequency ranging from 105 $\mathrm{Hz}$ to $115 \mathrm{~Hz}$. A silicon photodiode rotated on a $180 \mathrm{~mm}$ radial arm at incremental angle steps. The photodiode was $4 \mathrm{~mm}$ by $4 \mathrm{~mm}$. A $1^{\circ}$ step size was sufficient to sample all reflection within the horizontal plane. 


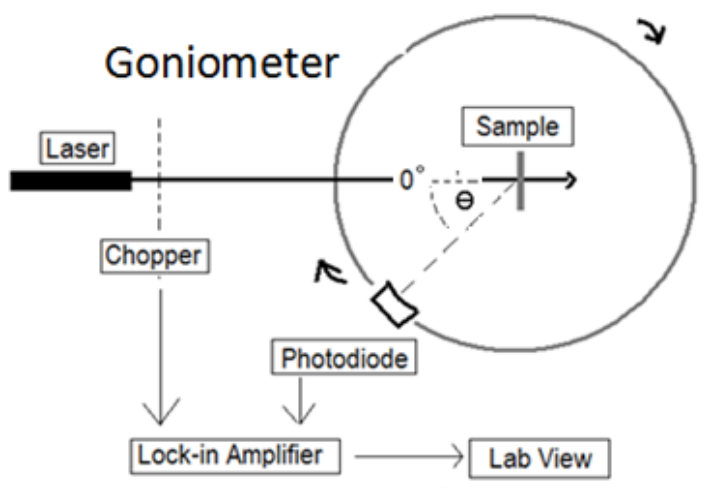

Figure 11. Top-view of the goniometer used to measure reflection by $\mathrm{ZnO}$ nanowires

The photodiode was oriented with its face perpendicular to the sample, to avoid light scattering from other surfaces or coming directly from the laser. A reflective piece of silicon or a glass beam splitter situated behind the photodiode was used to reflect light from the sample into the photodiode. The goniometer sample holder and photodiode arm were attached to separate stepper motors.

The current from the diode and the frequency from the chopper were fed into a Stanford Research Systems SR830 lock-in amplifier. The amplifier reduced noise from ambient light sources and was capable of measuring currents from $10^{-12} \mathrm{~A}$ to $10^{-6} \mathrm{~A}$. At times, a neutral density filter was placed in front of the laser to attenuate signal. Attenuating the signal, $I_{o}$, with a $50 \Omega$ resistor in parallel with the lock-in amplifier, however, often proved more effective. With the $1000 \Omega$ input impedance of the lock-in amplifier, the attenuated current $I_{a}$ was equal to $0.0476 I_{o}$. This attenuation was verified experimentally. A LabVIEW program received the current read from the lock-in amplifier and controlled the stepper-motors on the goniometer.

Two programs were used to take data. The first was a scatter scan. The sample was held normal to the incident laser beam while the photodiode moved incrementally to 
collect the reflected light in the horizontal plane. A scatter scan provided measures of both diffuse and specular reflection of the sample. The measurements could be integrated assuming isotropic reflection to obtain the total reflectance. The difficulty of accurately measuring the amplitude of the specular peak for highly reflecting samples led to the conclusion that an integrating sphere was more reliable for total reflectance measurements.

The second type of scan was a specular peak scan. The sample was moved in incremental angles with respect to the laser with the photodiode measuring the specular reflection peak. A polarizer was placed in front of the laser to determine the specular reflectance for $\mathrm{ZnO}$ nanowire samples for both TE and TM polarized light.

\subsubsection{Integrating Sphere}

An integrating sphere has a diffusely reflection coating on its inner surface. The inner surface multiply reflects light that is incident on the sample, producing a diffuse radiance that is measured by a photodetector. Integrating spheres are used to measure the total reflectance, transmittance, and absorptance of a sample. In a substitution reflection measurement, where the sample is inserted into the sphere in place of a reflectance standard, the reflectance of the sample is calculated based on the change of radiance that hits the detector. Since the reflectance is calculated from diffuse radiance, the detector must not receive direct illumination from the sample. The detector is commonly protected by baffles or in a separate sphere compartment [41]. Figure 12 shows the configuration of a substitution integrating sphere. 
150 MM SPHERE

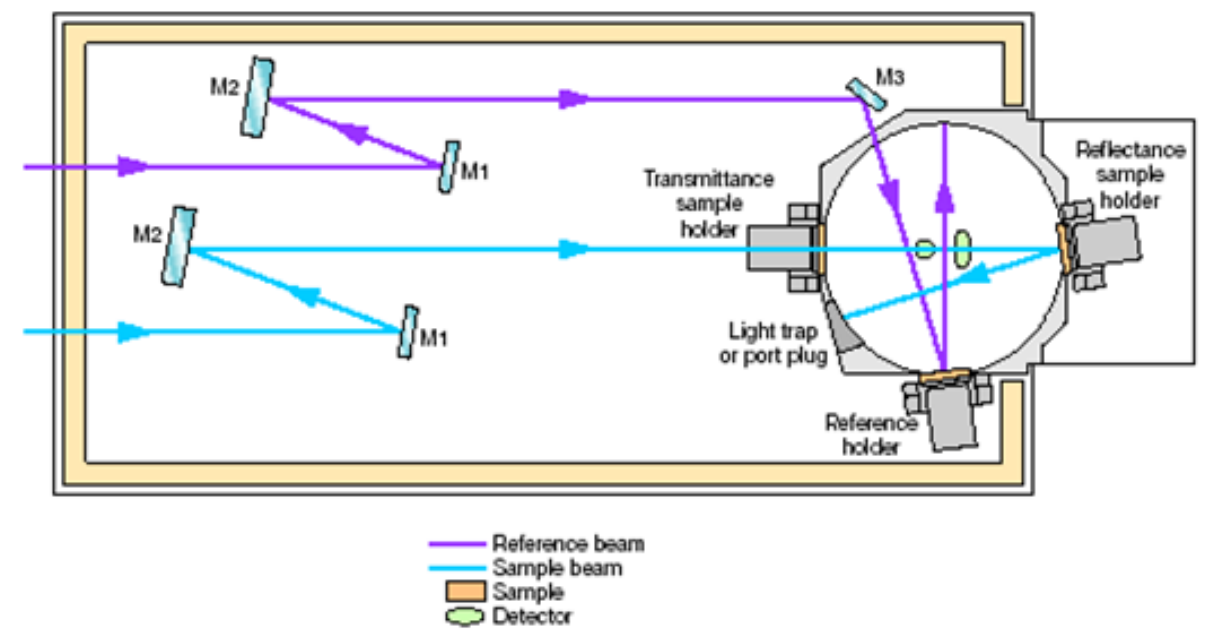

Figure 12. Design of Lambda 950 UV/VIS/NIR $150 \mathrm{~mm}$ integrating sphere [42].

Two integrating spheres were used to measure the reflectances of $\mathrm{ZnO}$ nanowire arrays. The first integrating sphere was a $150 \mathrm{~mm}$ integrating sphere attached to PerkinElmer 950 UV/VIS/NIR spectrometer. The spectrometer could be scanned from $300 \mathrm{~nm}$ to $1100 \mathrm{~nm}$. It provided broadband reflectances of the $\mathrm{ZnO}$ nanowire samples which could be compared to a silicon substrate.

For measurements with the Lambda 950 spectrometer, the $\mathrm{ZnO}$ nanowire sample was placed at the back of the sphere at a standard angle of $8^{\circ}$ incidence. The internal surfaces of the sphere were coated with Spectralon ${ }^{\circledR}$, which has a diffuse reflectance of 0.99 for light $400 \mathrm{~nm}-1100 \mathrm{~nm}$. The integrating sphere was operated in the two-bream mode with a reference beam which helped eliminate substitution errors arising from the placement of the samples. Reflected light from the sample was diffusely reflected around the sphere. As the $\mathrm{ZnO}$ nanowire samples were smaller than the $25 \mathrm{~mm}$ diameter reflectance port, a sample holder was made with a circular aperture of $13 \mathrm{~mm}$. The sample 
holder caused an offset in the measured reflectance, which will be addressed in the results section.

The second integrating sphere was attached to a Fluorolog III spectrometer, commonly used for fluorescence measurements. The Fluorolog III integrating sphere allowed reflectance measurements at different angles of incidence thereby providing insight into the angular dependence of the sample reflectance. The sphere was 4 inches in diameter with a center mount sample holder that could be placed at different angles with respect to the incident beam. The sample holder allowed for a sample $12 \mathrm{~mm}$ by $12 \mathrm{~mm}$. in dimension. Figure 13 shows images of the sphere and sample holder.

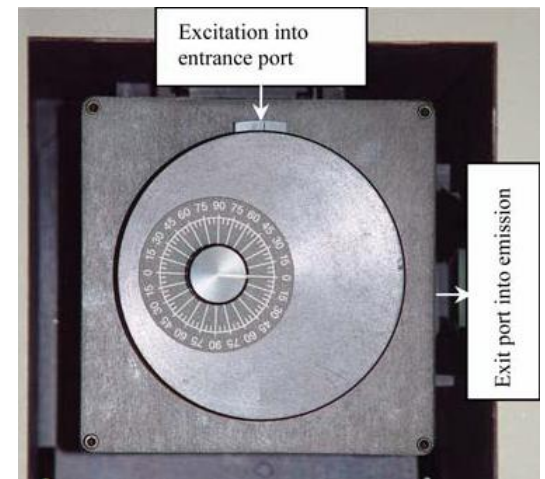

(a)

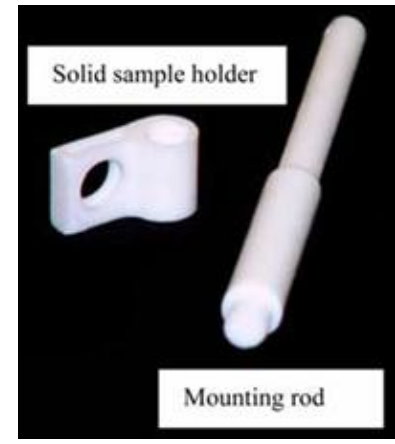

(b)

Figure 13. (a) Configuration of Fluorolog III - 4 inch integrating sphere. Sample is mounted in the center mount below the angular control. (b) Solid sample holder used for nanowire samples [43].

The geometry of the sphere allowed for sample reflectance measurements at the incident angles ranging from $15^{\circ}$ to $40^{\circ}$. At angles smaller than $15^{\circ}$, light reflected by the sample was directed towards the detector. At angles greater than $40^{\circ}$, incident light hit the sample holder. A background scan was taken with the sample in the sphere but with the light source not hitting the sample. While this background scan eliminated substitution errors caused be placing the sample inside the sphere, the measurements were not as reliable as those made with a sphere operating in the two-beam mode [44]. 
Measurements using the Fluorolog III were taken in Real Time Control (RTC) mode by setting the light emission beam and detector to the same frequency of light. This method was more efficient than using the software for fluorescence scans as the samples were not expected to fluoresce at visible wavelengths. Measurements were taken manually by inserting a $\mathrm{ZnO}$ sample, turning the sample at $5^{\circ}$ increments, and recording the counts. The measurements were performed at set wavelengths from $300 \mathrm{~nm}$ to 800 $\mathrm{nm}$ and at angles from $15^{\circ}$ to $60^{\circ}$. 


\section{Results and Discussion}

$\mathrm{ZnO}$ nanowires were grown using two different methods, aqueous chemical growth (ACG) and electrodeposition. All wires exhibited $c$-axis, hexagonal crystal growth, however, nanowire array morphology depended on the growth method. ACG grown nanowires exhibited vertical orientation while electrodeposited nanowires tended to have a random orientation. The use of a planar $\mathrm{ZnO}$ layer as a seeding layer affected nanowire morphology for both deposition methods. A wide range of morphologies was explored. Optimization of growth was focused on creating AR coatings. According to theory, these should have long, thin nanowires, with substantial height variations. ACG is a more versatile method than electrodeposition since it can be performed on both conductive and non-conductive substrates. In addition, the morphology of the wires grown using ACG showed greater promise as an optimum AR coating. Thus, more attention went toward developing the ACG method experimentally. Appendix 1 lists the properties of all $\mathrm{ZnO}$ nanowires samples grown.

\subsection{SEM images and Analysis of ZnO Nanowire Morphology}

Scanning Electron Microscope images were made of the samples grown by ACG and electrodeposition. The images were used to evaluate the average $\mathrm{ZnO}$ nanowire lengths, diameters, and number density for each growth. Images also provided information about the orientation of the nanowires. 


\subsubsection{Aqueous Chemical Growth (ACG)}

Wires grown by ACG tended to be orientated vertically. Initial trials indicated that the growth of $\mathrm{ZnO}$ nanowire arrays required a seed layer provided by the spray pyrolysis of zinc acetate. Optimal growth occurred in a steady state, covered bath. Figure 14 shows results from initial trials of $0.05 \mathrm{M}, 0.02 \mathrm{M}$ and $0.1 \mathrm{M}$ concentrations. Without a seed layer, large crystals formed and there was no uniform nanowire growth. With a seed layer, stirring or moving the solution would result in large crystals deposited on nanowire arrays.

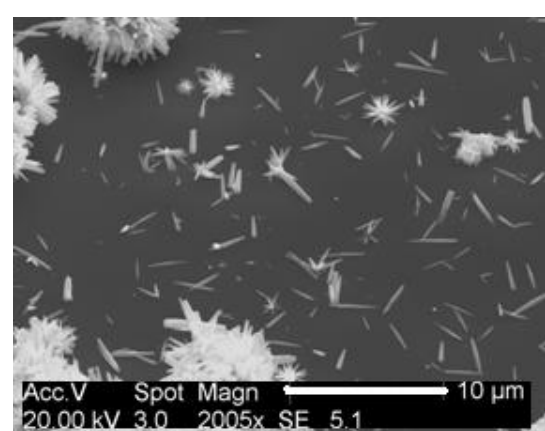

(a)

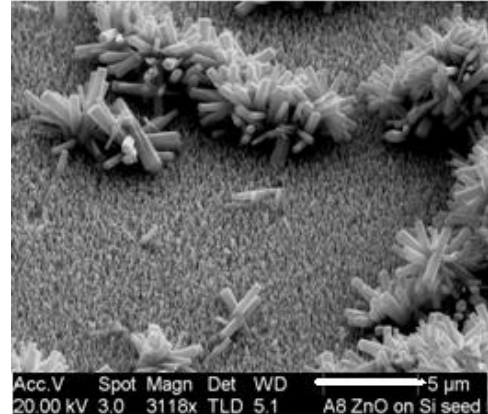

(b)

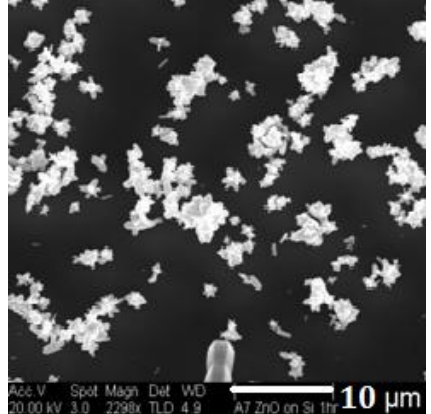

(c)

Figure 14. Initial attempts to grow uniform $\mathrm{ZnO}$ nanowire arrays by ACG. (a) Sample A1: $0.05 \mathrm{M}$. No seed layer. (b) Sample A8: 0.02 M. Large $\mathrm{ZnO}$ crystals deposited on wires due to stirring solution. (c) Sample A7: 0.1 M. No seed layer.

The seeding layer was created by spray pyrolysis of zinc acetate. The seed layer acts as a nucleation site for the polar growth of the $\mathrm{ZnO}$ nanowires. Figure 15 shows the various numbers of layers that were used to seed the silicon substrate. Uniform nanowire growth took place using 5, 10, 20 and 40 spray layers. Nanowire height varied from $200 \mathrm{~nm}$ to $1100 \mathrm{~nm}$, with a diameter range of $32 \mathrm{~nm}$ to $120 \mathrm{~nm}$. 


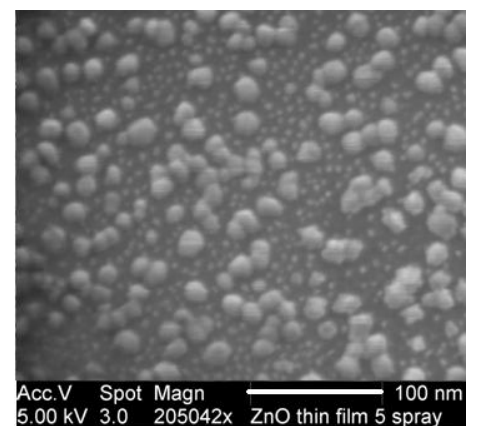

(a)

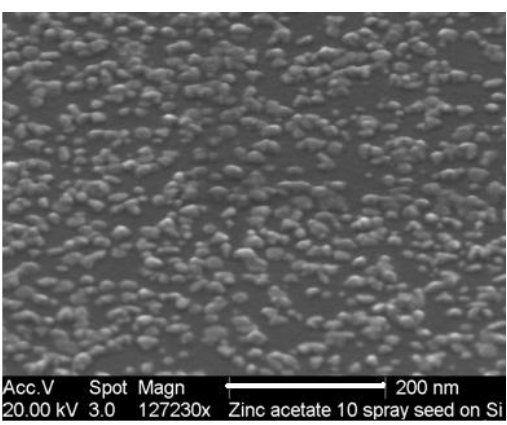

(b)

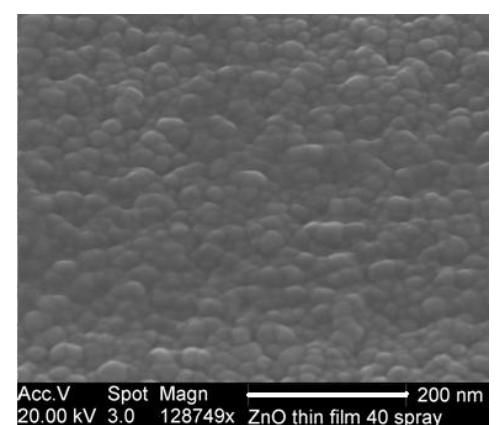

(c)

Figure. 15. (a) 5 Spray layers of zinc acetate leave $\mathrm{ZnO}$ "seeds" on Si. The seeds average $15 \mathrm{~nm}$ in diameter. (b) 10 spray layers of zinc acetate leads to seeds with an average diameter of $20 \mathrm{~nm}$. (c) 40 spray layers of zinc acetate leads to a planar $\mathrm{ZnO}$ surface estimated to be between $40 \mathrm{~nm}-60 \mathrm{~nm}$ in thickness.

Regardless of the seeding layer, samples with uniform vertical nanowire growth appeared visually opaque when deposited on the silicon surface. Examples of uniform nanowires grown by ACG are shown in Figure 16.

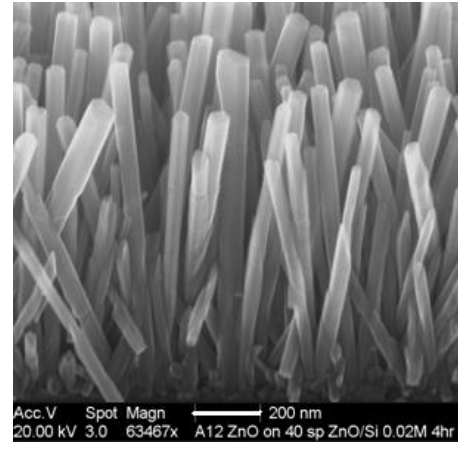

(a)

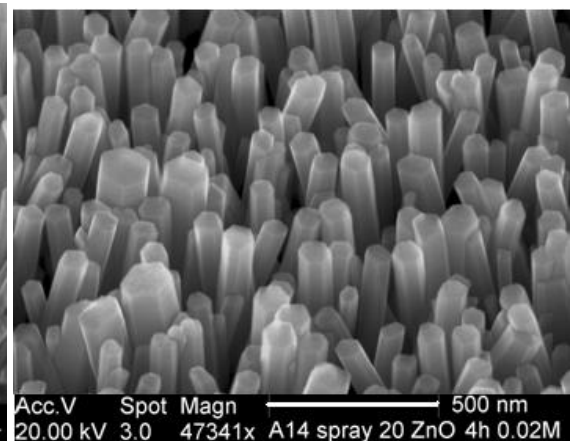

(b)

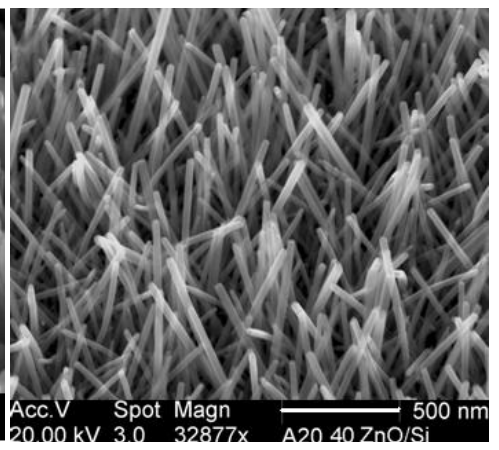

(c)

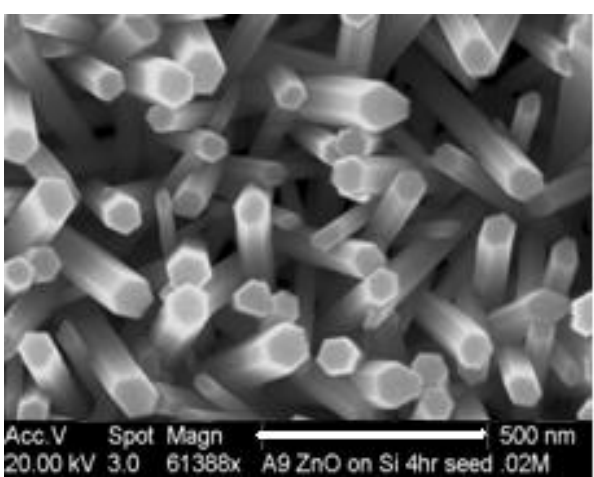

(d)

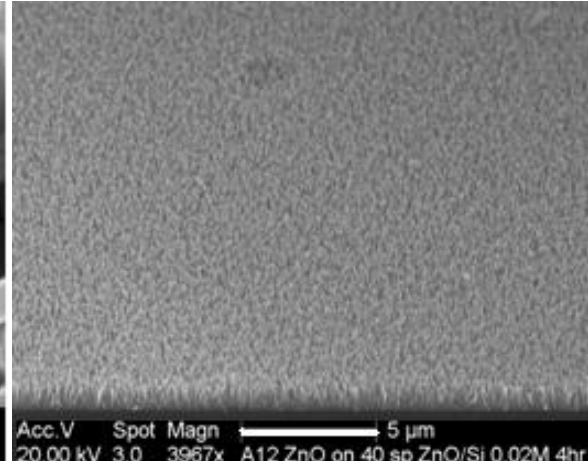

(e)

Figure 16. (a) Side view of $0.02 \mathrm{M}$ vertical wires (Sample A12). (b) $30^{\circ}$ tilted view of nanowire density (Sample A14). (c) 0.01 M nanowire growth (Sample A22) (d) Top view of nanowire hexagonal faces (Sample A9) (e) Uniformity of sample growth (Sample A12). 
Table 2 summarizes the properties of ACG nanowires evaluated from SEM images. The average length and diameter were found by averaging 7 to 10 nanowires. The standard deviation of the diameters was $20 \mathrm{~nm}$ to $30 \mathrm{~nm}$. The length was difficult to assess from the images because of dense nanowire growth, and had a greater deviation of $100 \mathrm{~nm}$ to $200 \mathrm{~nm}$. The fractional area is the product of the number of nanowires per unit area and the average cross-sectional area of the wire. Appendix 1 lists all samples grown by ACG.

\begin{tabular}{|c|c|c|c|c|c|c|c|}
\hline \multicolumn{8}{|c|}{ Table 2: Uniform ZnO Nanowires Grown on Silicon by ACG } \\
\hline No. & $\begin{array}{l}\text { Sample } \\
\text { ID }\end{array}$ & $\begin{array}{l}\text { Pre-growth } \\
\text { (Sprays of } \\
\text { Zinc acetate) }\end{array}$ & $\begin{array}{l}\text { Avg. } \\
\text { Length } \\
(\mathrm{nm})\end{array}$ & $\begin{array}{c}\text { Avg. } \\
\text { Diameter } \\
(\mathrm{nm})\end{array}$ & $\begin{array}{c}\text { Number } \\
\text { Density } \\
\left(\text { Wires } / \mu \mathrm{m}^{2}\right)\end{array}$ & $\begin{array}{c}\text { Fractional } \\
\text { surface } \\
\text { area }\end{array}$ & Notes: \\
\hline 1 & A9 & 20 sprays & 1100 & 94 & 62 & 0.430 & $0.02 \mathrm{M} / 4 \mathrm{hr}$ \\
\hline 2 & A10 & 10 sprays & 900 & 120 & 32 & 0.362 & $0.02 \mathrm{M} / 4 \mathrm{hr}$ \\
\hline 3 & A11 & 5 sprays & $\mathrm{X}$ & 48 & 170 & 0.307 & $0.02 \mathrm{M} / 4 \mathrm{hr}$ \\
\hline 4 & A12 & 40 sprays & 960 & 68 & 90 & 0.327 & $\begin{array}{l}0.02 \mathrm{M} / 4 \mathrm{hr} \\
\quad(95 \mathrm{C})\end{array}$ \\
\hline 5 & A13 & 40 sprays & $\mathrm{X}$ & 80 & 54 & 0.271 & $0.02 \mathrm{M} / 4 \mathrm{~h}$ \\
\hline 6 & A14 & 20 sprays & 950 & 90 & 67 & 0.426 & $0.02 \mathrm{M} / 4 \mathrm{hr}$ \\
\hline 7 & A15 & 10 sprays & 845 & 56 & 86 & 0.211 & $0.02 \mathrm{M} / 4 \mathrm{hr}$ \\
\hline 8 & A16 & 40 sprays & 1060 & 100 & 43 & 0.338 & $0.02 \mathrm{M} / 4 \mathrm{hr}$ \\
\hline 9 & A19 & 40 sprays & 900 & 63 & 65 & 0.203 & $0.02 \mathrm{M} / 4 \mathrm{hr}$ \\
\hline 10 & A20 & 40 sprays & 418 & 32 & 190 & 0.153 & $0.01 \mathrm{M} / 5 \mathrm{hr}$ \\
\hline 11 & A22 & $\begin{array}{c}40 \text { sprays/ } \\
50 \mathrm{~nm} \mathrm{TiO}_{2}\end{array}$ & 1070 & 110 & 20 & 0.190 & $0.02 \mathrm{M} / 4 \mathrm{hr}$ \\
\hline
\end{tabular}

The seeding layer affected the morphology and density of nanowire growth; however, the relationship between the layer and nanowire density was unclear. Uncontrollable variation in the spray pyrolysis method led to an indeterminate relationship between nanowire growth and the seed layer. A 40 spray layer was found to produce the most dependable growth. The 40 layers provided a uniform $\mathrm{ZnO}$ planar surface estimated to be $40 \mathrm{~nm}-50 \mathrm{~nm}$ thick. A planar layer between the nanowires and 
the silicon provides the best match for a gradient-index optical coating made of $\mathrm{ZnO}$ nanowires.

The $\mathrm{ZnO}$ nanowires arrays showed a clear relationship between growth density, nanowire diameter, and nanowire length as shown in Figure 17.

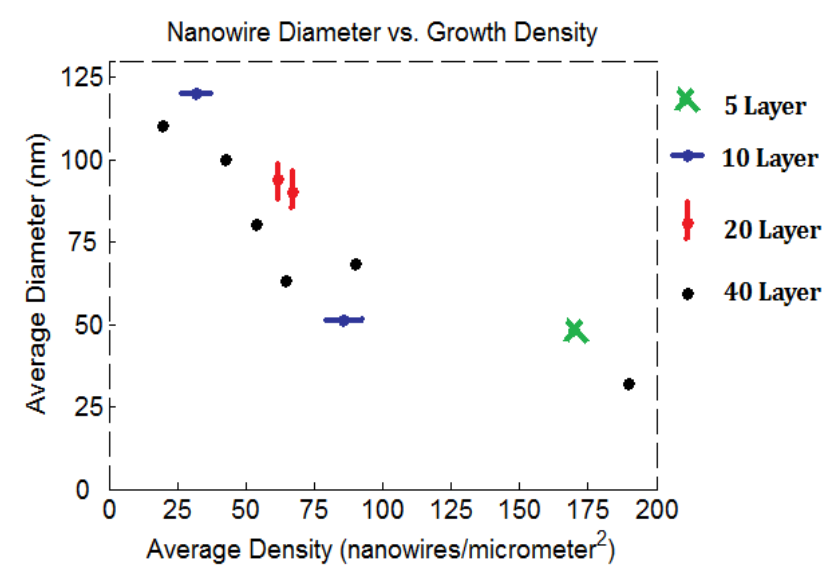

(a)

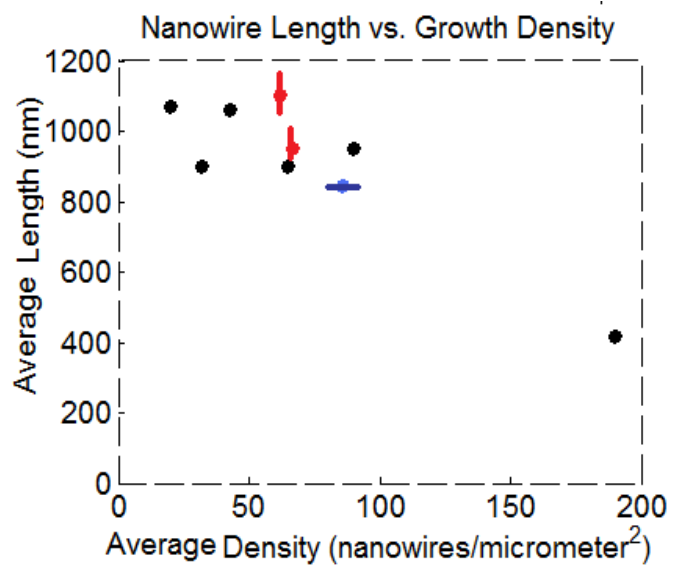

(b)

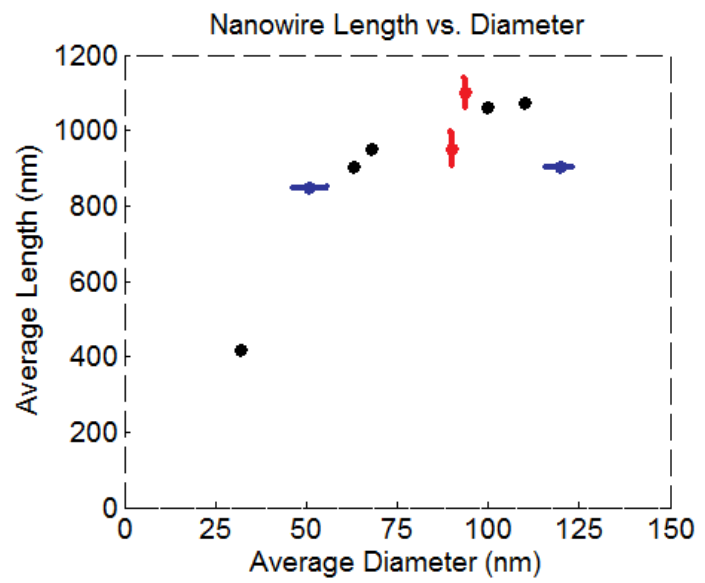

(c)

Figure 17. ACG growth results. Different symbols indicate the number of zinc acetate layers used to seed the substrate. (a) Nanowire diameter and growth density. (b) Nanowire length and growth density and (c) Nanowire length and diameter.

As nanowires increased in diameter they decreased in number density. No other correlations were obvious between the diameter, length, number density, and the fraction of surface area coved by the nanowires. $\mathrm{ZnO}$ nanowires grown in a $0.02 \mathrm{M}$ bath had 
vertical alignment, with vertical tilt less than $15^{\circ}$. Nanowires grown at $0.01 \mathrm{M}$

concentration had vertical tilts less than $30^{\circ}$.

\subsubsection{Electrodeposition}

$\mathrm{ZnO}$ nanowires grown by electrodeposition tended to be randomly orientated.

Their vertical tilt could extend to $80^{\circ}$. They were also longer and had larger diameters than those grown by aqueous bath. Wires were initially grown on ITO covered quartz to determine the optimum conditions for growth. Figure 18 shows examples of nanowires on ITO/quartz.

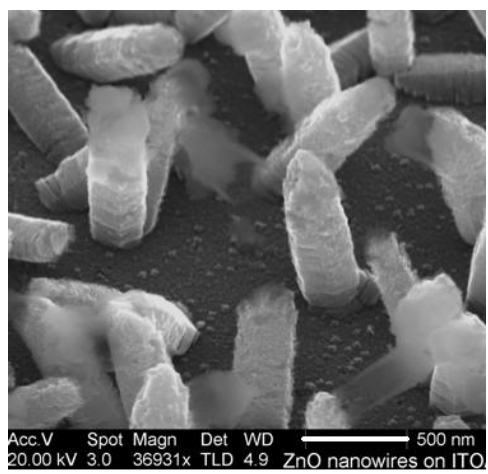

(a)

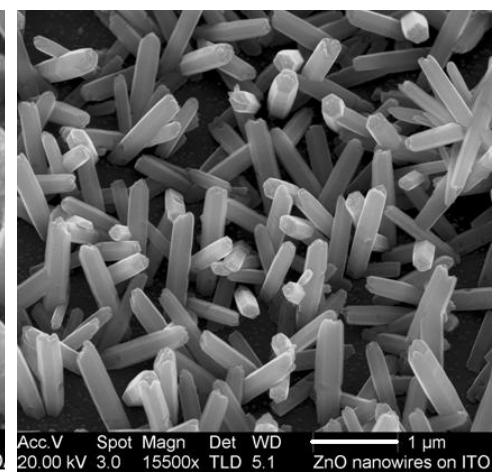

(b)

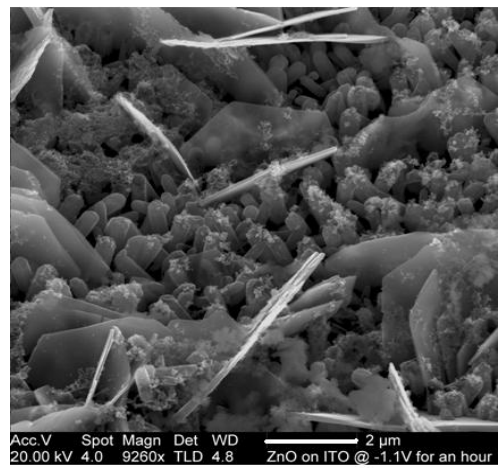

(c)

Figure 18. ZnO nanowires grown by electrodeposition on ITO/Glass, with the relative voltage of the cathode at: (a) Sample G1: -1.00V (b) Sample G2: -1.05V and (c) Sample G3: -1.10V.

Table 3 lists the nanowire lengths, diameters and number densities.

\begin{tabular}{|c|c|c|c|c|c|}
\hline \multicolumn{6}{|c|}{ Table 3. Electrodeposited ZnO Nanowires on ITO/Quartz } \\
\hline No. & $\begin{array}{c}\text { Sample } \\
\text { ID }\end{array}$ & $\begin{array}{c}\text { Voltage } \\
(\mathrm{V})\end{array}$ & $\begin{array}{c}\text { Avg. Length } \\
(\mathrm{nm})\end{array}$ & $\begin{array}{c}\text { Avg. Diameter } \\
(\mathrm{nm})\end{array}$ & $\begin{array}{c}\text { Density } \\
\left(\text { Wires/ } / \mu \mathrm{m}^{2}\right)\end{array}$ \\
\hline 1 & G1 & -1.00 & 700 & 225 & 0.72 \\
\hline 2 & G2 & -1.05 & 1000 & 250 & 4.44 \\
\hline 3 & G3 & -1.10 & NA & NA & Platelets \\
\hline
\end{tabular}

For AR coatings, the best density and length of $\mathrm{ZnO}$ nanowires were produced by

electrodeposition at a potential difference of $-1.05 \mathrm{~V}$. After trials on ITO/quartz, electrodeposition was then used to grow nanowires on ITO/silicon substrates. 
Three different samples were prepared on ITO/silicon, two without a seeding layer and one with a planar $\mathrm{ZnO}$ layer created by spray pyrolysis. Sample I1 was grown directly on ITO/Si with a potential of $-1.05 \mathrm{~V}$, and is shown in Figure 19.

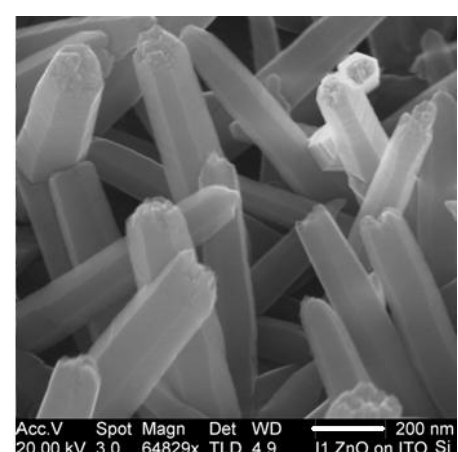

(a)

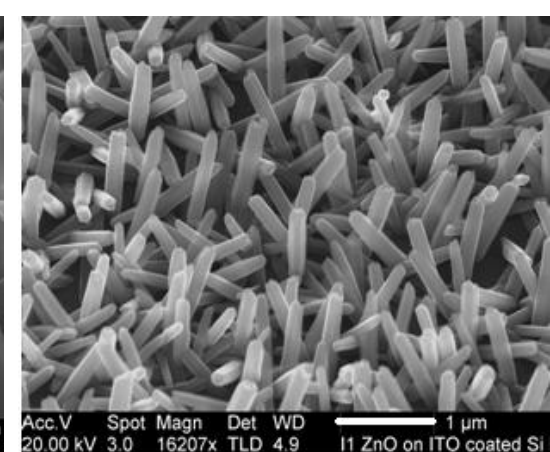

(b)

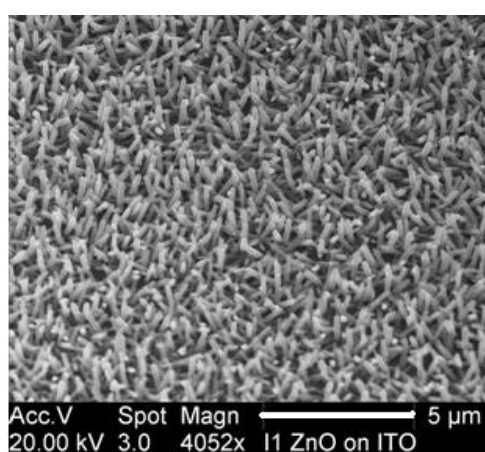

(c)

Figure 19. Sample I1: $\mathrm{ZnO}$ deposited at $-1.05 \mathrm{~V}$ on ITO/SI with scale bars (a) $200 \mathrm{~nm}$ (b) $1 \mu \mathrm{m}$ and (c) $5 \mu \mathrm{m}$.

The $\mathrm{ZnO}$ nanowires have diameters of $150 \mathrm{~nm}$ to $200 \mathrm{~nm}$ and lengths of roughly $1 \mu \mathrm{m}$.

These wires have similar dimensions as those grown on ITO/quartz. Sample I3 was

grown with the same growth conditions, but could have had anomalous electrical contact with the substrate. The $\mathrm{ZnO}$ nanowires of Sample I3 exhibited a flower like morphology as shown in Figure 20.

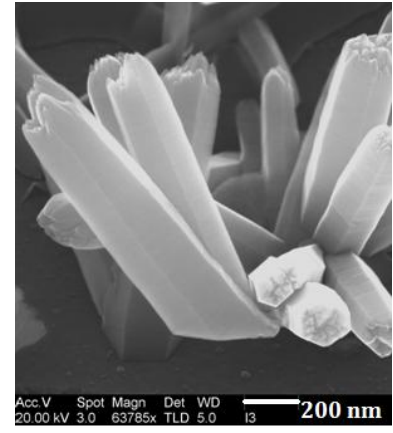

(a)

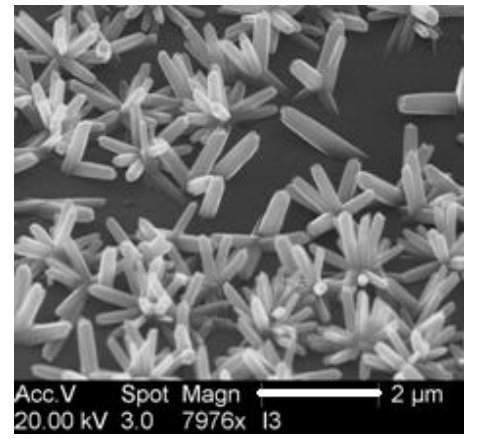

(b)

Figure 20. Sample I3: ZnO deposited at $-1.05 \mathrm{~V}$ on ITO/SI with scale bars (a) $200 \mathrm{~nm}$ (b) $2 \mu \mathrm{m}$.

The third sample grown by electrodeposition was grown on a planar layer of $\mathrm{ZnO}$ deposited by spray pyrolysis on ITO/silicon. The planar layer created a dense array of 
nanowires with dimensions comparable to those of the vertical $\mathrm{ZnO}$ nanowires grown by ACG. Figure 21 shows sample I2, which had average diameters of $85 \mathrm{~nm}$ and average lengths of $500 \mathrm{~nm}$.

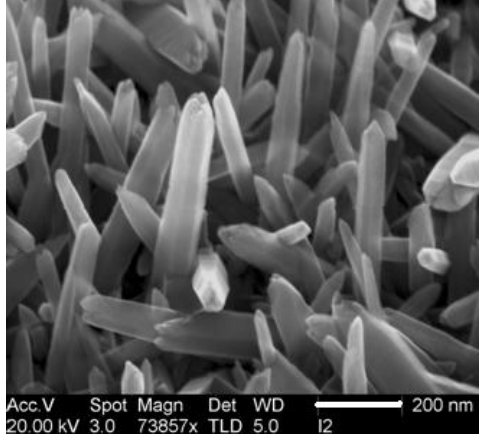

(a)

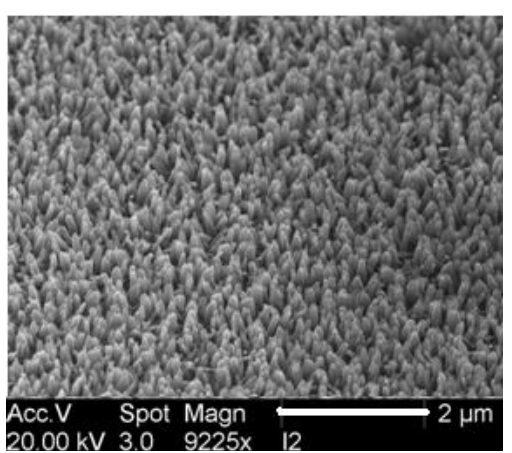

(b)

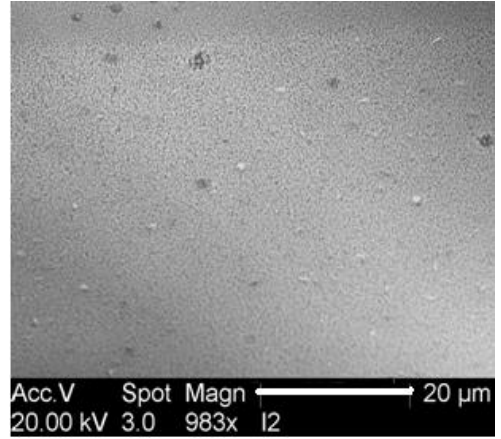

(c)

Figure 21. Sample I2: $\mathrm{ZnO}$ deposited at $\mathbf{- 1 . 0 5} \mathrm{V}$ on planar $\mathrm{ZnO}$ on ITO/SI with scale bars (a) $200 \mathrm{~nm}$ (b) $2 \mu \mathrm{m}$ and (c) $20 \mu \mathrm{m}$.

Table 4 lists the dimensions and morphology of $\mathrm{ZnO}$ nanowires deposited by electrodeposition on ITO/Si.

\begin{tabular}{|c|c|c|c|c|c|c|c|}
\hline \multicolumn{7}{|c|}{ Table 4. Electrodeposited ZnO Nanowires on ITO/Si at $\mathbf{- 1 . 0 5 ~ V}$} \\
\hline No. & $\begin{array}{c}\text { Sample } \\
\text { ID }\end{array}$ & $\begin{array}{c}\text { Pre-growth } \\
(\text { Sprays of Zinc } \\
\text { acetate) }\end{array}$ & $\begin{array}{c}\text { Avg. } \\
\text { Length } \\
(\mathrm{nm})\end{array}$ & $\begin{array}{c}\text { Avg. } \\
\text { Diameter } \\
(\mathrm{nm})\end{array}$ & $\begin{array}{c}\text { Density } \\
\left(\text { Wires/ } \mu \mathrm{m}^{2}\right)\end{array}$ & $\begin{array}{c}\text { Fractional } \\
\text { surface } \\
\text { area }\end{array}$ & Visual \\
\hline 1 & I1 & None & 1050 & 180 & 5.5 & 0.140 & White \\
\hline 2 & I2 & 40 sprays & 500 & 85 & 30 & 0.170 & Opaque \\
\hline 3 & I3 & None & 850 & 200 & 5 (Flowers) & 0.157 & White \\
\hline
\end{tabular}

The samples differed visually. The samples with larger wires and smaller number densities appeared white on the ITO/Si surface, whereas the dense nanowire sample I2, appeared as an opaque layer. All wires exhibited a hexagonal shape with random orientations and variations in length and diameter. Although they differed in length and diameter, the fractional area covered by nanowires was similar for all samples, and generally less than the fractional area covered by ACG wires. 


\subsection{Goniometer}

\subsubsection{Introduction to Measurements}

The goniometer was used to measure the diffuse and specular reflectivities for the $\mathrm{ZnO}$ nanowire samples. These reflectivities were compared with the reflectivity of silicon. Random and systematic errors for goniometer measurements made them primarily useful for qualitative comparisons.

The $532 \mathrm{~nm}$ diode laser required a 1 hour warm-up to reach constant power. Following this warm-up, the laser output varied 2-3\% during the scan. The lock-in amplifier had difficulty measuring the weak diffusely reflected radiances from the samples. A signal level below $5 \times 10^{-12} \mathrm{~A}$ was generally considered to be in the noise. Currents $5 \times 10^{-12} \mathrm{~A}$ and below appeared to vary randomly. At the other extreme, samples with high specular reflectivity often overloaded the lock-in amplifier, requiring attenuation of the signal with resistors and neutral density filters.

The most common source of measurement error was the alignment of the samples with respect to the laser and photodiode. A beam splitter or mirror was used to reflect scattered laser light from the sample into the photodiode. If the sample made a slight vertical tilt in the sample holder $\left(<1^{\circ}\right)$ the specular peak would not be measured accurately. For diffusely reflecting samples, it was difficult to identify the specular reflection peak, leading to error in alignment and measurement. For specular reflecting samples, small movements, such as the vertical tilt mentioned above, could cause $>10 \%$ errors in the reflectivity. 
The following alignment procedure was used for the goniometer. First, the laser was aligned in the horizontal plane. Second, the two stepper motors that controlled the photodiode arm and the sample stage, respectively, were calibrated in angle increments around a circle. Last, the sample was placed in the sample holder and positioned normal to the laser in both the vertical and horizontal plane by using the specular reflection of the laser's beam. Even with thorough calibration, systematic errors could be introduced through the scattering of light by the sample holder and the edges of the beam slitter. For these reasons, multiple scans were taken for each sample in order to verify the repeatability of measurements.

Despite the sources of error, the precision of the multiple scan measurements was high, provided the sample was not moved. This precision is illustrated in Figure 22a. If the sample was moved, slight changes in the sample surface and alignment contributed to different results, as seen in Figure 22b.

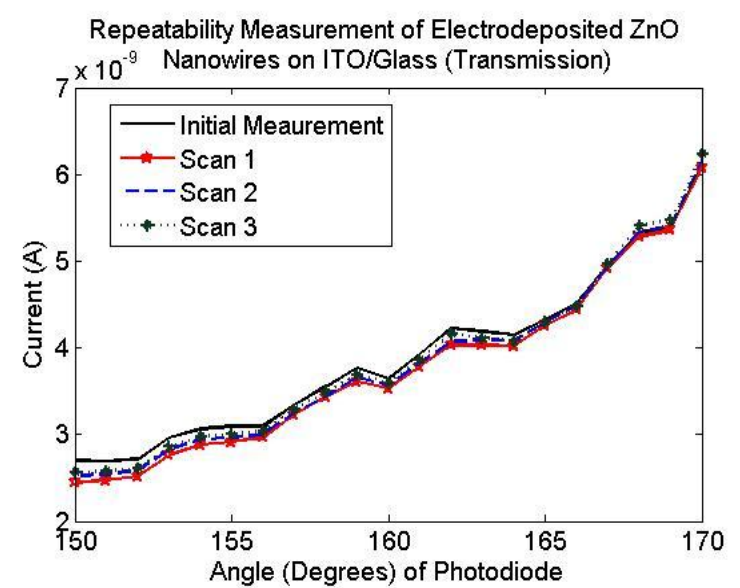

(a)

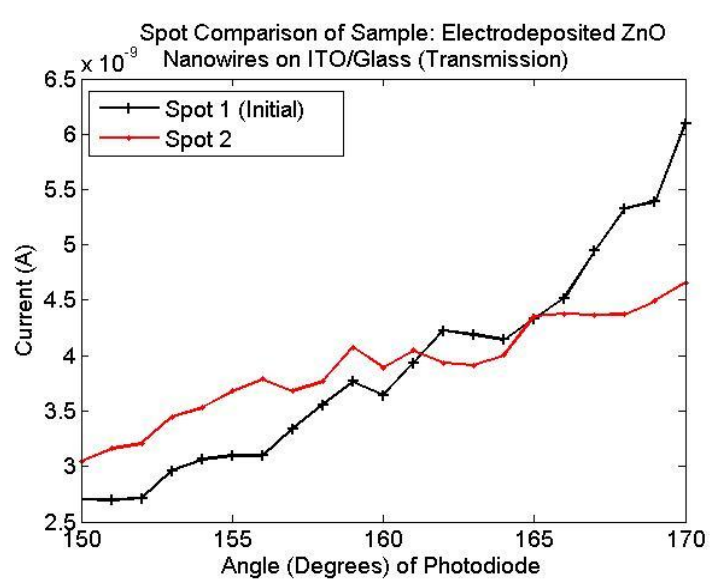

(b)

Figure 22. Repeatability of goniometer measurements for electrodeposited $\mathrm{ZnO}$ nanowires on ITO/quartz glass: (a) precision of spot repeatability and (b) difference caused by moving the sample. 
Owing to the variability caused by alignment, the drift of laser power over time, and the need to introduce filtering, the goniometer scans were used primarily for qualitative comparisons.

\subsubsection{Scatter Scan}

A scatter scan of reflected light was performed by illuminating the sample with the laser at normal incidence, and rotating the photodiode at $1^{\circ}$ increments in the horizontal plane. The angles were measured with respect to normal incident light at $0^{\circ}$. To measure the reflectivity, light was reflected from the sample by a beam splitter or silicon mirror. While measuring reflectivity at normal incidence, the glass beam splitter interfered with the laser beam, thereby reducing the specular reflection peak. For a silicon mirror, the sample was turned $2^{\circ}$ with respect to normal in order to measure the specular reflection at $4^{\circ}$. Measurements taken with a small angle offset were plotted with respect to normal incident light in order to qualitatively compare samples. The current was used for scatter scan plots as it was proportional to the irradiance of the photodiode and thus to the reflectivity.

Measurements showed that vertically oriented $\mathrm{ZnO}$ nanowires grown by ACG exhibited diffuse reflection, with a specular reflection peak below that of silicon, as presented in Figure 23. ACG samples A9, A12, and A15, shown in Figure 23, had diameters of $65 \mathrm{~nm}$ to $90 \mathrm{~nm}$. Repeatability measurements and scans on different parts of the same samples are shown in Figure 24. The results illustrate the consistency of the signal and the dependence of the reflectivity on the sample surface and alignment. 


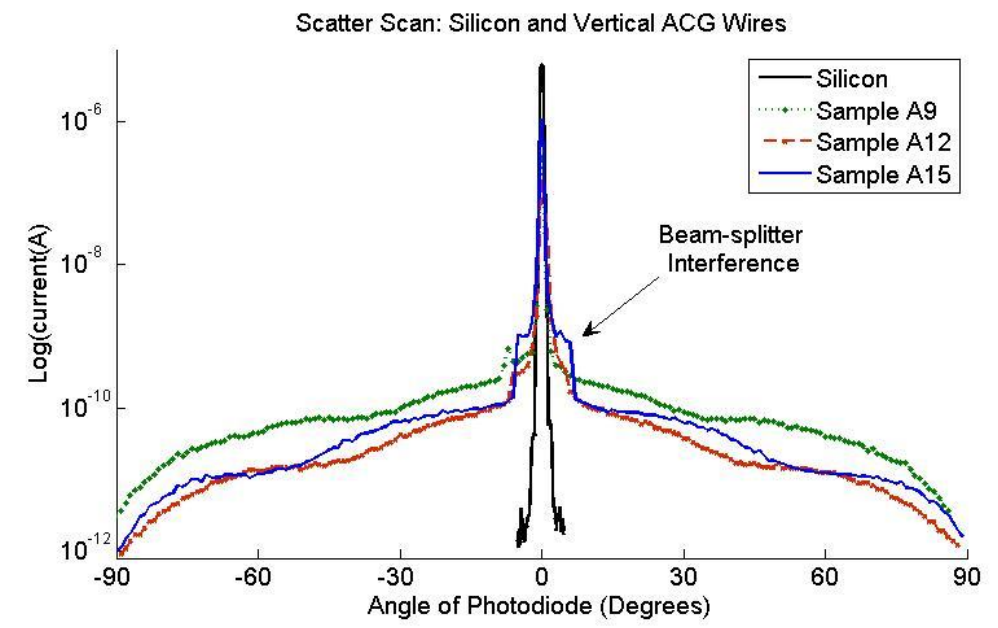

Figure 23. Scatter scan for ACG ZnO nanowires grown using a $4 \mathrm{hr} 0.02 \mathrm{M}$ bath. Measurements were performed with a glass beam splitter.

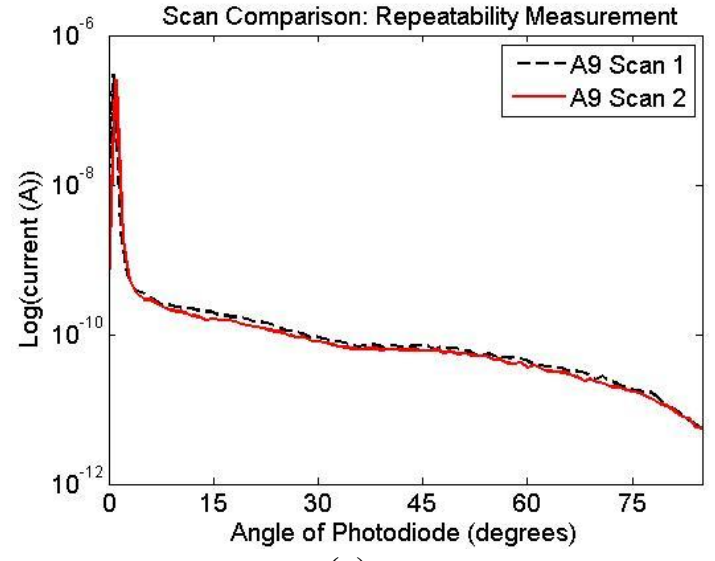

(a)

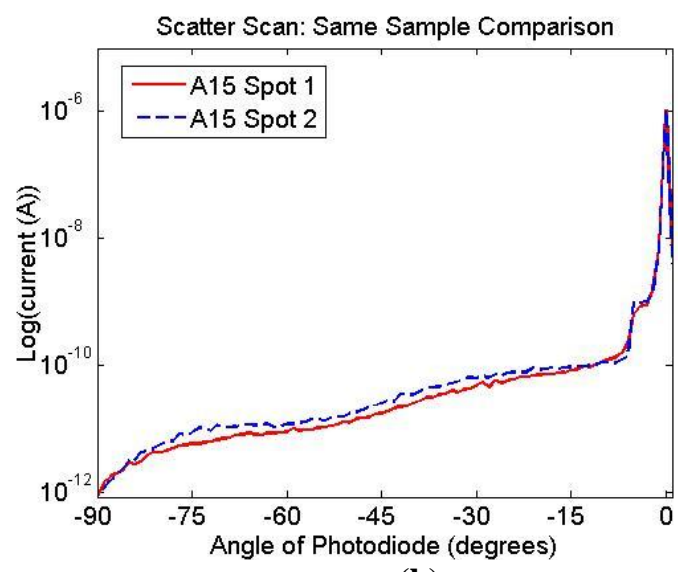

(b)

Figure 24. Reflectivities at normal incidence using a glass beam-splitter (a) Repeatability measurement of sample A9 without moving sample. (b) Comparison of reflectivities for sample A15 where the sample was moved in between measurements.

The scattering by the ACG vertical nanowire samples is not Lambertian, and is characteristic of the vertical orientation and size of the nanowires. In contrast, samples that had large crystal growth, such as sample A8 shown in Figure 14b, exhibited Lambertian scattering. The reflectivity was proportional to $\cos (\theta)$ function, where $\theta$ is the angle from the normal. 


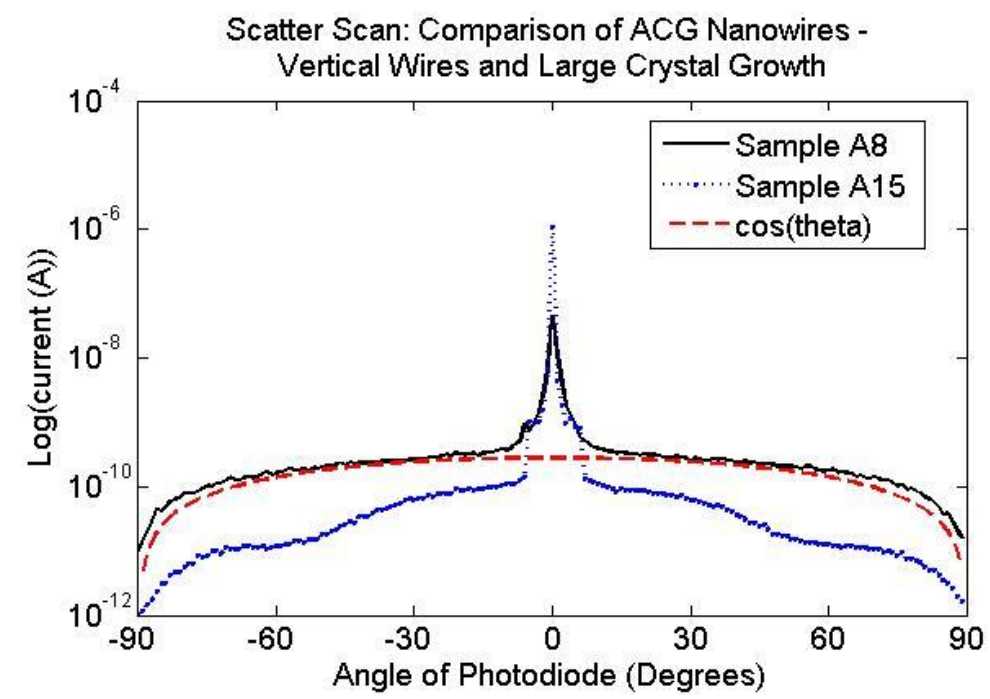

Figure 25. Comparison of the Lambertian scattering for sample A8 with large crystal growth of sample A8 to the reduced diffusivity for sample A15 with no crystal growth.

Figure 25 shows $\cos (\theta)$ compared to the reflectivity for vertical nanowires with and without large crystal growth. The specular reflection peak for sample A8 was not accounted for by Lambertian scattering.

Randomly oriented $\mathrm{ZnO}$ nanowires grown by electrodeposition showed diffuse reflectivity similar to that caused by the large crystal growth on sample A8. Figure 26 compares the reflectivity of randomly oriented nanowires to the reflectivity of silicon. Most randomly oriented nanowires exhibited Lambertian reflectivity and a smaller specular reflectivity. Nanowire dimension and orientation may contribute to diffuse scattering. Sample I1 had a diameter of $185 \mathrm{~nm}$, which was less than the $500 \mathrm{~nm}$ diameter of the large crystal growths, but greater than the diameters of the vertical $\mathrm{ZnO}$ nanowires. 


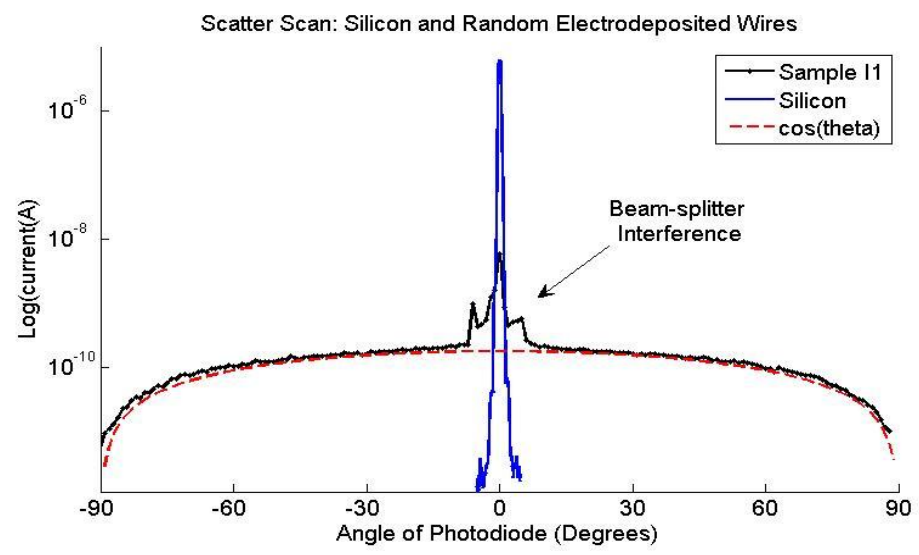

Figure 26. Lambertian fit of Sample I1, randomly oriented $\mathrm{ZnO}$ nanowires grown by electrodeposition.

Compared with randomly oriented nanowires with larger sizes, sample I2

exhibited strong specular reflection and smaller diffuse reflectivity. Sample I2, grown by electrodeposition on a planar $\mathrm{ZnO}$ layer, had randomly oriented nanowires and average diameters of $85 \mathrm{~nm}$, which were within the range of the diameters of the vertical nanowires. Figure 27a compares the scattered light for samples I1 and I2. Compared with vertical nanowire samples having a similar nanowire diameters, sample I2 had larger diffuse reflectivity and smaller specular reflectivity, as shown in Figure 27b.

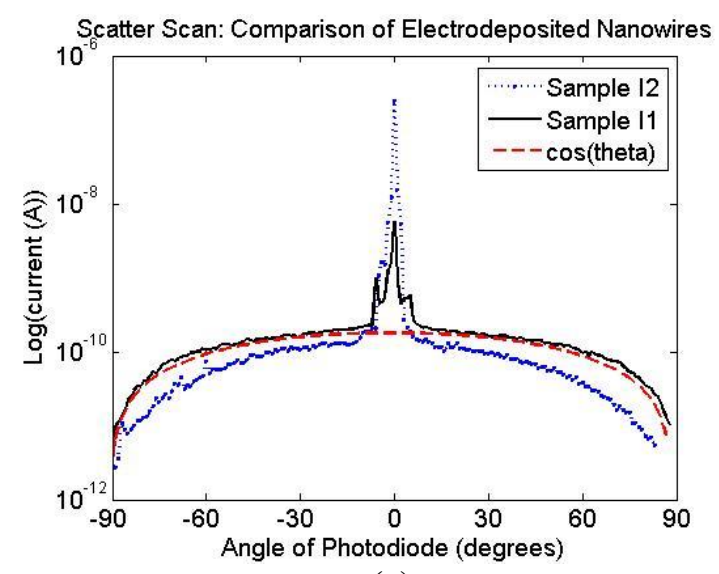

(a)

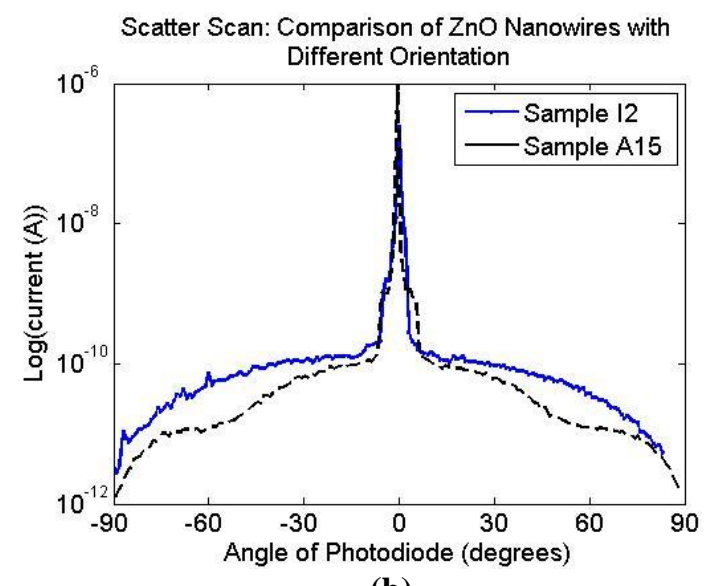

(b)

Figure 27. (a) Reflectivity of randomly orientated nanowires with large diameter (I1) and small diameter (I2). Only I1 showed Lambertian scattering. (b) Reflectivity for nanowires with different orientations but similar diameters. Sample I2 had randomly oriented nanowires and sample A15 had vertically oriented nanowires. 
Reflectivity data collected with goniometer scatter scans was integrated for normal incident light, assuming symmetry about the incident beam, to yield the total power of the scattered light. The integrations depended on accurate measurements of the specular peak, and samples with large specular reflectivities were measured with angular steps of $0.1^{\circ}$. Errors of up to $11 \%$ in the total reflectance were unavoidable due to variations in amplitude caused by sample alignment. The integration of the current gave the total current over a hemisphere: $I_{\text {total }}=\sum \frac{I\left(\theta_{i}\right)}{L^{2}} \cdot \alpha_{i} \cdot \frac{2 \pi R \sin \left(\theta_{i}\right)}{2} \cdot R d \theta$, where $I\left(\theta_{i}\right)$ is the measured current, $R$ is the radius at which the photodiode moves around the sample, and $\theta_{i}$ is the angle that the detector makes with the normal to the sample. Figure 28 shows the geometry used for integration.

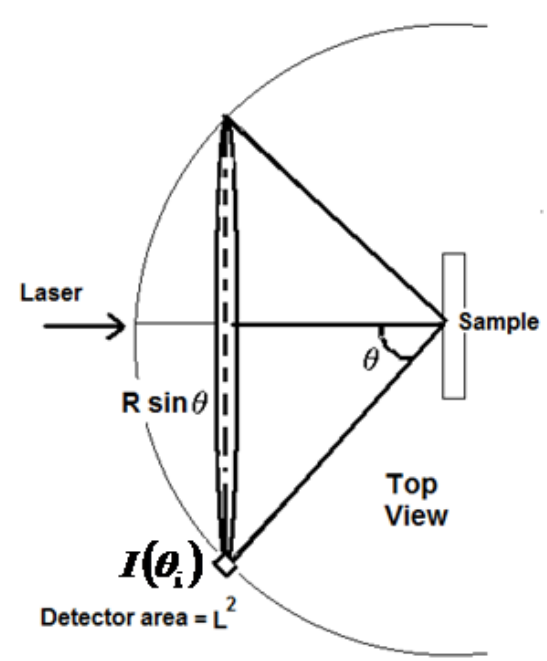

Figure 28. Top view of the geometry for goniometer integration

To account for the variations in the angular increment required for accurate integration, the increment $\Delta \theta=\frac{L}{R}$, where $L$ is the width of the detector, was adjusted by a factor $\alpha_{i}$. Measurements of samples were taken at $1^{\circ}$ angle increments so that $\alpha_{i} \approx 1$. Silicon and the incident beam, however, had large peaks of intensity for $\theta=0^{\circ}$. These peaks were 
measured at smaller increments, $\alpha_{i} \approx 0.1$. Integration of the current was over a hemisphere. The current was multiplied by a factor $\alpha_{i} 2 \pi R \sin (\theta) R d \theta$. The area of the detector was taken into consideration by dividing the measured current, $I_{i}$, by the area of the detector, $L^{2}$. The integration was for $\theta_{i}$ ranging from $-90^{\circ}$ to $90^{\circ}$. Since measurements were taken to be identical on both sides of the incident beam, the average value of the two measurements was used. The total was thus divided by a factor two. The total current is given by: $I_{\text {total }}=\sum \frac{I}{L} \alpha \cdot \Delta \theta \cdot \pi R \sin (\theta)$. The same integration was performed for the incident beam. Unfortunately, large percent uncertainties arose from the errors in the amplitudes of the specular peaks caused by misalignment of the sample.

\begin{tabular}{|c|c|c|}
\hline \multicolumn{2}{|c|}{ Table 5: Goniometer: Total Integrated Currents and Reflectances } \\
\hline Sample & $\begin{array}{c}\text { Total Integrated Current } \\
+/ \mathbf{~ 1 1 \%}\end{array}$ & $\begin{array}{c}\text { Reflectance } \\
+/-\mathbf{1 5 \%}\end{array}$ \\
\hline Silicon & $3.42 \times 10^{-6} \mathrm{~A}$ & $33 \%$ \\
\hline Sample A12 & $7.29 \times 10^{-7} \mathrm{~A}$ & $7 \%$ \\
\hline Sample A13 & $6.83 \times 10^{-7} \mathrm{~A}$ & $7 \%$ \\
\hline Sample I1 & $2.36 \times 10^{-6} \mathrm{~A}$ & $23 \%$ \\
\hline Incident beam* & $1.05 \times 10^{-5} \mathrm{~A}$ & \\
\hline
\end{tabular}

*Integrated current of $532 \mathrm{~nm}$ laser beam measured at $180^{\circ}$ with no sample in holder

All nanowire samples had reflectances less than that for silicon. Large, diffusely reflecting nanowires such as sample I1, had a greater reflectances than the smaller, vertical nanowire samples. The vertically oriented nanowire samples A12 and A13 had the smallest reflectances. The results of the integrations indicated the relative reflectances of the nanowire samples. Owing to the difficulty of measuring the specular peaks, the reflectances of the samples may be artificially low. Consequently, an integrating sphere was used to verify the total reflectances for the nanowire samples. Section 3.3 discusses the integrating sphere results. Although measurements by the goniometer were uncertain, 
they provided an advantage over an integrating sphere by differentiating between specular and diffuse reflectivity. By using the goniometer, the type of scattering which was measured for each sample could be associated with the nanowire morphology.

Scatter scans of the $\mathrm{ZnO}$ nanowires were also performed with the sample at oblique angles to the incidence light. However, turning the sample with respect to the incident light ruined the symmetry about the axis of the incident laser beam. Therefore, conclusions about the total reflection of the sample as a function of angle could not be made. Alternatively, angular measurements were taken of the specular reflection peak as a function of angle.

\subsubsection{Angle Dependent Specular Reflectivity}

The angle dependent specular reflectivity was measured for the $\mathrm{ZnO}$ nanowires using the goniometer specular scan program. The goniometer sample holder turned at $0.5^{\circ}$ increments to the incident laser beam, while the photodiode tracked the specular reflection peak by positioning itself automatically at twice the angle of incident light.

In the specular scan measurement, a variable linear polarizer was placed in front of the laser beam chopper, along with a filter to attenuate the signal. A silicon mirror was used in place of a glass beam splitter to reduce noise. Alignment of the sample and photodiode was critical for consistent measurement of the specular peak. Alignments were performed between each scan. Specular reflectivities of the sample were measured from $0^{\circ}$ to $83^{\circ}$ for TE and TM polarized light. 
The difficulty of the alignment for the specular scans led to fewer samples being measured. Figure 29 shows the specular reflectivity of silicon which fits the theory for an index of refraction $n=3.95$. The reflectivity of the silicon at $4^{\circ}$ was used to normalize the measurements to the theoretical values. The amplitude of the measured current from $0^{\circ}$ to $83^{\circ}$ was divided by the amplitude of the current measured at $4^{\circ}$, then multiplied by the theoretical reflectivity for normal incidence. Normalization of the measured silicon reflectivity at near-normal incidence allowed the TE and TM polarized reflectivities to be compared to the theoretical values.

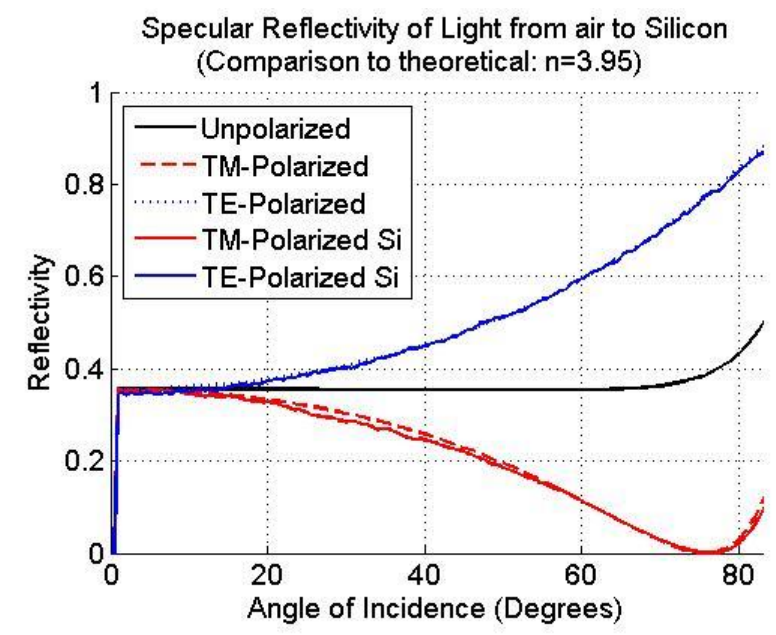

Figure 29. Specular reflection for silicon normalized to a theoretical reflection for a material with index of refraction $n=3.95$. The experimental reflectivity for TE polarized light covers the theoretical value.

The index of refraction used for the theoretical fit was the value which best fit the measured reflectivities for both the TE and TM polarized waves. Although the reflectivity of the laser with a nominal wavelength of $532 \mathrm{~nm}$ indicates a larger index of refraction for silicon, $n=4.2$ [2], this discrepancy might be attributed to the laser calibration and alignment errors. In addition, reflection by the silicon mirror used to direct light from the sample into the photodiode might also have cause aberrations in the 
polarization. Despite the discrepancies, a qualitative comparison could be made between the specular reflectivities for silicon and those for $\mathrm{ZnO}$ nanowire arrays.

Specular reflection measurements were performed for vertical nanowire sample A15 and randomly oriented nanowire samples I1 and I2. The samples were normalized using the same factors used for silicon normalization. Measurements were taken multiple times to verify their amplitudes.

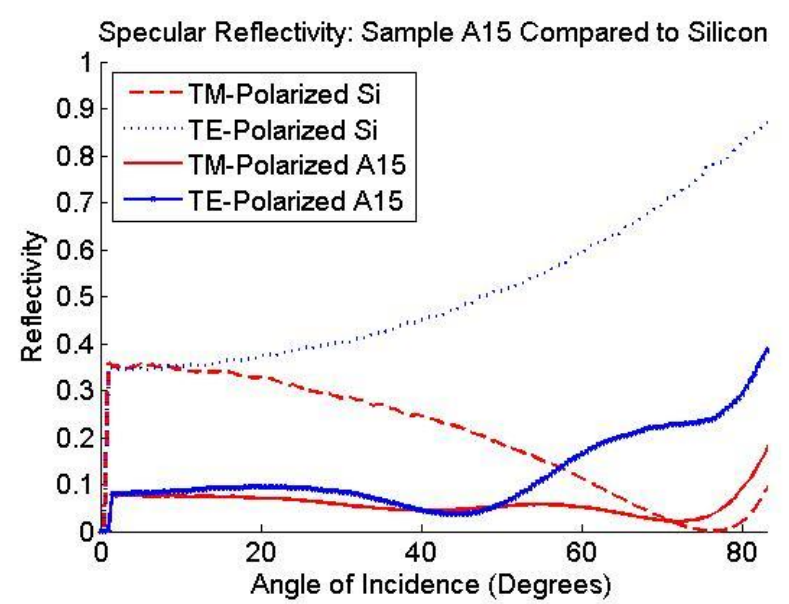

Figure 30. Specular reflectivity for polarized light for silicon and sample A15, vertical nanowires, with a diameter of $51 \mathrm{~nm}$. Values were experimentally found and were normalized with the same coefficients used for silicon normalization.

Figure 30 shows the polarization dependence of the specular reflectivity for vertical $\mathrm{ZnO}$ nanowires. Scatter scans of the vertical nanowires had shown high specular reflection peak and low diffuse reflection. Although significantly less than the specular reflectivities of silicon, the nanowire reflectivities still exhibited polarization dependence.

Compared with vertical nanowire samples, samples I1 and I2 with randomly oriented $\mathrm{ZnO}$ nanowires had much smaller specular reflectivities with little variability in the reflection for TE and TM polarized light. Figure 31 shows the specular reflectivities for electrodeposited samples and silicon. Sample I1, with average nanowire diameters of $180 \mathrm{~nm}$, showed nearly identical specular reflectivities for TE and TM polarized light. 
The reflectivities were much smaller than those for silicon, except when approaching grazing angles of incidence. Sample I2, with average nanowire diameters of $85 \mathrm{~nm}$, showed polarization dependent specular reflectivities at angles greater than $40^{\circ}$.

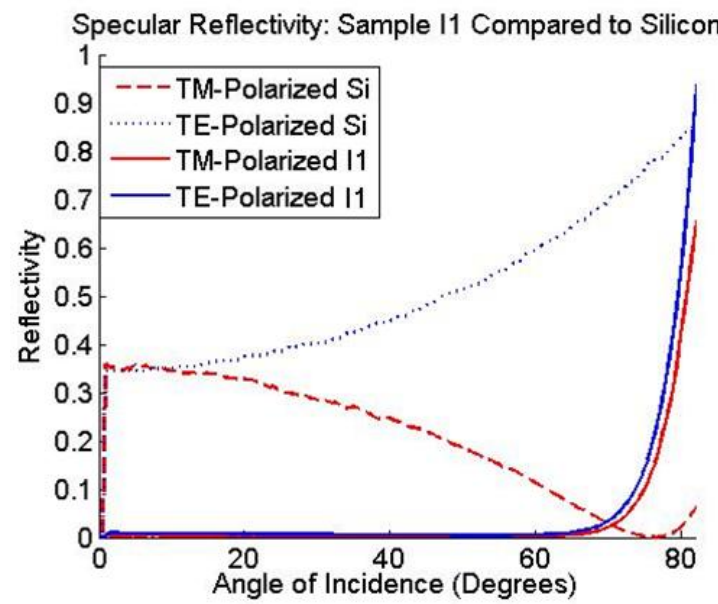

(a)

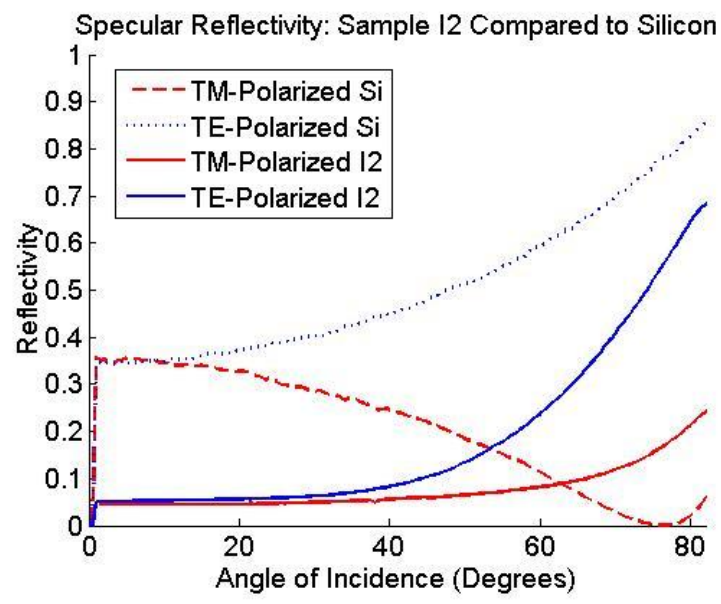

(b)

Figure 31. Specular reflection of polarized light compared to that of silicon for (a) Sample I1, randomly oriented nanowires with a diameter of $180 \mathrm{~nm}$ (b) Sample I2,vrandomly oriented nanowires with a diameter of $85 \mathrm{~nm}$. Values were determined experimentally and normalized to those for silicon.

The differences in specular reflectivity might be characteristic of the sizes of the nanowires. Indeed, the smaller nanowires of Sample I2 showed a specular reflectivities similar to those of vertical nanowires with similar diameters. At large angles of incidence, all nanowire samples had sharp increases in specular reflectivities, with the largest increase for highly diffuse reflecting samples. Section 3.3.2 discusses the total reflectance of the nanowire samples as a function of angle using an integrating sphere.

\subsection{Integrating Sphere}

Two integrating spheres were used to perform total reflectance measurements, a $150 \mathrm{~mm}$ integrating sphere attached to a Perkin Elmer Lambda 950 UV/VIS/NIR spectrometer, and a 4 inch integrating sphere attached to a Horiba Jobin Yvon 
Fluorolog III spectrometer. The Lambda 950 integrating sphere was larger and operated in two-beam reflectance mode. It thus provided better total reflectance measurements. The Fluorolog III integrating sphere was capable of performing angle dependent total reflectance measurements but had a geometry that might have caused quantitative errors. The Fluorolog III measurements were used to make qualitative comparisons of the reflectances for the $\mathrm{ZnO}$ nanowire arrays at oblique angles of incidence.

\subsubsection{Introduction to Total Reflectance Measurements}

Total reflectance measurements of the $\mathrm{ZnO}$ nanowire samples were performed with the samples at the reflectance port of the Lambda 950 integrating sphere. The port was located at the back of the sphere at $8^{\mathrm{o}}$ incidence to the light source. The sample port, $25 \mathrm{~mm}$ in diameter, was larger than most of the $\mathrm{ZnO}$ nanowire samples. To center them in the port, the samples were place behind a holder with a $13 \mathrm{~mm}$ diameter hole.

Figure 32 shows the configuration for the Lambda 950. The holder was made from aluminum and painted with white acrylic paint. Samples measured using the Fluorolog III were $12 \mathrm{~mm}$ squares. For measurements in the Lamda 950, these samples required a modified sample holder. White vinyl electrical was used to cover the additional area in the aperture of the sample holder. 


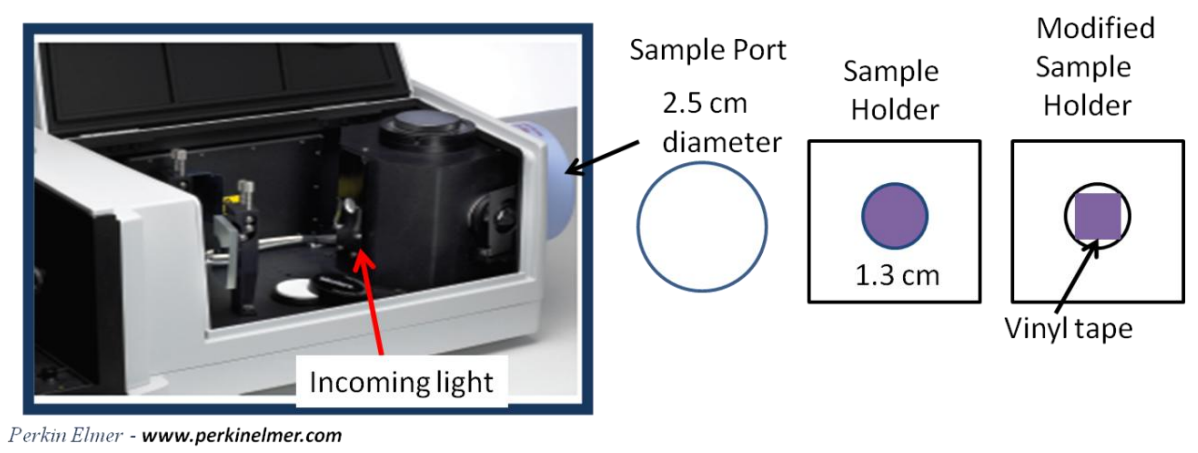

Figure 32. Configuration of the Lambda 950 Integrating sphere showing the reflectance sample port, sample holder for small samples, and modified sample holder used for the $12 \mathbf{~ m m}$ square samples.

The coloring shows how the was sample mounted behind the holder before being placed in the reflectance sample port.

Integrating sphere measurements should not be performed with sample holders as they alter the total reflectance of the sphere. The holders might also contribute to the light initially reflected by the sample. On the other hand, the small sample sizes were advantageous for their relatively small cost, and the ease of characterization measurements.

An adjustment was determined to compensate for the contribution to the total reflectance by the sample holder. Adjustments depended on the change in the average reflectance of the integrating sphere and the contribution to the initial reflection by the sample holder. Although the adjustment parameters could not be independently determined they were obtained by comparing experimental data collected with the holder and data collected without the holder.

In an integrating sphere, the radiance, $L$, from an incident flux $\varphi_{i}$, on a surface of reflectivity $\rho$, is given by $L=\frac{\varphi_{i} \rho}{\pi A}\left(w / m^{2} / s r\right)$, where $\pi$ is the projected solid angle, and $A$ is the illuminated area. By radiative transfer, the amount of radiant flux an area receives is proportional to the fraction it occupies in the sphere's surface area. Assuming diffuse 
reflection, and equal radiation from each point, multiple reflections increase the total flux. Taking into account these multiple reflections and the port openings, the total radiance of the sphere, $L_{s}$, is given by: $L_{s}=\frac{\varphi_{i}}{\pi A_{s}} \cdot M$, where $A_{s}$ is the surface area of the sphere and $M$ is referred to as the sphere multiplier. The sphere multiplier depends on the initial reflectance of light $\rho_{o}$ and the average sphere reflectance $\bar{\rho}$ and is given by $M=\frac{\rho_{o}}{1-\bar{\rho}}$. The average sphere reflectance depends on the reflectivity of the sphere wall, the fractional area of the port openings, and the reflectivity of the ports. The reflectivity of the sphere, $\rho_{\text {sphere }}$ is calculated from the ratio of the measured sphere radiance to the radiance of a sphere coated with a reference standard, $L_{s}$. The reflectance is given $\rho_{\text {sphere }}=\frac{L_{s}}{L_{r}} \cdot \rho_{r}$, where $\rho_{r}$ is the reflectivity of the reference standard [42]. The reference standard used was Spectralon ${ }^{\circledR}$.

The sample holder altered the average reflectance of the sphere and reflected a fraction of the incident light. The integrating sphere software controlled the slit width, and would adjust it to maintain an optimal irradiance for the light detector. As a result, light was incident not only on the nanowire sample but also on the white metal plate. The radiance of the sphere thus depended on the reflectivity of the sample holder and the sample:

$$
L_{s}=\left(\frac{\varphi_{\text {sample }}}{\pi A_{s}} \cdot \frac{\rho_{\text {sample }}}{1-\bar{\rho}_{\text {modified }}}\right)+\left(\frac{\varphi_{\text {holder }}}{\pi A_{s}} \cdot \frac{\rho_{\text {holder }}}{1-\bar{\rho}_{\text {modified }}}\right)
$$

The fluxes were $\varphi_{\text {sample }}=\varphi_{i} f$ and $\varphi_{\text {holder }}=\varphi_{i}(1-f)$. Here $f$ represents the fraction of the area of incident flux hitting the sample, and $(1-f)$ the fractional area occupied by the sample holder. The above modified equation for the radiance was introduced into the 
equation used to find the reflectance of the sphere. The reflectance of the sample is given by:

$$
\begin{gathered}
\rho_{\text {sample }}=\rho_{\text {sphere }} \cdot \frac{L_{r}}{\rho_{r}} \cdot \frac{\pi A_{s}\left(1-\bar{\rho}_{\text {modified }}\right)}{\varphi_{\text {sample }}}-\frac{\varphi_{\text {holder }} \cdot \rho_{\text {holder }}}{\varphi_{\text {sample }}} \\
\text { or } \quad \rho_{\text {sample }}=\rho_{\text {sphere }} \cdot \frac{L_{r}}{\rho_{r}} \cdot \frac{\pi A_{s}\left(1-\bar{\rho}_{\text {modified }}\right)}{\varphi_{i} f}-\frac{(1-f) \cdot \rho_{\text {holder }}}{f}
\end{gathered}
$$

Exact quantities of the variables were not known. In addition, variables were wavelength dependent. Nonetheless, the sample reflectance was given by: $\rho_{\text {sample }}=\left(\rho_{\text {sphere }}\right) \cdot \beta-\gamma$, where $\beta$ and $\gamma$ could be considered fitting parameters. The fitting parameters could be found experimentally by creating a linear fit between the sample reflectances measured with the sample holder to the reflectances measured without the sample holder. Three samples were used to find the fitting parameters for the sample holder. Reflectance spectra were taken for silicon, ITO/silicon, and sample A23, vertical $\mathrm{ZnO}$ nanowires grown by ACG. All three samples completely covered the reflectance port.

First, the reflectance of silicon and ITO/silicon were measured without the sample holder. They were compared with theoretical curves to assess the reasonableness of the calibration, as shown in Figure 33. The theoretical values were obtained using MATLAB using the wavelength dependent indices of refraction for intrinsic silicon [45] and ITO [46]. For silicon, the reflectances diverged from the theoretical values below $550 \mathrm{~nm}$. Measurements, however, were consistent with other measurements of polished $n$-type silicon wafers. The reflectance of the ITO/silicon was obtained for a $27.5 \mathrm{~nm}$ layer of ITO on a silicon layer. The thickness of the ITO layer was optimized by a thin film 
program in MATLAB. The thickness was consistent with the corresponding resistivity and transmittance of the ITO.

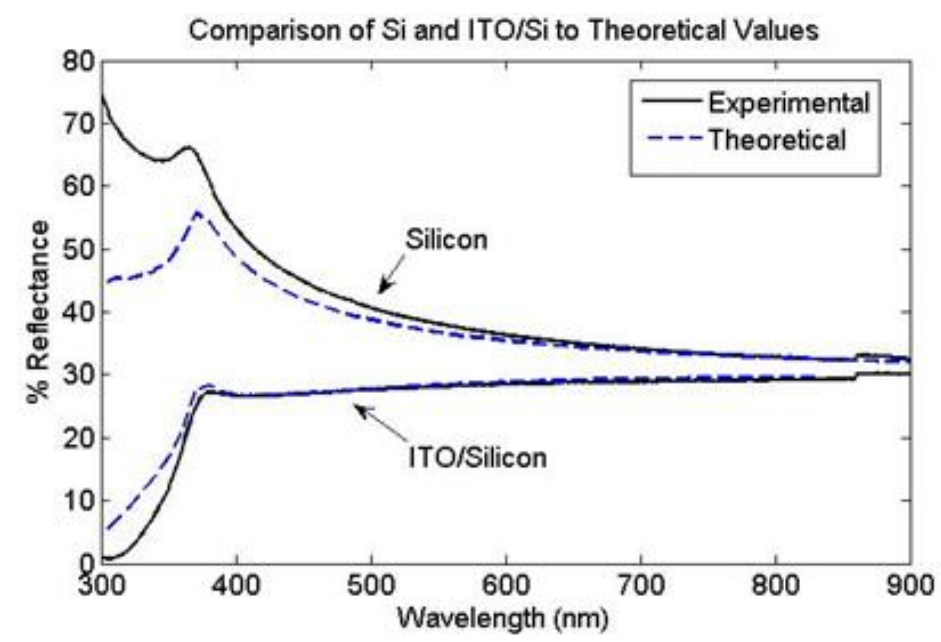

Figure 33. Measured and theoretical reflectances for silicon and ITO/Silicon. For ITO/Si a $27.5 \mathrm{~nm}$ layer of ITO was used.

Second, the reflectances for sample A23 were measured with the sample at the reflectance port of the integrating sphere. The sample holder was not used. Figure 34 compares the three reflectances. The band-gap of bulk $\mathrm{ZnO}$ was marked with a dotted line at $370 \mathrm{~nm}$. ITO, which has a larger band gap of $3.7 \mathrm{eV}$, absorbed photons with wavelengths below $330 \mathrm{~nm}$.

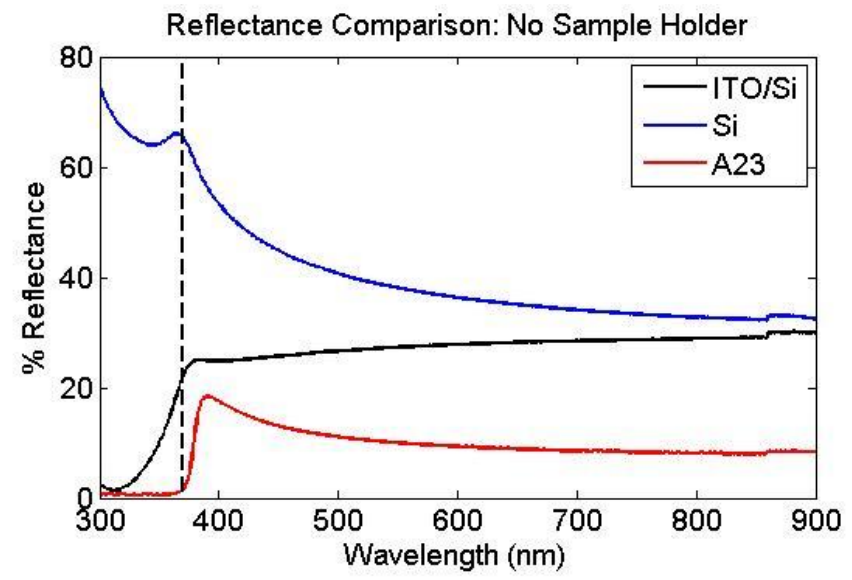

Figure 34. Reflectances of Silicon, ITO/Si, and vertical $\mathrm{ZnO}$ nanowire sample A23. All samples covered the reflectance port. The dotted line indicates the band-gap of $\mathrm{ZnO}$. 
Measurements preformed with the sample holder present had higher reflectances than without the sample holder, differing by roughly 4 percentage points, as shown in Figure 35a. Fitting parameters were found by a simultaneous linear fit of all three samples, shown in Figure 35b.

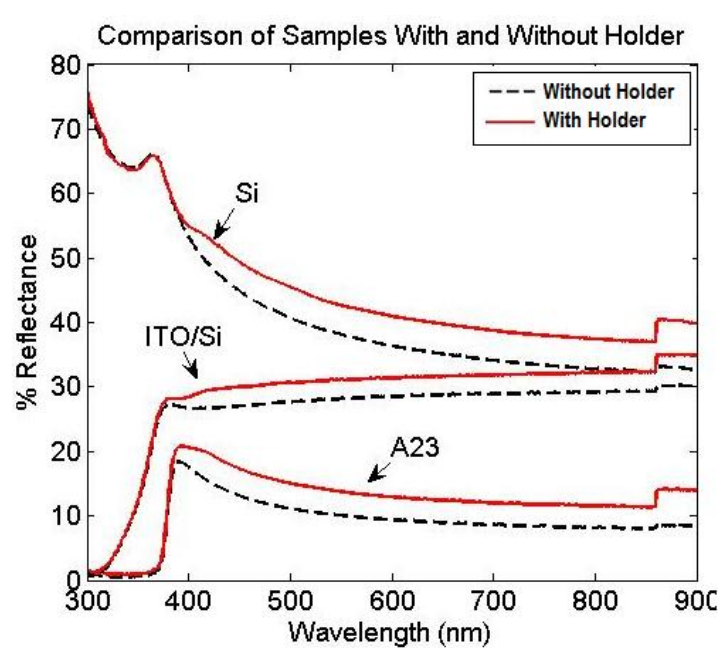

(a)

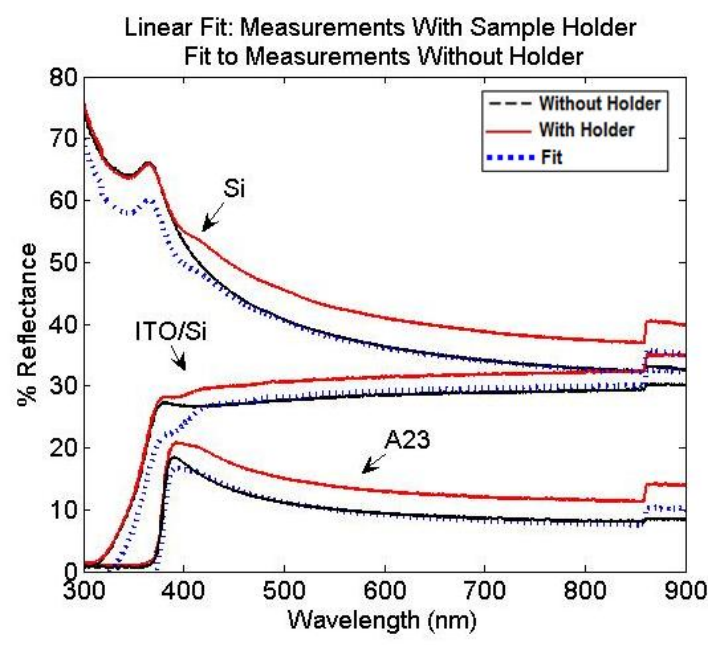

(b)

Figure 35. (a) Reflectances measured with and without sample holder for $\mathrm{Si}$, ITO/Si, and A23. (b) Fit of reflectances to actual experimental values. $\beta=0.963+/-0.001 ; \gamma=3.3+/-0.6$.

The fit parameters were found to be $\rho_{\text {sample }}=\left(\rho_{\text {sphere }}\right) \cdot 0.963-3.3$. The

values were found by a linear fit over the wavelength range from $400 \mathrm{~nm}$ to $860 \mathrm{~nm}$. The $R^{2}$ was 0.998 . Below $400 \mathrm{~nm}$, the sample holder absorbed light. At $860 \mathrm{~nm}$ the detector changed from PbS to a photomultiplier tube (PMT), a filter changed, and the slit width governing the amount of light from the spectrometer decreased from $20 \mathrm{~nm}$ to $2 \mathrm{~nm}$. Fit parameters could be found for wavelengths outside this range, but $\mathrm{ZnO}$ and ITO absorb below $400 \mathrm{~nm}$ and data collection did not extend far into the near-infrared. For these reasons, fit parameters were found only for the reflectances between $400 \mathrm{~nm}$ and $860 \mathrm{~nm}$. 
For smaller samples, the holder was modified with white vinyl tape to make the aperture a $12 \mathrm{~mm}$ square. Light hitting the vinyl tape of the modified sample holder caused an additional offset, now roughly 12 percentage points, as shown in Figure 36a.

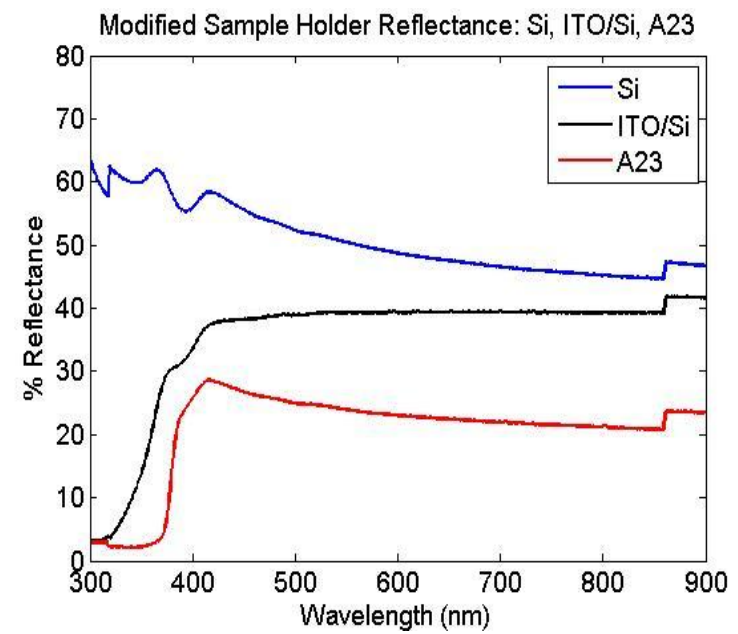

(a)

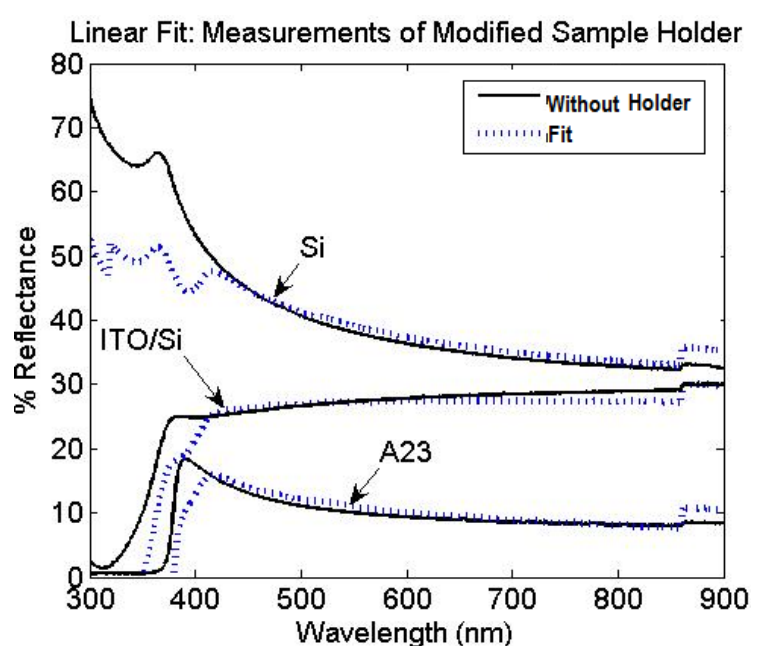

(b)

Figure 36. (a) Reflectances with modified sample holder. (b) Linear fit for the reflectances with the modified sample holder to those without the sample holder. $\beta=1.063+/-0.003$ and $\gamma=-14.4+/-0.01$.

The vinyl tape began to absorb near $450 \mathrm{~nm}$ leading to a sharp reduction in reflectances.

Thus the linear fit was applied only between $450 \mathrm{~nm}$ and $860 \mathrm{~nm}$. The fit parameters were found to be $\rho_{\text {sample }}=\left(\rho_{\text {sphere }}\right) \cdot .1 .063-14.4$. The $R^{2}$ was 0.992 .

A fit was attempted to incorporate the wavelength dependent reflectance of the sample holder with the white vinyl tape. The fit parameters $\beta=1.063$ and $\gamma=3.3+0.12 \cdot \rho_{\text {tape }}$ were used, where $\rho_{\text {tape }}$ is the reflectance of the white vinyl tape, shown in Figure 37a. Accounting for the absorption at $450 \mathrm{~nm}$ by introducing the reflectivity of the white tape improved the entire fit. 


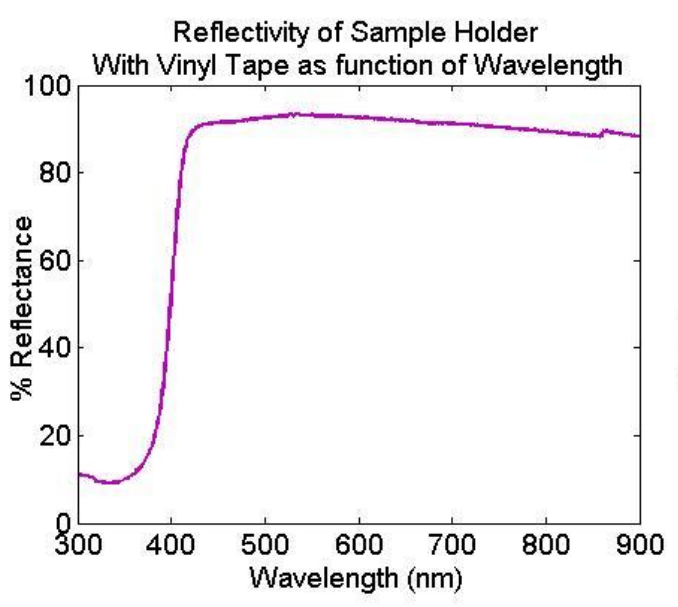

(a)

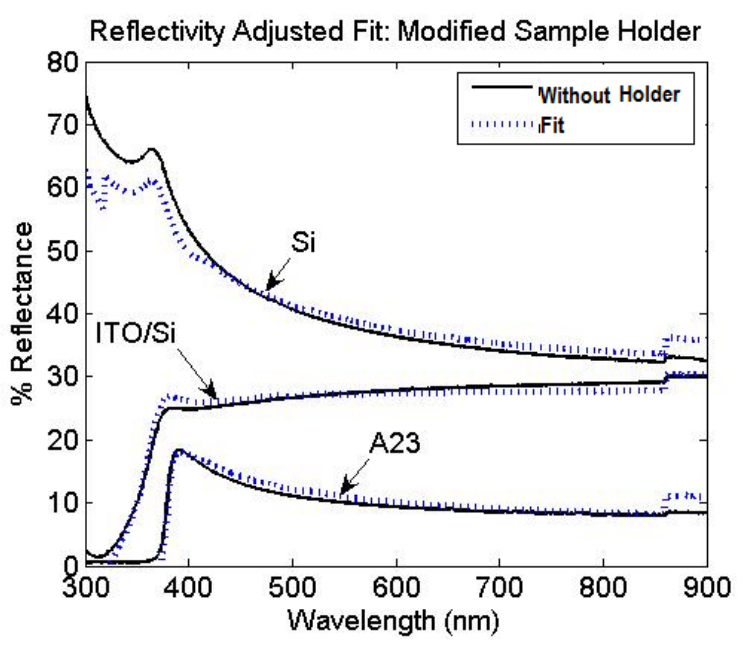

(b)

Figure 37. (a) Reflectances for the tape used to modify the sample holder. (b) Fit for the reflectances with the modified sample holder accounting for the reflectances of the white tape. $\beta=1.063$ and $\gamma=$ $3.3+0.12 \rho_{\text {tape }}$ where $\rho_{\text {tape }}$ is the reflectance of the tape.

The results shown in Figure 37 imply that fit parameters were more consistent with earlier results once the reflectance of the vinyl tape had been incorporated. As the reflectances were wavelength dependent, multiple regressions might have provided a better fit. Nonetheless, the simple linear fitting scheme appeared to work for wavelengths from $450 \mathrm{~nm}$ to $860 \mathrm{~nm}$. As a result, the linear scheme was applied when comparing the relative reflectances of the samples measured using different holders. Both measured data and data fit using the parameters are reported below. In the results, reflectances calculated using the linear fit parameters associated with the sample holder were identified with "Fit 1". Reflectance calculated using the fit parameters incorporating the reflectivity for the modified sample holder were referred to as "Fit 2". 


\subsubsection{Total Reflectance}

The reflectance spectra of vertical nanowires grown by ACG varied with the concentration of the bath, the number of zinc acetate seed layers, and the growth density of the wires.

The majority of ACG nanowire growth was performed with a $0.02 \mathrm{M}$ bath concentration and grown for 4 hours. Figure 38 show the reflectance spectra for samples A14, A15, A16, A19 and A23, grown using these conditions. The figure shows measured spectra and the fits of the data to illustrate how the fit modified the amplitudes but only slightly modified the relative reflectance.

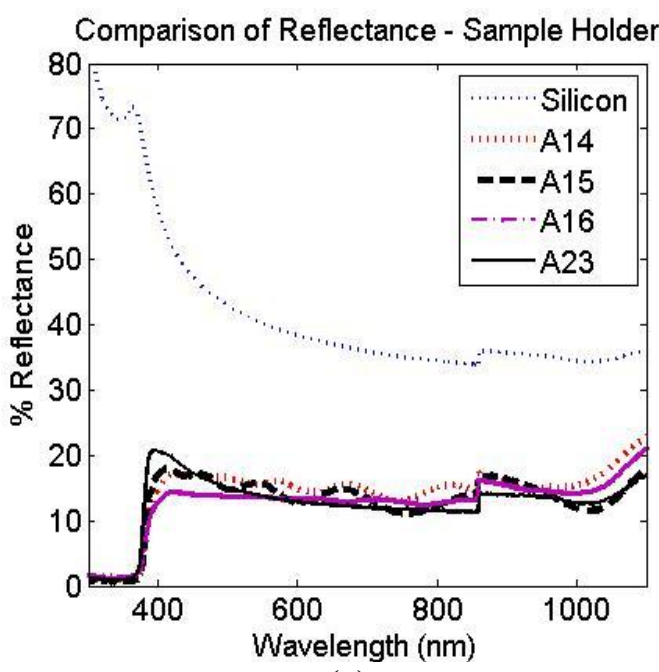

(a)

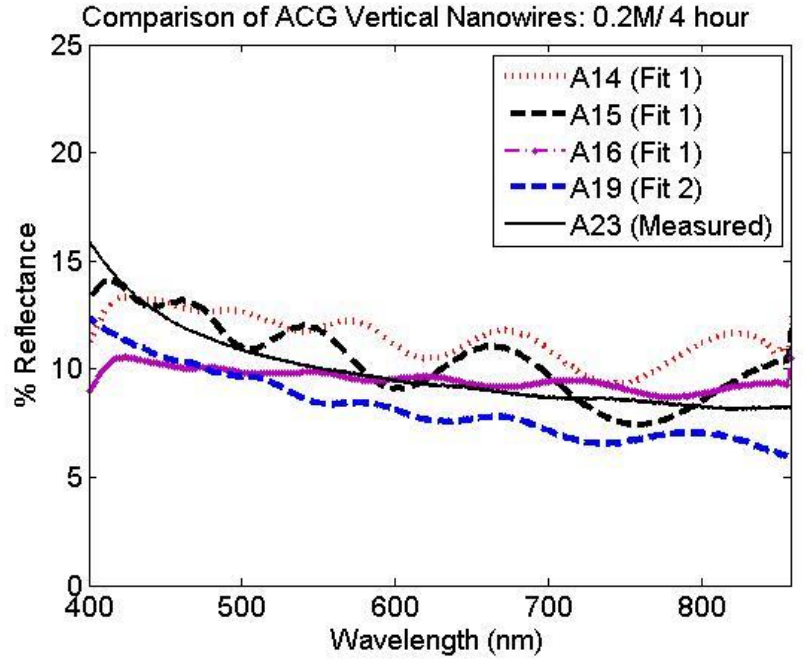

(b)

Figure 38. Reflectances for vertical nanowires grown by ACG in a $0.02 \mathrm{M}$ bath for 4 hours.

(a) Measurements with sample holder. (b) Fits to allow comparison of relative amplitudes.

The nanowires had average diameters of $55 \mathrm{~nm}$ to $100 \mathrm{~nm}$. Sample A14 had 20 spray layers of zinc acetate, sample A20 had 10 spray layers and samples A16, A19, and A23 had 40 spray layers. As predicted, nanowires grown on a 40 spray, planar $\mathrm{ZnO}$ seed layer had lower average reflectance than nanowires grown on an inhomogeneous seed layer. This reduction in reflectance appeared to be unrelated to the nanowire diameters. 
Thin film interference was probably the cause of the waviness in the reflectance spectra. Nanowire density, diameter, and length might all contribute to this effect. The larger number densities of nanowires had interference patterns with larger amplitudes. Figure 39 shows SEM images of sample A15, A14, and A16.

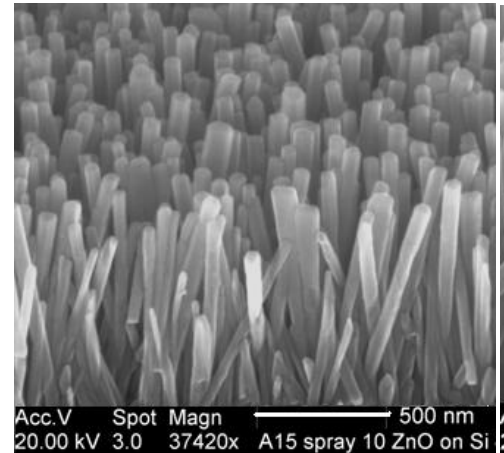

(a) A15 - 10 Spray

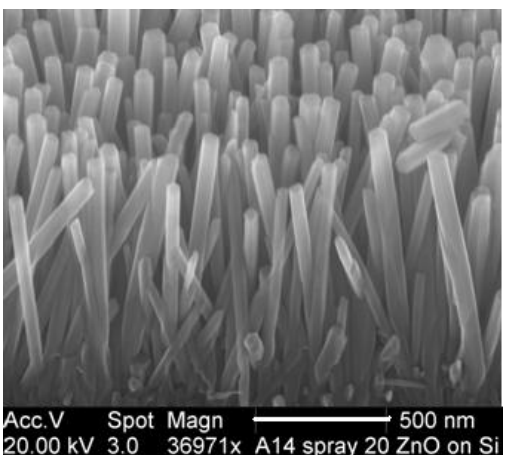

(b) A14 - 20 Spray

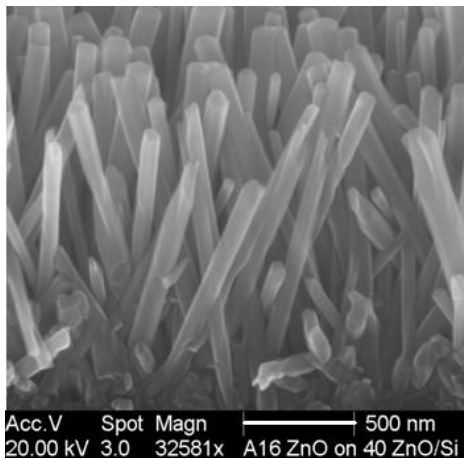

(c) A16 - 40 Spray

Sample A15 had the smallest nanowire diameters and lengths, followed by samples A14 and A16. Nanowires with larger number densities appeared to have less vertical tilt than those with smaller number density. Vertical tilt may have caused additional scattering, eliminating the interference. Interference may also be associated with nanowire length.

The above comparison did not apply for the short, thin nanowires grown by ACG in a $0.01 \mathrm{M}$ bath. Vertical nanowires grown in a $0.01 \mathrm{M}$ bath for 5 hours had an average diameter of $30 \mathrm{~nm}$ and an average length of $400 \mathrm{~nm}$. An example was shown in Figure 16c. The broadband reflectances for $0.02 \mathrm{M}$ nanowires were significantly lower than the reflectances of nanowires grown in a $0.01 \mathrm{M}$ bath. Figure 40 shows the reflectances for sample A23 grown in a $0.02 \mathrm{M}$ bath and sample A20 grown in a $0.01 \mathrm{M}$ bath.

A layer of $\mathrm{TiO}_{2}$ was deposited on one sample between the planar $\mathrm{ZnO}$ layer and silicon. Since $\mathrm{TiO}_{2}$ has a higher index of refraction than $\mathrm{ZnO}$, it might improve the gradient index between the nanowires and the silicon. Sample A22 had a $50 \mathrm{~nm}$ layer of 
$\mathrm{TiO}_{2}$ between the planar $\mathrm{ZnO}$ layer and the silicon substrate, with nanowires grown in a $0.02 \mathrm{M}$ bath for 4 hours on the planar $\mathrm{ZnO}$. Figure 40 shows the reflectances of sample A22. Figure 40a shows measurements performed with the modified sample holder.

Figure 40b shows the reflectances obtained using the fit parameters in order to compare the relative magnitudes.
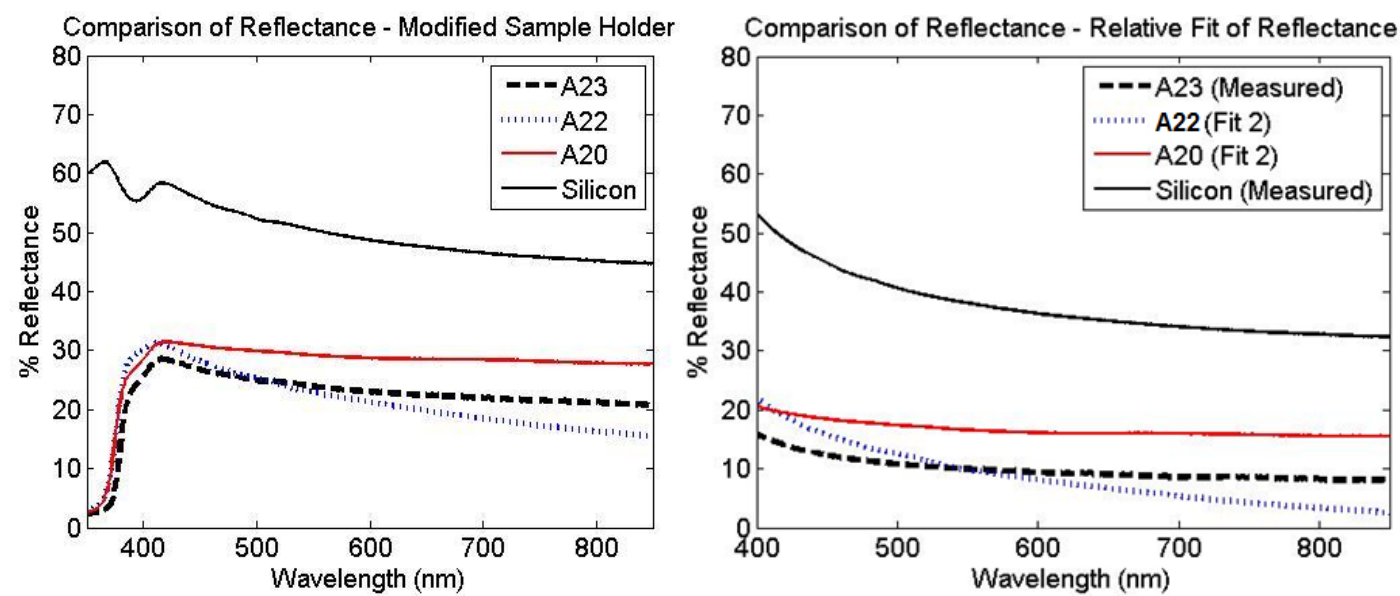

Figure 40. (a) Reflectances measured with modified sample holder for samples A23, A22, A20 and silicon. (b) Reflectances measured for sample A23 and for silicon compared with the fitted reflectances for samples A21 and A20.

The $\mathrm{TiO}_{2}$ layer in sample A22 reduced the reflectance over only part of the spectrum, which may mean that layer thickness needs to be optimized.

Nanowires which were strong Lambertian scatterers, such as sample I1 and I3 grown by electrodeposition, did not exhibit interference patterns. Sample I2, which did not have as much diffuse reflectivity, showed a waviness which may be associated with the thickness of the layer. Figure 41 shows the reflectances for randomly oriented samples grown by electrodeposited, silicon, and ITO/silicon. 


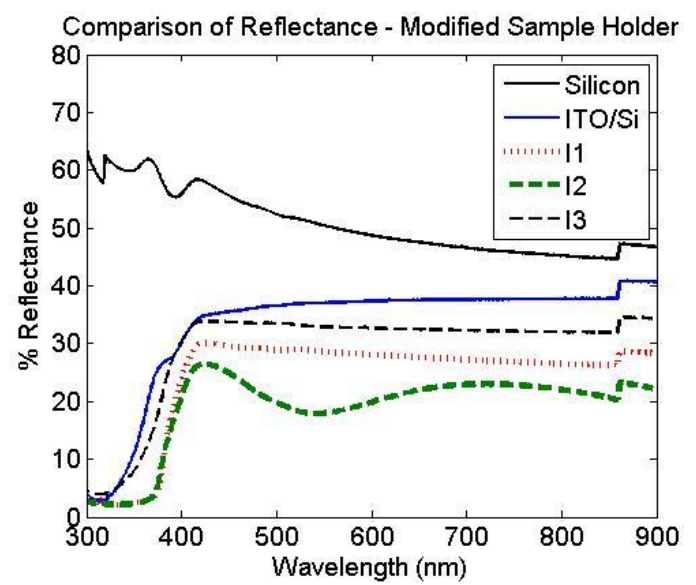

(a)

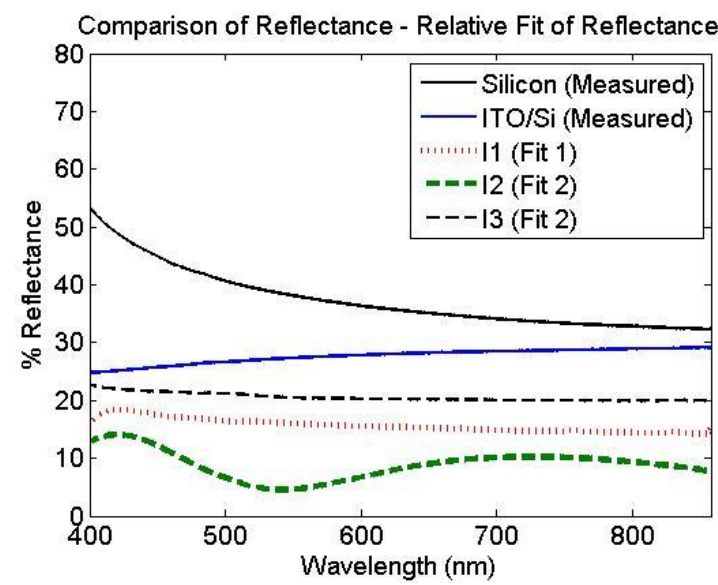

(b)

Figure 41. (a) Reflectance for electrodeposited samples mounted on the modified sample holder. (b) Fit of electrodeposited reflectances compared with ITO/Si and Si reflectances measured without a sample holder.

Figure 41a shows measurements taken with the modified sample holder and Figure 41b shows reflectances obtained using the fit parameters. Sample I3, with large $\mathrm{ZnO}$ flower like growth, had the highest reflectances of the three samples. Lambertian reflecting samples, samples I1 and I3, had uniform broadband reflectance. The reflectances for these samples were greater than the reflectances of sample I2. Sample I2, shown in Figure 21, had nanowires with an average diameter of $85 \mathrm{~nm}$ and length of $500 \mathrm{~nm}$, less than half the average diameter and length of those for sample I1.

The reflectances for sample $\mathrm{I} 2$ were similar to those for the vertical nanowires samples. These samples had similar diameters and were also grown on a planar $\mathrm{ZnO}$ layer. Vertical nanowires and the randomly oriented nanowires of sample I 2 had average reflectance of $8 \%$ to $15 \%$. Nanowire orientation does not appear to affect the total reflectances, despite differences in scattering. Figure 42 shows the reflectances for a few vertical nanowires grown by ACG and for sample I2. 


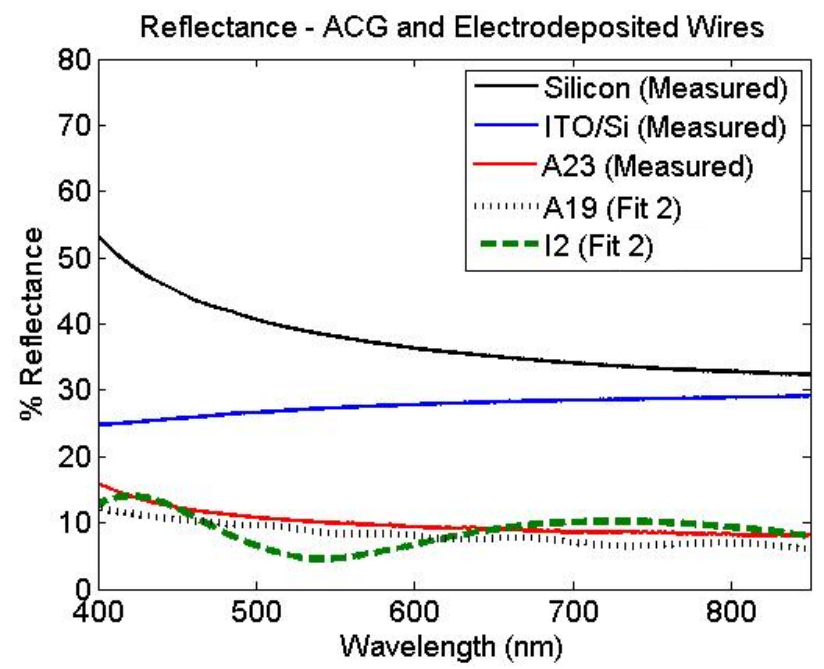

Figure 42. Reflectances for vertical ACG nanowire samples A19 and A23 and the electrodeposited randomly oriented sample $\mathbf{I} 2$.

Despite the measurement offsets introduced by the sample holders, qualitative and quantitative comparisons could be made for the broadband reflectances for the nanowire arrays. The best performing nanowire arrays reduced the broadband reflectance of silicon by a factor of five.

\subsubsection{Angle Dependent Reflectance}

Reflectances of $\mathrm{ZnO}$ nanowires on silicon were measured at angles of incidence incidence greater than $8^{\circ}$. The measurements were performed with the Fluorolog III integrating sphere using a $12 \mathrm{~mm}$ diameter center mount sample holder. The geometry of the sphere and the center mount allowed incident angles from $15^{\circ}$ to $35^{\circ}$. Large entrance and exit ports and sample substitution error contributed to errors in the total reflectance calculations. Nonetheless qualitative comparisons of reflectances could be made for vertically and randomly arrayed nanowire samples. 
The Fluorolog III was programmed for fluorescence measurements. Under normal control, the spectrometer sets the excitation wavelength and detects the scattered or fluoresced light over a range of wavelengths. For reflectance measurements, it was not possible to scan and detect at the same wavelengths. Consequently, the spectrometer was operated under real time control (RTC), by setting the wavelength and recording the instrument counts. The angle of incidence was changed by turning the knob which controlled the center mount, as shown in Figure 13a. For each wavelength and angle of incidence, data was collected three times and averaged. Appendix 2 presents a sample table for collected data.

Figure 43 shows the internal sphere geometry. To avoid reflecting light towards the emission port, the sample was turned counter-clockwise. The axis of rotation was near the edge of the sample. The sample holder encased the sample so that at incident angles greater than $35^{\circ}$, the incident light began to hit the sample holder. At $60^{\circ}$ none of the incident beam illuminated the sample.

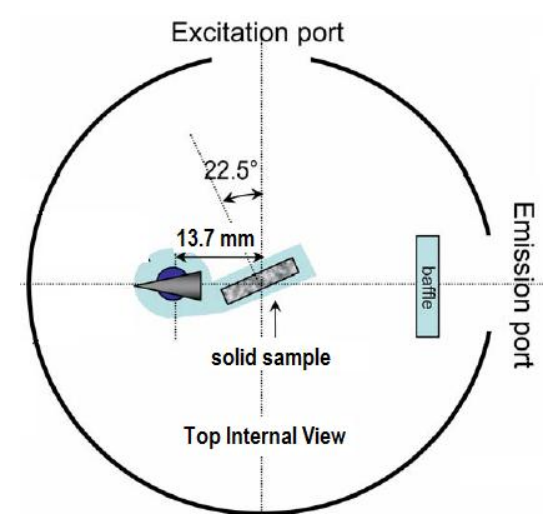

Figure 43. Internal view of Fluorolog III integrating sphere [43].

The sample holder and integrating sphere were covered with Spectralon ${ }^{\circ}$. The sample holder was shown in Figure 13b. The sample was placed in the holder so that it 
faced toward the excitation port. Initially, reflectances for 8 samples were measured at $500 \mathrm{~nm}$, including silicon and ITO/Si. At other wavelengths, only the vertical nanowire sample A19 and the randomly oriented sample I2, the samples of greatest interest, were measured. These samples had similar dimensions, yet different orientations.

Measurements were performed at $300 \mathrm{~nm}, 400 \mathrm{~nm}, 500 \mathrm{~nm}, 650 \mathrm{~nm}$, and $800 \mathrm{~nm}$ for incident angles of $15^{\circ}$ to $60^{\circ}$. At $60^{\circ}$ incidence, light hit the sphere wall and sample holder, thus providing the total reflectance of the sphere with the sample in place. To produce instrument counts in the range of $10^{4}$ to $10^{6}$, the slit width was varied from 1.47 nm to $3 \mathrm{~nm}$.

The first reflectances were measured at $500 \mathrm{~nm}$, as shown in Figure 44 .

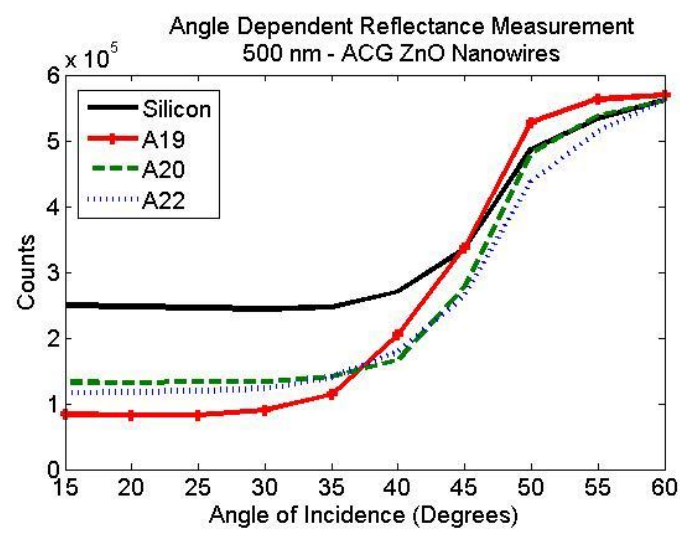

(a)

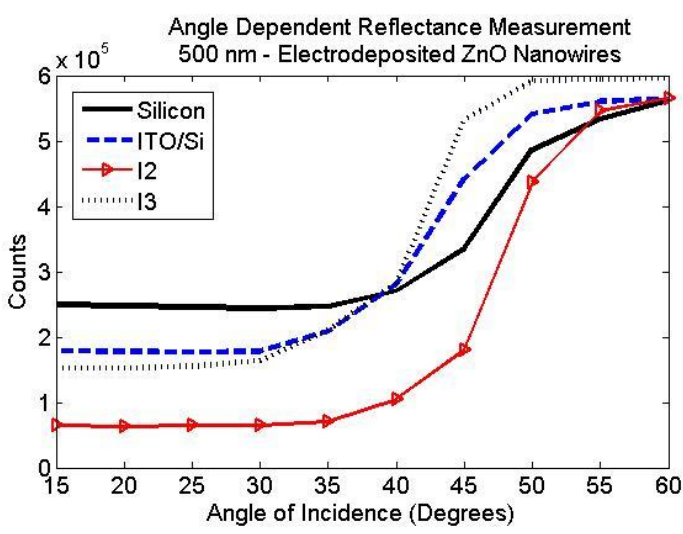

(b)

Figure 44. Angle dependent reflectances at $500 \mathrm{~nm}$ (a) vertical ACG nanowires and (b) randomly arrayed electrodeposited nanowires. Measurements performed with a slit width of $1.47 \mathrm{~nm}$.

The light was unpolarized and therefore the reflectance of silicon should have remained constant for angles of incidence less than $65^{\circ}$, as was shown in Figure 29. The sharp increases in reflection for silicon between $35^{\circ}$ and $40^{\circ}$ indicated that light began to hit the sample holder. At angles less than $35^{\circ}$ there were no significant variations in the reflectances for silicon, or for the nanowire samples. The reflectance obtained with the 
Fluorolog III were roughly calculated by dividing the instrument counts recorded at $15^{\circ}$ by those recorded at $60^{\circ}$, where the incident light did not hit the samples. Table 6 compares these reflectances to the measurements obtained with the Lambda 950 integrating sphere.

\begin{tabular}{|c|c|c|c|c|c|c|c|c|}
\hline \multicolumn{10}{|c|}{ Table 6. Angle Dependent Reflectances at 500 nm } \\
\hline Sample & Angle & Silicon & ITO/Si & I2 & I3 & A19 & A20 & A22 \\
\hline $\begin{array}{c}\text { Fluorolog } \\
\% \text { Reflectance }\end{array}$ & $15^{\circ}$ & $44.5 \%$ & $31.7 \%$ & $11.4 \%$ & $25.4 \%$ & $14.8 \%$ & $23.6 \%$ & $20.7 \%$ \\
\hline $\begin{array}{c}\text { Lambda 950 } \\
\% \text { Reflectance }\end{array}$ & $8^{\circ}$ & $40.8 \%$ & $27.7 \%$ & $6.6 \% *$ & $21.4 \% *$ & $9.7 \% *$ & $17.5 \% *$ & $12.6 \% *$ \\
\hline
\end{tabular}

There was a discrepancy between the reflectances of the samples provided by the two spheres. A correction factor may be needed for the Fluorolog III to account for sphere geometry and average wall reflectance. Since the Lambda 950 sphere could provide more reliable reflectance measurements due to its two-beam mode and size, the Fluorolog III was used to determine the relative reflectance change caused by changing the angle of incidence.

For the reflectances at other wavelengths, vertical nanowire sample A19 and randomly oriented nanowire sample I 2 were compared. For all wavelengths, there were negligible changes in the reflectance with changing angles of incidence for angles smaller than $35^{\circ}$. Figure 45 shows their relative reflectances. For measurements at $300 \mathrm{~nm}$ and $800 \mathrm{~nm}$ the slit width was $3 \mathrm{~nm}$. All other wavelengths were measured with a slit width set at $1.42 \mathrm{~nm}$. 


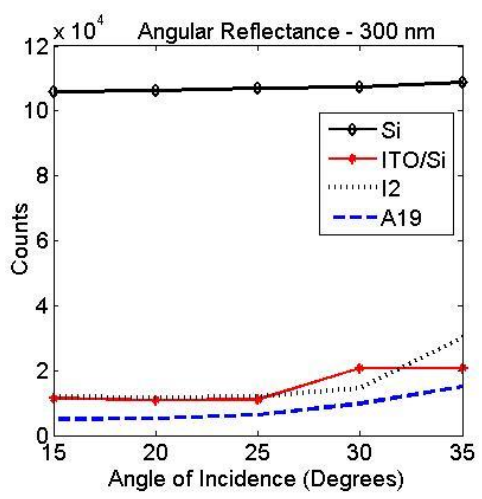

(a)

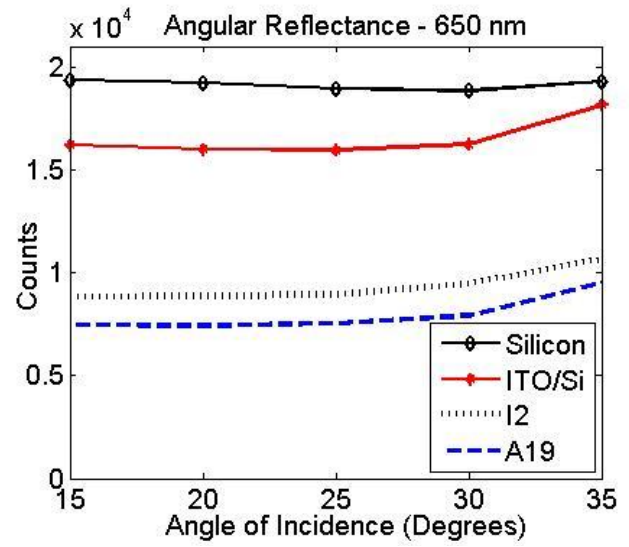

(d)

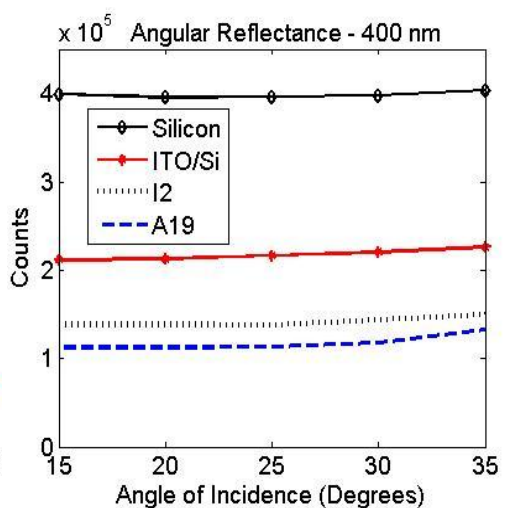

(b)

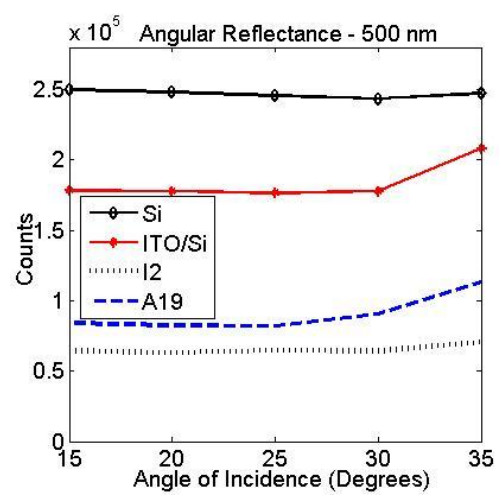

(c)

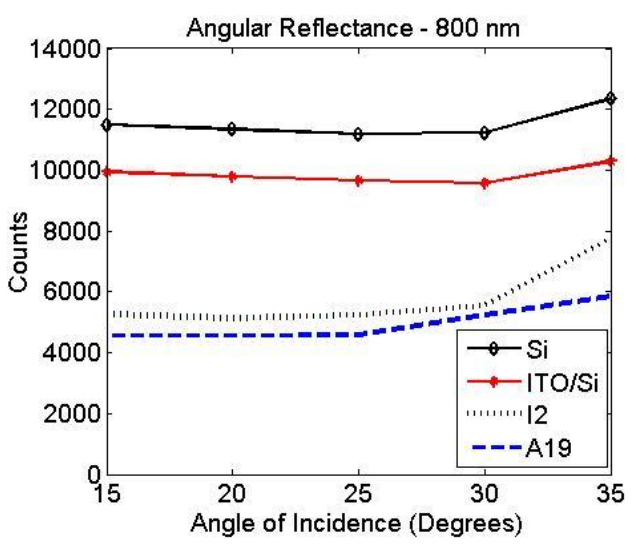

(e)

Figure 45. Angle dependent reflectances at wavelengths of (a) $300 \mathrm{~nm}$. (b) $400 \mathrm{~nm}$. (c) $500 \mathrm{~nm}$. (d) $650 \mathrm{~nm}$. and (e) $800 \mathrm{~nm}$.

At $300 \mathrm{~nm}$, very low instrument counts were observed for A19, I2, and ITO/Si.

The small reflectances were associated with the absorption by these samples. Although the absolute amplitudes of the reflectances were not determined, the relative reflectances of samples I2 and A19 were consistent with those measured by the Lambda 950 integrating sphere, as was shown in Figure 40. At 400 nm, 650 nm, and 800 nm, vertical nanowire sample A19 had a lower reflectance than sample I2. At $500 \mathrm{~nm}$, on the other hand, sample I 2 had a lower reflectance. Ideally, measurements would have been performed at angles of incidence greater than $35^{\circ}$. The increase in the reflectance of silicon for incident angles greater than $65^{\circ}$ suggests that measurements at larger angles of 
incident were necessary. Owing to equipment limitations, however, it was not possible to perform total reflectance measurements at angles of incidence greater than $35^{\circ}$.

\subsection{Theoretical Comparison}

Various methods are used to model the reflectances of the nanowire arrays. The simplest uses an effective media approximation (EMA) for the nanowire layer. Effective media approximations are based on a random unit cell distribution of two materials [47]. The transfer of light, however, is dependent on the size, shape, and spatial distribution of cells. The critical minimum thickness of the layer for which the EMA becomes valid is 50 times the nanowire diameter [27]. A film thickness of $4.5 \mu \mathrm{m}$ is much greater than the average $900 \mathrm{~nm}$ length of nanowire samples, which had typical diameters of $85 \mathrm{~nm}$. Nonetheless, the EMA has been employed by several researchers. Chen et al. [18] successfully modeled the interference of highly uniform GaN nanowire arrays based on the volume-fill of the nanowires. Diedenhofen et al. [21] used EMA to model GaP nanorods. Another method to model the nanowires is Rigorous Coupled Wave Analysis (RCWA). It solves Maxwell's equations for a 2-D grating structure [48]. To account for the nanowire morphology and scattering, however, solving Maxwell's equations in threedimensions would be the most accurate approach.

Even though the EMA method fails to account for the effects of nanowire size and geometry on light scattering, it remains the simplest method. Consequently, it was used in this study to model the reflectances of the $\mathrm{ZnO}$ nanowire arrays. SEM images were used 
to determine the height variation of the nanowires. Figure 46 shows the height variation for sample A12, vertical nanowires grown by ACG.

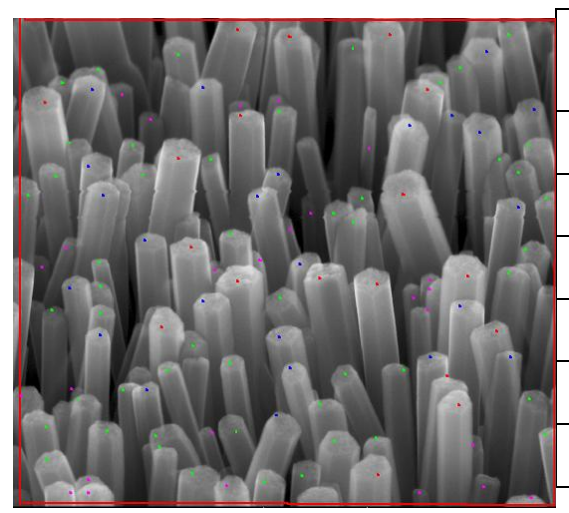

\begin{tabular}{|c|c|c|c|c|}
\hline Level & $\begin{array}{c}\text { Max. } \\
\text { Height }\end{array}$ & $\begin{array}{c}\text { Fractional } \\
\text { area }\end{array}$ & $\begin{array}{c}\text { Fractional } \\
\text { Volume }\end{array}$ & $\begin{array}{c}\text { Index of } \\
\text { Refraction }\end{array}$ \\
\hline 1 & 960 & .1070 & .11 & 1.09 \\
\hline 2 & 860 & .2129 & .21 & 1.18 \\
\hline 3 & 760 & .3514 & .35 & 1.33 \\
\hline 4 & 660 & .3892 & .39 & 1.36 \\
\hline $5^{*}$ & 460 & .5892 & .58 & 1.56 \\
\hline 6 & 60 & 1 & 1 & 2 \\
\hline
\end{tabular}

* Inferred from side view of wires

Figure 46. Nanowire height variations for Sample A12. The fractional area and volume apply to each area and were used to determine the index of refraction. Fractional area and volume determined from the average diameter and number of nanowires present in that layer.

The average diameter, height of the layer, and number of nanowires in the layer, were used to find the fractional volume. The fractional volume of $\mathrm{ZnO}, f_{Z n o}$, was used in the EMA to find the effective index of refraction, $n_{e f f}$, for the layer:

$$
f_{Z n o} \frac{n_{Z n o}^{2}-n_{e f f}^{2}}{n_{Z n o}^{2}+2 n_{e f f}^{2}}+\left(1-f_{Z n o}\right) \frac{n_{\text {air }}^{2}-n_{e f f}^{2}}{n_{\text {air }}^{2}+2 n_{e f f}^{2}}=0
$$

For simplicity, the wavelength dependence of the index of refraction for $\mathrm{ZnO}$ was not taken into account. The index of refraction of $\mathrm{ZnO}$ varies only slightly for visible light, from $n=1.9$ to $n=2.1$. An index of refraction of $n=2$ was assumed in the EMA calculations. Figure 47 shows the calculated reflectance for a TE wave for the 6-layer and 10-layer gradient-index films. 


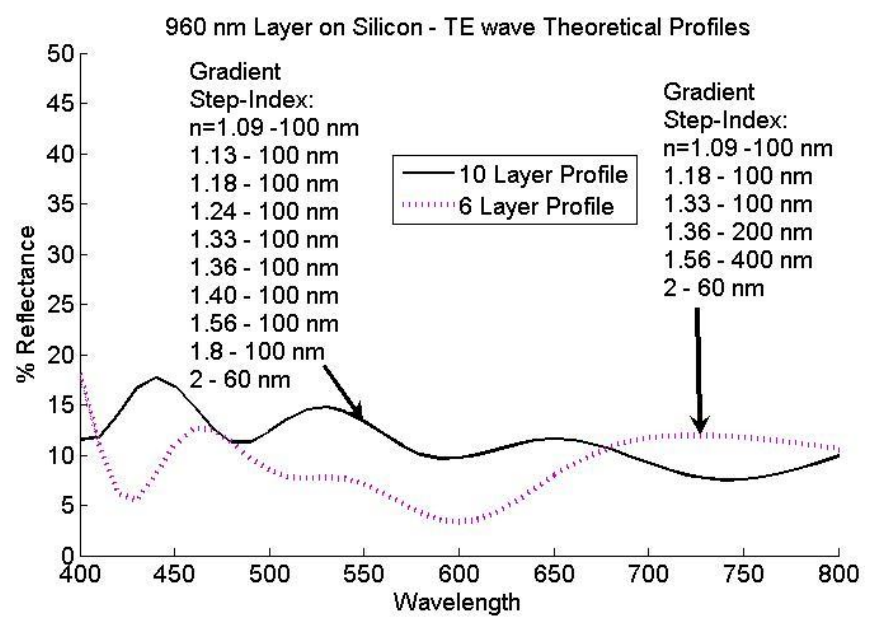

Figure 47. Theoretical reflectances for 10- and 6- gradient layers of a $960 \mathrm{~nm}$ thick film calculated by the transfer-matrix using MATLAB.

The 6-layer gradient layer was dissimilar to reflectances experimentally found for vertical nanowires. The conclusion was that 6-layers were too coarse to model the nanowire morphology. By stratifying the 6 layers into 10 layers, with a total thickness of $960 \mathrm{~nm}$, a reflectance profile similar to that of vertical nanowire sample A15 was obtained. Figure 48 compares the reflectances calculated for the 10 gradient layer film to those measured for sample A15.

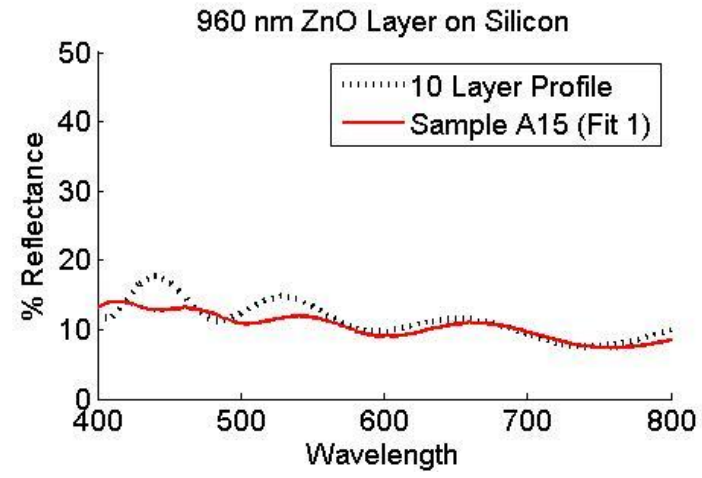

Figure 48. Reflectances measured for the vertical nanowire sample A15 and calculated for a 10gradient layer film.

The modeled reflectances were similar to the experimental values. Errors determining the height profiles and the sensitivity of the reflectances to small changes in 
the height profile suggested that the modeling process will require further investigation. The modeling requires better measures of the height profile, such as those obtained using an Atomic Force Microscope (AFM). Nonetheless, the EMA was useful when estimating the reflectance changes caused by adding additional layers to a sample profile, as for example in the case of the $\mathrm{TiO}_{2}$ layer added to vertical nanowire sample A22. 


\section{Summary of Results and Conclusions}

$\mathrm{ZnO}$ nanowire arrays significantly reduced the broadband reflectance of silicon. Nanowires that were grown by ACG and electrodeposition had distinct morphologies. The morphology of the nanowires influenced their reflectivity. Vertical nanowires grown by ACG had relatively small diffuse reflectivity and relatively large specular reflectivities. Randomly arrayed nanowires grown by electrodeposition exhibited greater diffuse reflectivity and less specular reflectivities than the vertical nanowire samples.

Total reflectance measurements compared the reflectances of $\mathrm{ZnO}$ nanowires on a silicon substrate to the reflectances of a bare silicon substrate. Large, diffusely scattering nanowires and $\mathrm{ZnO}$ crystals did not perform as well as smaller nanowires at reducing the reflectance for silicon. Despite differences in diffuse and specular reflection, alignment of nanowires did not appear to determine reflectance. Vertical nanowires grown in a $0.02 \mathrm{M}$ concentration bath and randomly arrayed electrodeposited nanowires had similar reflectances when grown on a planar $\mathrm{ZnO}$ layer. These $\mathrm{ZnO}$ arrays had average diameters between $60 \mathrm{~nm}$ and $100 \mathrm{~nm}$, and average lengths between $500 \mathrm{~nm}$ and $1100 \mathrm{~nm}$. They created a 30 percentage point reduction in the total reflectance of silicon, a five-fold decrease. Shorter, thinner nanowires reduced the broadband reflectance of silicon by half, or 20 percentage points. Large, thick crystal growth reduced the broadband reflectance of silicon by an average of 15 percentage points.

The reflectances for the $\mathrm{ZnO}$ nanowire arrays were constant at angles of incidence less than $35^{\circ}$. Measurements of the total reflectance of the nanowires at higher angles of incidence are still needed. 
The relative power density transmittances of the $\mathrm{ZnO}$ nanowires were compared to those of an idealized single layer $\mathrm{AR}$ coating of $\mathrm{ZnO}$, optimized for solar irradiance at $520 \mathrm{~nm}$. Figure 49 shows the Global air mass 1.5 spectral irradiance and the reflectances for a single layer $\mathrm{ZnO} \mathrm{AR}$ coating and vertical $\mathrm{ZnO}$ nanowires. The spectral irradiance was obtained from the American Society for Testing and Materials (ASTM). The spectrum includes direct and diffuse irradiance for a tilted surface in the northern hemisphere, and is a standard for the photovoltaic industry [49]. The total power density from $250 \mathrm{~nm}$ to $4000 \mathrm{~nm}$ is $895 \mathrm{~W} / \mathrm{m}^{2}$.

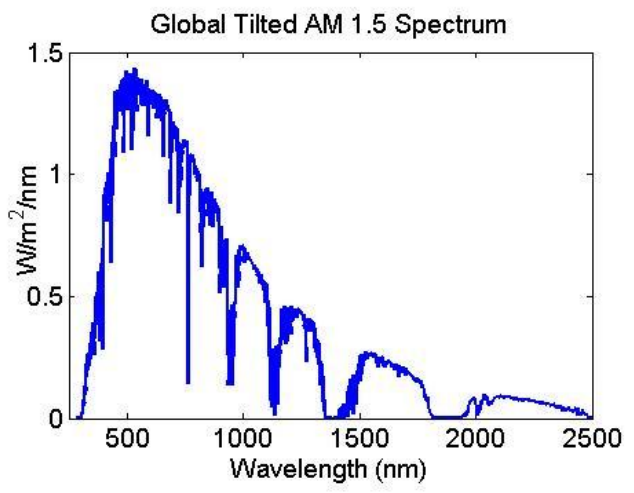

(a)

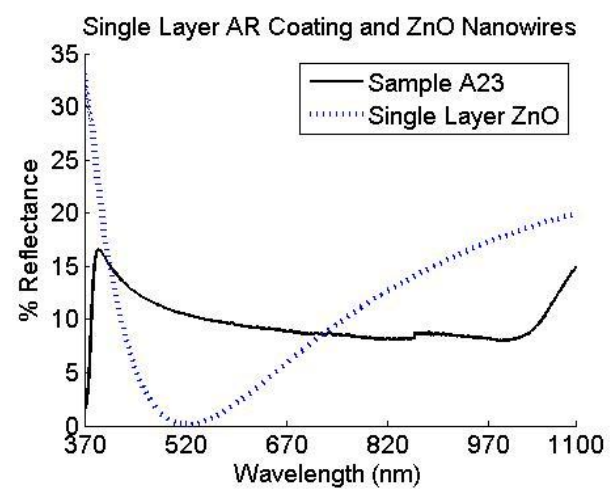

(b)

Figure 49. (a) Spectral irradiance in the Northern Hemisphere, tilted spectrum with a total irradiance of $895 \mathrm{~W} / \mathrm{m}^{2}$ (b) Reflectances for vertical $\mathrm{ZnO}$ nanowire sample $\mathrm{A23}$ on silicon, and for a theoretical single layer $\mathrm{ZnO}$ AR coating, $n=2$, on silicon.

Table 7 presents the spectral irradiance that would be transmitted by three different $\mathrm{ZnO}$ nanowire samples and a single $\mathrm{ZnO}$ layer optimized for $520 \mathrm{~nm}$. The total irradiance in Table 7 is provided for two different ranges of wavelengths. Both the single layer $\mathrm{ARC}$ and the $\mathrm{ZnO}$ nanowires reflect much less energy than a bare silicon substrate. For the lower range of wavelengths, the single layer AR coating perfomed better than the $\mathrm{ZnO}$ nanowires. For a wavelength range extended to $1100 \mathrm{~nm}$, the $\mathrm{ZnO}$ nanowire array performed as well as the single layer AR coating. 


\begin{tabular}{|c|c|c|}
\hline \multicolumn{3}{|c|}{ Table 7. Transmittance of Solar Irradiance $\left(895 \mathrm{~W} / \mathrm{m}^{2}\right)$} \\
\hline Material & $\begin{array}{c}\text { Wavelengths } \\
400 \mathrm{~nm}-900 \mathrm{~nm} \\
\text { Total Irr. }=564 \mathrm{~W} / \mathrm{m}^{2}\end{array}$ & $\begin{array}{c}\text { Wavelengths } \\
400 \mathrm{~nm}-1100 \mathrm{~nm} \\
\text { Total Irr. }=677 \mathrm{~W} / \mathrm{m}^{2}\end{array}$ \\
\hline Silicon & $353 \mathrm{~W} / \mathrm{m}^{2}$ & $437 \mathrm{~W} / \mathrm{m}^{2}$ \\
\hline ZnO SLARC & $529 \mathrm{~W} / \mathrm{m}^{2}$ & $620 \mathrm{~W} / \mathrm{m}^{2}$ \\
\hline ZnO A23 Sample & $509 \mathrm{~W} / \mathrm{m}^{2}$ & $610 \mathrm{~W} / \mathrm{m}^{2}$ \\
\hline ZnO I2 Sample & $516 \mathrm{~W} / \mathrm{m}^{2}$ & $621 \mathrm{~W} / \mathrm{m}^{2}$ \\
\hline ZnO A19 Sample & $518 \mathrm{~W} / \mathrm{m}^{2}$ & $620 \mathrm{~W} / \mathrm{m}^{2}$ \\
\hline
\end{tabular}

However, low energy photons with wavelengths above $1000 \mathrm{~nm}$ will not be strongly absorbed by silicon. Shown in Figure 50 is the absorption of bare silicon. A multi-crystalline solar cell will have an overall higher absorption due to doping, back surface reflectors, and surface passivation, but a similar decrease in the absorption for photons above $1000 \mathrm{~nm}$ due to the bandgap of silicon at $1.1 \mathrm{eV}$.

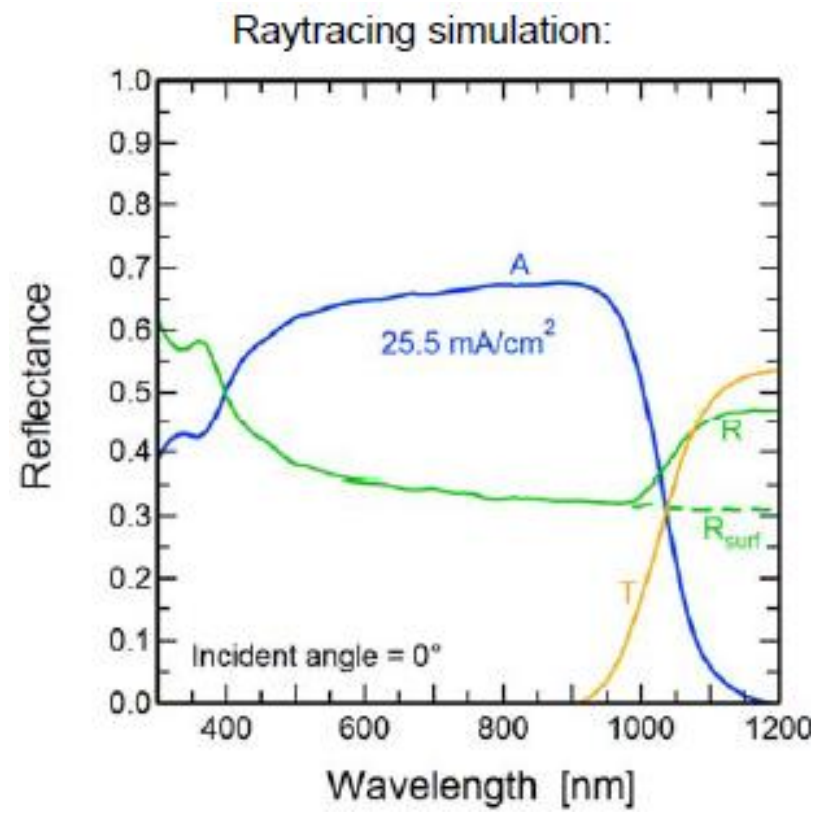

Figure 50. Raytracing simulation of an Air $\rightarrow$ Silicon $\rightarrow$ Air layer. The absorption, A, decreases at longer wavelengths since the band-gap of silicon is $1.1 \mathrm{eV}[50]$. 
The comparison illustrates the need to reduce reflection by the $\mathrm{ZnO}$ nanowire arrays at wavelengths near the maximum for solar irradiance, from $500 \mathrm{~nm}$ to $600 \mathrm{~nm}$, to be optimized for a silicon substrate.

The transmittance of the AR coatings should also be compared for a range of incident angles. There was little change in the reflectances for either the theoretical single layer $\mathrm{ZnO}$ AR coating or the measured $\mathrm{ZnO}$ nanowires for angles of incidence below $35^{\circ}$. The transmittance of a single layer AR coating begins to degrade for large angles of incident light. At $65^{\circ}$, power density transmitted falls to $596 \mathrm{~W} / \mathrm{m}^{2}$ for the $400 \mathrm{~nm}$ to $1100 \mathrm{~nm}$ wavelength range. The transmittance of $\mathrm{ZnO}$ vertical and randomly arrayed nanowires is unknown for high angles of incidence. Measurements are still needed of reflectances by nanowire arrays at large angles of incidence.

Results from this research agree with those found by Chen and Sun [24] and Lee et al. [25], shown in Figure 51.

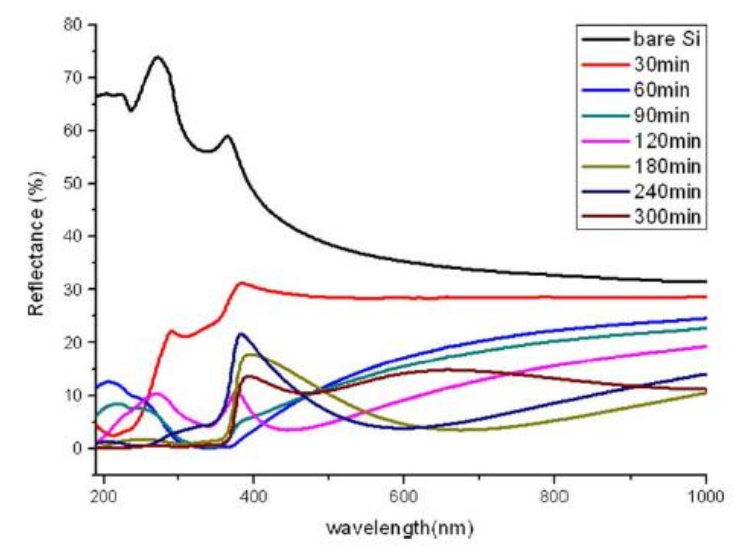

(a)

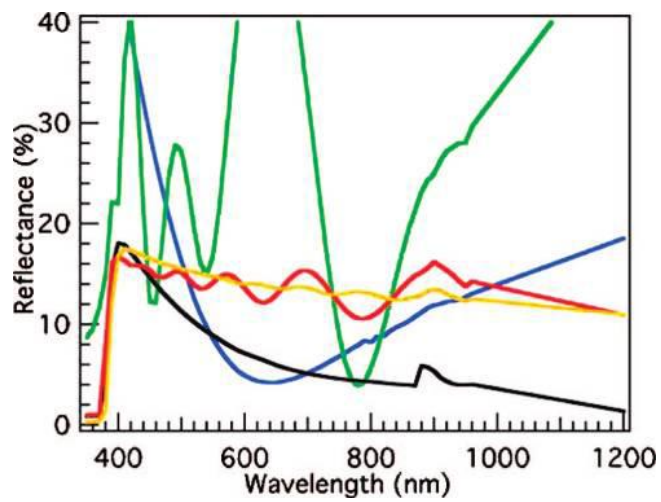

(b)

Figure 51. (a) Reflectances of nanowires grown by Chen and Sun [24]. Concentration of bath between 0.01M to 0.04M. Nanowire growth times as listed. (b) Reflectances of nanowires grown by Lee et al. [25]. Flat top nanowires (red), tapered nanowires (gold), and highly tapered nanowires (black). Blue indicates a single layer AR coating on a solar cell. 
Reflectances for the $\mathrm{ZnO}$ nanowires grown by ACG and by electrodeposition, which were shown in Figure 42, compared favorably with those obtained by a $240 \mathrm{~min}$ $\mathrm{ZnO}$ nanorod sample grown by Chen and Sun, and with the flat top nanowires grown by Lee et al. The reflectances of the nanowires in this study, however, were not as small as the tapered nanowire reflectances shown in Figure 51b.

A reduction in the reflectance by $\mathrm{ZnO}$ nanowires at visible wavelengths would be the best way to increase the transmittance of light into the substrate. Random height variation of the nanowires may not be sufficient to create an optimal gradient-index AR coating. Lee et al. created the tapered nanowires by introducing a hazardous chemical agent, diaminopropane (DAP), into the zinc nitrate and methenamine chemical bath. A less toxic, low temperature method might be found to create similar tapering. For instance, galvanostatic electrodeposition of $\mathrm{ZnO}$ nanowires from a zinc nitrate solution, in the presence of potassium hydroxide and sodium hydroxide, also lead to tapered nanowire tips. The drawback of electrodeposition is that it requires a conductive substrate. The aqueous chemical growth is thus the preferred large scale method. Further knowledge of the scattering properties of nanowires is necessary to determine whether nanowires will improve the efficiency of solar cells over the use of traditional AR coatings. Creation of a simple silicon solar device on which to test the $\mathrm{ZnO}$ nanowires would be the best way to make comparisons. Another approach would be to improve the modeling techniques for the nanowire arrays. Broadband total reflectances for $\mathrm{ZnO}$ nanowires have been successfully measured. Characterization of the nanowires 
at large angles of incidence is still needed to determine their viability as directional AR coatings. 


\section{REFERENCES}

[1] Archer M.D. Clean Electricity from Photovoltaics, Series on Photoconversion of Solar Energy - Vol 1. Archer M, Hill R, editor, London: Imperial College Press; 2001. $844 \mathrm{p}$.

[2] Green MA. "Self-consistent optical parameters of intrinsic silicon at $300 \mathrm{~K}$ including temperature coefficients". Solar Energy Materials \& Solar Cells. July 2008; 92: 13051310.

[3] Yablonovich E, Cody G. "Intensity Enhancement in Textured Optical Sheets for Solar Cells.” IEEE Tran. on electron devices. Feb. 1982; 29: 300-304.

[4] Thorp D, Wenham S R. "Ray-tracing of arbitrary surface textures for light-trapping in thin silicon solar cells." Solar Energy Materials and Solar Cells. 1997; 48: 295-301.

[5] Willeke G, Nussbaumer H, Bender H and Bucher E."A simple and effective light trapping technique for polycrystalline silicon solar cells". Solar Energy Materials and Solar Cells. 1992; 26 : 345-356.

[6] Bennet, CA. Principles of Physical Optics. Hoboken, N.J.: Wiley, 2008. 492 p.

[7] Born M, Born E, et al. Principles of Optics: electromagnetic theory of propagation, interference and diffraction of light. Oxford; New York : Pergamon Press, 1980. 809 p.

[8] Pedrotti FL, Pedrotti LS. Introduction to Optics. Englewood Cliffs, N.J.: PrenticeHall, 1987. 551 p.

[9] Markvart, T. and Castañer, L. Practical Handbook of Photovoltaics: Fundamentals and Applications. Oxford: Elsevier Advanced Technology, 2003. 984 p.

[10] Moore DT. “Gradient-index optics: a review”. Applied Optics. 1 April 1990; 19: 1035-1038.

[11] Lord Rayleigh, "On reflection of vibrations at the confines of the two media between which the transition is gradual". Proceedings of the London Mathematical Society. 12 February 1980; 11: 51-60.

[12] Bergner BC, Germer TA, Suleski TJ. "Effective medium approximations for modeling optical reflectance from gratings with rough edges" Journal of the Optical Society of America, A. May 2010; 27: 1083-1010.

[13] Southwell WH. "Gradient-index antireflection coatings". Optics Letters. November 1983; 8: 584-586. 
[14] Poitras D and Dobrowolski JA. "Toward perfect antireflection coatings. 2. Theory" Applied Optics. 20 February 2004; 43: 1286-1295.

[15] Chen M, Chang H, Chang ASP, Lin SY, and Xi JQ. "Design of optical path for wide-angle gradient-index antireflection coatings". Applied Optics. 10 September 2007; 43: 6533-6538.

[16] Southwell WH and Sankur H. "Broadband gradient-index antireflection coating for ZnSe”. Applied Optics. 15 August 1984 ; 23: 2770-2773.

[17] Kuo ML, Poxson D, Kim YS et al. "Realization of a near-perfect antireflection coating for silicon solar energy utilization”. Optics Letters. 1 November 2008; 33: 25272529.

[18] Chen HY et al. "Gallium nitride nanorod arrays as low refractive-index transparent media in the entire visible spectral region”. Optics Express. 26 May 2008; 16: 8106-8116.

[19] Huang YF, et al. "Improved broadband and quasiomnidirectional anti-reflection properties with biomimetic silicon nanostructures". Nature Nanotechnology. 2 December 2007; 2: 770-774.

[20] Kanamori Y, Sasaki M and Hane K. "Broadband antireflection gratings fabricated upon silicon substrates”. Optics Letters. 15 October 1999; 24: 1422-1425.

[21] Didenhofen SL, et al. "Broad-band and Omnidirectional Antireflection Coatings Based on Semiconductor Nanorods." Advanced Materials. 2009; 21: 973-978.

[22] Yu Z, Raman A and Fan S. "Fundamental limit of light trapping in grating structures". Optics Express. 13 September 2010 ; Vol. 18: A366-A380.

[23] Musken OL, Rivas JG, Algra RE, Bakkers E, and Lagendijk A. "Design of Light Scattering in Nanowire” NanoLetters. July 2008; 8: 2638-2642.

[24] Chen JY and Sun KW. "Growth of vertically aligned $\mathrm{ZnO}$ nanorod arrays as antireflection layer on silicon solar cells". Solar Energy Materials and Solar Cells. 22 January 2010; 94: 930-934.

[25] Lee YJ, Ruby DS, Peters DW, McKenzie BB and Hsu JWP. “ZnO Nanostructures as Efficient Antireflection Layers in Solar Cells.” NanoLetters. 2008; 8: 1501-1505.

[26] Moharam MG, Pommet DA, and Grann EB. "Stable implementation of the rigorous coupled-wave.” Journal of the Optical Society of America, A. 1995; 12: 1077-1086. 
[27] Braun MM and Pilon L. "Effective optical properties of non-absorbing nanoporous thin films." Thin Solid Films. 2006; 496: 505-514.

[28] Jagadish C and Coleman VA. Zinc oxide bulk, thin films and nanostructures: processing, properties and applications. Editors Jagadish $\mathrm{C}$ and Pearton S. Hong Kong: Elsevier; 2006. 589 p.

[29] Nadarajah, Athavan. Electroluminescence from annealed and un-annealed electrodeposited $\mathrm{ZnO}$ nanowires. Masters of Science Thesis. Portland State University. 2006; 90 p.

[30] Kittel C. Introduction to Solid State Physics, Eigth edition. Hoboken, NJ: Wiley and Sons; 2005. 680p.

[31] Vayssieres L, Keis K, Lindquist SE, and Hagfeldt A. "Purpose-Built Anisotropic Metal Oxide Material: 3D Highly Oriented Microrod Array of ZnO." Journal of Physical Chemistry, B. 2001; 105: 3350-3352.

[32] Willander M, et al. "Zinc oxide nanorod based photonic devices: recent progress in growth, light emitting diodes and lasers" Nanotechnology. 28 July 2009; 332001: 332040 .

[33] Xu S, Lao C, Weintraub B and Wang ZL. "Density-controlled growth of aligned $\mathrm{ZnO}$ nanowire arrays by seedless chemical approach on smooth surfaces." Journal of Materials Research. August 2008; 23: 2072-2077.

[34] Vayssieres, L. "Growth of arrayed nanorods and nanowires from aqueous solutions.” Advanced Materials. 4 March 2003; 15: 464-466.

[35] Vernardou D, Kenanakis G, Couris S, Koeoumas E, Kymakis E and Katsarakis N. "pH effect on the morphology of $\mathrm{ZnO}$ nanostructures grown with aqueous chemical growth.” Thin Solid Films. 1 April 2007; 515: 8764-8767.

[36] Li Q, Kumar V, Li Y, Zhang H, Marks T and Chang R. "Fabrication of ZnO Nanorods and Nanotubes in Aqueous Solutions." Chemical Materials. 1 February 2005; 17: 1001-1006.

[37] Baruah S and Dutta J. "pH-dependent growth of zincoxide nanorods". Journal of Crystal Growth. 4 February 2009; 311:2549-2554.

[38] Greene LE, Law M, Tan DH, Montano M, Goldberger J, Somorjai G, and Yang P. "General Route to Vertical ZnO Nanowire Arrays Using Textured ZnO Seeds." NanoLetters. 18 June 2005; 5: 1231-1236. 
[39] Krunb M and Mellikov E. "Zinc oxide thin films by the spray pyrolysis method." Thin Solid Films. 1 December 1995; 270: 33-36.

[40] Peulon S and Lincot D. "Mechanistic Study of Cathodic Elecfrodeposition of Zinc Oxide and Zinc Hydroxychioride Films from Oxygenated Aqueous Zinc Chloride Solutions" Journal of the Electrochemical Society. March 1998; 145: 864:874.

[41] LabSphere. "A Guide to Integrating Sphere Theory and Applications." Technical Application. Available from: http://www.labsphere.com/technical/technical-guides.aspx 18 April 2011; 19p.

[42] Perkin Elmer application notes. "Applications and Use of Integrating Spheres With the LAMBDA 650 and $850 \mathrm{UV} / \mathrm{V}$ is and LAMBDA $950 \mathrm{UV} / \mathrm{Vis} / \mathrm{NIR}$

Spectrophotometers". Available from: http://www.perkinelmer.com. 2 March 2010.

[43] Horiba Jobin Yvon. "Integrating Sphere, F-3018 Operation Manual, Part number 81089 version 1.2.” Integrating Sphere. 3 Jul 2008; 44 p.

[44] Storm S, Springsteen A, Ricker T. "The Use of Center Mount Sample Holders in Reflectance Spectroscopy”. LabSphere Application Note 2. January 1998; 8p.

[45] Green, MA and Keevers MJ. "Optical properties of intrinsic silicon at $300 \mathrm{~K}$ " Progress in Photovoltaics: Research and Applications. 1995; 3: 189-192.

[46] Filmetrics: Refractive Index Database. Available from: http://www.filmetrics.com/refractive-index-database. 21 April 2010.

[47] Niklasson GA and Granqvist CG. "Optical properties and solar selectivity of coevaporated Co-AI20 3 composite films" Journal of Applied Physics. 1 May 1984; 55: 3382-3410.

[48] Moharam MG, Pommet DA, Grann EB, and Gaylor Tk. "Stable implementation of the rigorous coupled-wave analysis for surface-relief gratings: enhanced transmittance matrix approach." Journal of the Optical Society of America. May 1995; 12: 1077-1076.

[49] Reference Solar Spectral Irradiance: ASTM G-173. National Renewable Energy Laboratory. Available from:

http://rredc.nrel.gov/solar/spectra/am1.5/ASTMG173/ASTMG173.html. 21 May 2011

[50] Altermatt, Pietro. Special Topics in Solar Cells, Portland State University. 25 July 2010. Day 3, Photogeneration, pg 5. 


\section{Appendices}

\subsection{Appendix 1}

$\mathrm{ZnO}$ nanowires grown by $\mathrm{ACG}$ and Electrodeposition.

\begin{tabular}{|c|c|c|c|c|c|c|c|}
\hline \multicolumn{8}{|c|}{ ZnO Sample Preparation by Aqueous Chemical Growth (ACG) on Silicon } \\
\hline No. & Date & ID & Solution & Pre-Growth & $\begin{array}{c}\text { Temp. } \\
\left({ }^{\circ} \mathrm{C}\right)\end{array}$ & Time & NOTES: \\
\hline 1 & $5 / 26 / 2010$ & A1 & $\begin{array}{c}.05 \mathrm{M} \text { Zinc } \\
\text { Nitrate/.05M } \\
\text { methenamine }\end{array}$ & $\begin{array}{c}20 \text { sprays Zinc acetate } \\
\text { (every } 30 \mathrm{sec} \text { ) at } \\
\text { 300deg / Anneal } \\
\text { 380deg 20min }\end{array}$ & $85-90$ & $1 \mathrm{hr}$ & $\begin{array}{l}\text { Spray left funny } \\
\text { blue residue. Too } \\
\text { much heat? }\end{array}$ \\
\hline 2 & $5 / 26 / 2010$ & A2 & $\begin{array}{c}.05 \mathrm{M} \text { Zinc } \\
\text { Nitrate/.05M } \\
\text { methenamine }\end{array}$ & $\begin{array}{c}20 \text { sprays Zinc acetate } \\
\text { (every } 30 \mathrm{sec} \text { ) at } \\
\text { 300deg / Anneal } \\
\text { 380deg 20min }\end{array}$ & $85-90$ & $3 \mathrm{hr}$ & $\begin{array}{c}\text { Evaporation. } \\
\text { After } 1 \mathrm{hr}-\text { only } \\
400 \mathrm{ml} \text { (instead of } \\
500 \mathrm{ml} \text { ) was there. } \\
\text { After } 3 \mathrm{hr}, 200 \mathrm{ml}\end{array}$ \\
\hline 3 & $5 / 26 / 2010$ & A3 & $\begin{array}{c}.05 \mathrm{M} \text { Zinc } \\
\text { Nitrate/.05M } \\
\text { methenamine }\end{array}$ & No & $85-90$ & $1 \mathrm{hr}$ & \\
\hline 4 & $5 / 26 / 2010$ & A4 & $\begin{array}{c}.05 \mathrm{M} \text { Zinc } \\
\text { Nitrate/.05M } \\
\text { methenamine }\end{array}$ & No & $85-90$ & $3 \mathrm{hr}$ & \\
\hline 5 & $6 / 2 / 2010$ & A5 & $\begin{array}{c}.02 \mathrm{M} \text { Zinc } \\
\text { Nitrate/.02 } \\
\text { methenamine }\end{array}$ & $\begin{array}{c}20 \text { sprays Zinc acetate } \\
\text { (every } 30 \mathrm{sec} \text { ) at } \\
\text { 300deg / Anneal } \\
\text { 380deg 20min }\end{array}$ & $85-90$ & $3 \mathrm{hr}$ & Initial $\mathrm{Ph} 5.77$ \\
\hline 6 & $6 / 2 / 2010$ & A6 & $\begin{array}{c}.02 \mathrm{M} \text { Zinc } \\
\text { Nitrate/.02 } \\
\text { methenamine }\end{array}$ & No & $85-90$ & $3 \mathrm{hr}$ & 80C Ph: 4.83 \\
\hline 7 & $6 / 23 / 2010$ & A7 & $\begin{array}{c}.1 \mathrm{M} \text { Zinc } \\
\text { Nitrate/ } .15 \\
\text { meth. }\end{array}$ & no & 90 & $1 \mathrm{hr}$ & $\begin{array}{c}10 \mathrm{x} \text { the } \\
\text { concentration. } \\
\text { Added } 5 \mathrm{ml} \mathrm{NH3} \\
\text { solution for } \mathrm{pH}\end{array}$ \\
\hline 8 & $6 / 24 / 2010$ & A8 & $\begin{array}{c}.02 \mathrm{M} \text { Zinc } \\
\text { Nitrate/.02 } \\
\text { methenamine }\end{array}$ & $\begin{array}{c}10 \text { sprays Zinc acetate } \\
\text { (every } 30 \mathrm{sec} \text { ) at } \\
\text { 280deg / Anneal } \\
\text { 380deg 20min }\end{array}$ & $85-90$ & $\begin{array}{l}5 \mathrm{hr}- \\
2 \text { sol. }\end{array}$ & $\begin{array}{c}\text { 40ml, covered } \\
\text { with thermometer. } \\
\text { No stir. Ph dip } \\
\text { test } \sim 6 \text {; Change } \\
\text { to new solution } \\
\text { after 3hours. Very } \\
\text { Uniform looking } \\
\text { growth }\end{array}$ \\
\hline 9 & $6 / 30 / 2010$ & A9 & $\begin{array}{c}.02 \mathrm{M} \text { Zinc } \\
\text { Nitrate/.02 } \\
\text { methenamine }\end{array}$ & $\begin{array}{c}10 \text { sprays Zinc acetate } \\
\text { (every } 30 \mathrm{sec} \text { ) at } \\
\text { 280deg / Anneal } \\
\text { 380deg 20min }\end{array}$ & $\begin{array}{l}85-95 \\
(\text { Avg. } \\
90)\end{array}$ & $4 \mathrm{hr}$ & $\begin{array}{l}40 \mathrm{ml} \text {, covered, } \\
\text { face down, slowly } \\
\text { add solution ( } 3 \mathrm{ml} \\
\text { or less /time), to } \\
\text { maintain volume } \\
\text { and T }\end{array}$ \\
\hline
\end{tabular}




\begin{tabular}{|c|c|c|c|c|c|c|c|}
\hline \multicolumn{8}{|c|}{ ZnO Sample Preparation by Aqueous Chemical Growth (ACG) on Silicon } \\
\hline No. & Date & ID & Solution & Pre-Growth & $\begin{array}{c}\text { Temp. } \\
\left({ }^{\circ} \mathrm{C}\right)\end{array}$ & Time & NOTES: \\
\hline 10 & $7 / 7 / 2010$ & A10 & $\begin{array}{c}.02 \mathrm{M} \text { Zinc } \\
\text { Nitrate/.02 } \\
\text { methenamine }\end{array}$ & $\begin{array}{c}10 \text { sprays Zinc } \\
\text { acetate (every } 30 \\
\text { sec) at } 280 \mathrm{deg} / \\
\text { Anneal } 380 \mathrm{deg} \\
20 \mathrm{~min}\end{array}$ & $\begin{array}{l}85-95 \\
\text { (Avg. } \\
90)- \\
\text { more } \\
\text { variation }\end{array}$ & $4 \mathrm{hr}$ & $\begin{array}{c}\text { 40ml, covered, no } \\
\text { stir, slowly add } \\
\text { more solution. } \\
\text { New hot plate- } \\
\text { more variability. } \\
\text { Solution older, } \\
\text { more white } \\
\text { platelets. }\end{array}$ \\
\hline 11 & $7 / 8 / 2010$ & A11 & $\begin{array}{c}.02 \mathrm{M} \text { Zinc } \\
\text { Nitrate/.02 } \\
\text { methenamine }\end{array}$ & $\begin{array}{c}5 \text { sprays Zinc } \\
\text { acetate (every } 30 \\
\text { sec) at } 280 \mathrm{deg} / \\
\text { Anneal } 380 \mathrm{deg} \\
20 \mathrm{~min}\end{array}$ & $\begin{array}{c}85-95 \\
\text { (Avg. } \\
90)\end{array}$ & $4 \mathrm{hr}$ & $\begin{array}{l}\text { 40ml, covered, no } \\
\text { stir, good angle, } \\
\text { didn't monitor } \\
\text { temp. Slowly add } \\
\text { solution. New } \\
\text { Solution }\end{array}$ \\
\hline 12 & $7 / 13 / 2010$ & A12 & $\begin{array}{c}.02 \mathrm{M} \text { Zinc } \\
\text { Nitrate/.02 } \\
\text { methenamine }\end{array}$ & $\begin{array}{c}40 \text { sprays Zinc } \\
\text { acetate (every } 30 \\
\text { sec) at } 280 \mathrm{deg} / \\
\text { Anneal } 380 \mathrm{deg} \\
20 \mathrm{~min}\end{array}$ & -95 & $4 \mathrm{hr}$ & $\begin{array}{c}40 \mathrm{ml} \text {, good angle, } \\
\text { boiled for about } \\
10 \mathrm{~min} \text { after half } \\
\text { hour. Started A13 } \\
\text { AT THIS POINT. } \\
\text { Slowly add } \\
\text { solution. Boil } \\
\text { again... }\end{array}$ \\
\hline 13 & $7 / 13 / 2010$ & A13 & $\begin{array}{c}.02 \mathrm{M} \text { Zinc } \\
\text { Nitrate/.02 } \\
\text { methenamine }\end{array}$ & $\begin{array}{c}40 \text { sprays Zinc } \\
\text { acetate (every } 30 \\
\text { sec) at } 280 \mathrm{deg} / \\
\text { Anneal } 380 \mathrm{deg} \\
20 \mathrm{~min}\end{array}$ & 88 & $4 \mathrm{hr}$ & $\begin{array}{c}\text { 40ml, covered, } \\
\text { small piece, had } \\
\text { to prop up. Did } \\
\text { not monitor temp } \\
\text { CONSISTENTLY } \\
\text { LOWER THAN } \\
\text { A12!!! }\end{array}$ \\
\hline 14 & $7 / 20 / 2010$ & A14 & $\begin{array}{c}.02 \mathrm{M} \text { Zinc } \\
\text { Nitrate/.02 } \\
\text { methenamine }\end{array}$ & $\begin{array}{c}20 \text { sprays Zinc } \\
\text { acetate (every } 30 \\
\text { sec) at } 280 \mathrm{deg} / \\
\text { Anneal } \\
\text { 380deg20min }\end{array}$ & $\begin{array}{c}85-95 \\
\text { (Avg. } \\
90)\end{array}$ & $4 \mathrm{hr}$ & $\begin{array}{c}\text { 40ml, covered, no } \\
\text { stir, good } \\
\text { angle, Good } \\
\text { temperature } \\
\text { control, usually } \\
\text { below 90C avg } \\
\text { 87C }\end{array}$ \\
\hline 15 & $7 / 20 / 2010$ & A15 & $\begin{array}{c}.02 \mathrm{M} \text { Zinc } \\
\text { Nitrate/.02 } \\
\text { methenamine }\end{array}$ & $\begin{array}{c}10 \text { sprays Zinc } \\
\text { acetate (every } 30 \\
\text { sec) at } 280 \mathrm{deg} / \\
\text { Anneal } 380 \mathrm{deg} \\
20 \mathrm{~min}\end{array}$ & $\begin{array}{l}85-95 \\
\text { (Avg. } \\
90)\end{array}$ & $4 \mathrm{hr}$ & $\begin{array}{c}\text { Good temperature } \\
\text { control, usually } \\
\text { below 90C avg } \\
87 \mathrm{C} \text { (not } \\
\text { monitored) }\end{array}$ \\
\hline 16 & $7 / 28 / 2010$ & A16 & $\begin{array}{c}.02 \mathrm{M} \text { Zinc } \\
\text { Nitrate/.02 } \\
\text { methenamine }\end{array}$ & $\begin{array}{l}\text { 40sprays Zinc } \\
\text { acetate (every } 30 \\
\text { sec) at } 280 \mathrm{deg} / \\
\text { Anneal } 380 \mathrm{deg} \\
20 \mathrm{~min}\end{array}$ & $\begin{array}{c}85-95 \\
\text { (Avg. } \\
90)\end{array}$ & $4 \mathrm{hr}$ & \\
\hline
\end{tabular}




\begin{tabular}{|c|c|c|c|c|c|c|c|}
\hline \multicolumn{8}{|c|}{ ZnO Sample Preparation by Aqueous Chemical Growth (ACG) on Silicon } \\
\hline No. & Date & ID & Solution & Pre-Growth & $\begin{array}{c}\text { Temp. } \\
\left({ }^{\circ} \mathrm{C}\right)\end{array}$ & Time & NOTES: \\
\hline 17 & $4 / 2 / 2011$ & A19 & $\begin{array}{c}.02 \mathrm{M} \text { Zinc } \\
\text { Nitrate/.02 } \\
\text { methenamine }\end{array}$ & $\begin{array}{l}\text { 40sprays Zinc acetate } \\
\text { (every } 30 \mathrm{sec} \text { ) at } \\
\text { 280deg / Anneal } \\
\text { 380deg } 20 \mathrm{~min}\end{array}$ & $85-90$ & $4 \mathrm{hr}$ & $\begin{array}{l}\text { 40ml, covered, } \\
\text { no stir. Avg } \\
\text { 87C. Large } \\
\text { sample size, } \\
\text { overall good } \\
\text { coverage. }\end{array}$ \\
\hline 18 & $4 / 14 / 2011$ & A 20 & $\begin{array}{c}.01 \mathrm{M} \text { Zinc } \\
\text { Nitrate/.02 } \\
\text { methenamine }\end{array}$ & $\begin{array}{l}\text { 40sprays Zinc acetate } \\
\text { (every } 30 \mathrm{sec} \text { ) at } \\
\text { 280deg / Anneal } \\
\text { 380deg } 20 \mathrm{~min}\end{array}$ & 90 & $5 \mathrm{hr}$ & $\begin{array}{c}\text { Good } \\
\text { temperature } \\
\text { control 90C. } \\
\text { Appears like } \\
\text { little or no wire } \\
\text { growth }\end{array}$ \\
\hline 19 & $4 / 15 / 2011$ & A 21 & $\begin{array}{c}.02 \mathrm{M} \text { Zinc } \\
\text { Nitrate/.02 } \\
\text { methenamine }\end{array}$ & $\begin{array}{c}4 \text { turns } \mathrm{TiO} 210 \% \text { vol } \\
\text { in ISP at } \\
\text { 2500RPM,/30sec, } \\
\text { anneal 5min at } 250 \mathrm{C} \\
\text { and } 380 \mathrm{deg} 1 \mathrm{hr} \text {. } \\
\text { 40sprays Zinc acetate } \\
\text { (every } 30 \mathrm{sec} \text { ) at } \\
\text { 280deg / Anneal } \\
\text { 380deg 20min }\end{array}$ & 90 & $4 \mathrm{hr}$ & $\begin{array}{l}\text { Thick, non } \\
\text { uniform TiO2 } \\
\text { layer - Good } \\
\text { wire growth }\end{array}$ \\
\hline 20 & $4 / 20 / 2011$ & A22 & $\begin{array}{c}.02 \mathrm{M} \text { Zinc } \\
\text { Nitrate/.02 } \\
\text { methenamine }\end{array}$ & $\begin{array}{l}1 \text { turn TiO2 } 10 \% \text { vol } \\
\text { in ISP at } \\
\text { 2500RPM,/30sec, } \\
\text { anneal 5min at } \\
\text { 100Cand 380deg } 1 \mathrm{hr} \text {. } \\
\text { 40sprays Zinc acetate } \\
\text { (every 30 sec) at } \\
\text { 280deg / Anneal } \\
\text { 380deg 20min }\end{array}$ & $88-92$ & $4 \mathrm{hr}$ & $\begin{array}{c}\text { Thin } \mathrm{TiO} 2 \\
\text { layer. }\end{array}$ \\
\hline 21 & $5 / 11 / 2011$ & A23 & $\begin{array}{c}.02 \mathrm{M} \text { Zinc } \\
\text { Nitrate/.02 } \\
\text { methenamine }\end{array}$ & $\begin{array}{l}\text { 40sprays Zinc acetate } \\
\text { (every } 30 \mathrm{sec} \text { ) at } \\
\text { 280deg / Anneal } \\
\text { 380deg } 20 \mathrm{~min}\end{array}$ & $88-92$ & $3.75 \mathrm{hr}$ & $\begin{array}{c}\text { Growth on } \\
\text { large silicon } \\
\text { substrate. Good } \\
\text { nanowire } \\
\text { coverage, not } \\
\text { entirely } \\
\text { uniform across } \\
\text { large substrate } \\
\text { area. }\end{array}$ \\
\hline
\end{tabular}




\begin{tabular}{|c|c|c|c|c|c|c|}
\hline \multicolumn{7}{|c|}{ Electrodeposited ZnO Nanowires on ITO/ Glass } \\
\hline No. & Date & ID & SAMPLE & Preparation & Anneal & Remarks \\
\hline 1 & $11 / 18 / 2009$ & G1 & $\begin{array}{l}\text { ZnO/ITO } \\
\text { WIRES }\end{array}$ & $\begin{array}{l}\text { Electrodeposition } \\
\mathrm{ZnCl} / \mathrm{KCl} / \mathrm{AlCl} 3 ; \\
\text { 3600s; -1.00V; } \\
\text { 80degC }\end{array}$ & $\begin{array}{l}2 \mathrm{hr} @ \\
380 \mathrm{C}\end{array}$ & Stubby Wires \\
\hline 2 & $11 / 25 / 2009$ & NA & $\begin{array}{l}\text { ZnO/ITO } \\
\text { Planar }\end{array}$ & Spray 45 Layers & $\begin{array}{l}2 \mathrm{hr} @ \\
380 \mathrm{C}\end{array}$ & $\begin{array}{l}\text { Didn't Work - } \\
\text { Not hot enough } \\
\text { at } 180 \mathrm{C}\end{array}$ \\
\hline 3 & $12 / 16 / 2009$ & $\mathrm{G} 2$ & $\begin{array}{l}\mathrm{ZnO} / \mathrm{ITO} \\
\text { WIRES }\end{array}$ & $\begin{array}{l}\text { Electrodeposition } \\
\mathrm{ZnCl} / \mathrm{KCl} / \mathrm{AlCl} 3 ; \\
3600 \mathrm{~s} ;-1.05 \mathrm{~V} ; \\
\text { 80degC }\end{array}$ & $\begin{array}{l}2 \mathrm{hr} @ \\
380 \mathrm{C}\end{array}$ & $\begin{array}{l}\text { Good wires- } \\
\text { SEM image } \\
\text { files }\end{array}$ \\
\hline 4 & $1 / 4 / 2010$ & G3 & $\begin{array}{l}\text { ZnO/ITO } \\
\text { WIRES }\end{array}$ & $\begin{array}{l}\text { Electrodeposition } \\
\mathrm{ZnCl} / \mathrm{KCl} / \mathrm{AlCl} 3 ; \\
3600 \mathrm{~s} ;-1.10 \mathrm{~V} ; \\
\text { 80degC }\end{array}$ & $\begin{array}{l}2 \mathrm{hr} @ \\
380 \mathrm{C}\end{array}$ & $\begin{array}{l}\text { Contamination; } \\
\text { Platelets } \\
\text { formed. }\end{array}$ \\
\hline 5 & $1 / 8 / 2010$ & NA & $\begin{array}{l}\mathrm{ZnO} / \mathrm{ITO} \\
\text { Planar }\end{array}$ & $\begin{array}{l}\text { Spray } 43 \text { Layers of } \\
\text { Zinc Acetate at } \\
\text { 280deg }\end{array}$ & $\begin{array}{l}1 \mathrm{hr} @ \\
380 \mathrm{C}\end{array}$ & $\begin{array}{l}\text { Uniform } \\
\text { Deposition; } \\
\text { transparent but } \\
\text { unknown } \\
\text { thickness }\end{array}$ \\
\hline 6 & $\begin{array}{c}2 / 4 / 2010 \text { and } \\
\text { 2/5/2010 }\end{array}$ & G4 & $\begin{array}{l}\mathrm{ZnO} / \mathrm{ITO} \\
\text { Planar with } \\
\text { ZnOSpray }\end{array}$ & $\begin{array}{l}\text { Electrodeposition } \\
\mathrm{ZnCl} / \mathrm{KCl} / \mathrm{AlCl} 3 ; \\
3600 \mathrm{~s} ;-1.05 \mathrm{~V} ; \\
\text { 80degC; Spray } 30 \\
\text { layers at 280degC }\end{array}$ & $\begin{array}{l}2 \mathrm{hr} @ \\
380 \mathrm{C}\end{array}$ & $\begin{array}{l}\text { SEM images - } \\
\text { thick wires } \\
\text { with some } \\
\text { scattered } \mathrm{ZnO} \\
\text { on top }\end{array}$ \\
\hline 7 & $\begin{array}{l}\text { 2/10/10 and } \\
\text { 2/11/10 }\end{array}$ & G5a & $\begin{array}{l}\mathrm{ZnO} / \mathrm{ITO} \\
\text { Planar with } \\
\text { PVK spin } \\
\text { coat }\end{array}$ & $\begin{array}{l}\text { Electrodeposition } \\
\mathrm{ZnCl} / \mathrm{KCl} / \mathrm{AlCl} 3 ; \\
3600 \mathrm{~s} ;-1.05 \mathrm{~V} ; \\
\text { 80degC; Spin coat } \\
\text { with PVK dilute with } \\
\text { Chloroform }(10 \mathrm{~g} / \mathrm{l}) \\
\end{array}$ & $\begin{array}{l}\text { UV light } \\
2 * 5 \mathrm{~min}\end{array}$ & $\begin{array}{l}2 \text { drop coats } \\
\text { and spins }\end{array}$ \\
\hline 8 & $\begin{array}{l}2 / 10 / 10 \text { and } \\
2 / 11 / 10\end{array}$ & G5b & $\begin{array}{l}\mathrm{ZnO} / \mathrm{ITO} \\
\text { Planar with } \\
\mathrm{TiO} 2 \text { drop }\end{array}$ & $\begin{array}{l}\text { Electrodeposition } \\
\mathrm{ZnCl} / \mathrm{KCl} / \mathrm{AlCl} 3 ; \\
\text { 3600s; -1.05V; } \\
\text { 80degC; Drop coat } \\
\text { TiO2 nanoparticles at } \\
\text { 50degC; blow off } \\
\text { excess }\end{array}$ & $\begin{array}{l}2 \mathrm{hr} @ \\
380 \mathrm{C}\end{array}$ & $\begin{array}{l}\text { Drop coat } 1 \\
\text { time }\end{array}$ \\
\hline
\end{tabular}




\begin{tabular}{|c|c|c|c|c|c|c|}
\hline \multicolumn{7}{|c|}{ Electrodeposited ZnO Nanowires on ITO/Silicon } \\
\hline No. & Date & ID & SAMPLE & $\begin{array}{c}\text { Pre- } \\
\text { growth }\end{array}$ & Growth & Notes \\
\hline 1 & $7 / 22 / 2010$ & I1 & $\mathrm{ZnO} / \mathrm{ITO} / \mathrm{Si}$ & None & $\begin{array}{c}\text { Electrodeposition } \\
\text { ZnCl/KCl/AlCl3; } \\
\text { 3600s; -1.05V; } \\
\text { 80degC; }\end{array}$ & $\begin{array}{c}\text { Problem with } \\
\text { electrode at first. } \\
\text { Current roughly } \\
9 \mathrm{e}-3 .\end{array}$ \\
\hline 2 & $4 / 6 / 2011$ & $\mathrm{I} 2$ & $\mathrm{ZnO} / \mathrm{ZnO} / \mathrm{ITO} / \mathrm{Si}$ & $\begin{array}{c}40 \\
\text { sprays } \\
\text { zinc } \\
\text { acetate }\end{array}$ & $\begin{array}{c}\text { Electrodeposition } \\
\mathrm{ZnCl} / \mathrm{KCl} / \mathrm{AlCl} 3 ; \\
\text { 3600s; -1.05V; } \\
\text { 80degC; }\end{array}$ & $\begin{array}{c}\text { Current roughly } \\
5 \mathrm{e}-3 \mathrm{~A}\end{array}$ \\
\hline 3 & $4 / 13 / 2011$ & I3 & $\mathrm{ZnO} / \mathrm{ITO} / \mathrm{Si}$ & none & $\begin{array}{c}\text { Electrodeposition } \\
\mathrm{ZnCl} / \mathrm{KCl} / \mathrm{AlCl} 3 ; \\
\text { 3600s; -1.05V; } \\
\text { 80degC; }\end{array}$ & $\begin{array}{c}\text { Current roughly } \\
4 \mathrm{e}-3 \mathrm{~A}\end{array}$ \\
\hline
\end{tabular}




\subsection{APPENDIX 2}

Example of sngle depedent reflectance measurements measured using Fluorolog III.

\begin{tabular}{|c|c|c|c|c|c|}
\hline \multicolumn{7}{|c|}{ Silicon - 500nm } \\
\hline Angle & $\mathbf{1}$ & $\mathbf{2}$ & $\mathbf{3}$ & Avg. & STDEV \\
\hline 15 & 249691 & 250236 & 249997 & 249974.67 & 273.18553 \\
\hline 20 & 247982 & 248085 & 247828 & 247965 & 129.34064 \\
\hline 25 & 245550 & 246131 & 245507 & 245729.33 & 348.51734 \\
\hline 30 & 243075 & 244349 & 243661 & 243695 & 637.68017 \\
\hline 35 & 247631 & 247037 & 246838 & 247168.67 & 412.5704 \\
\hline 40 & 270762 & 269821 & 270510 & 270364.33 & 487.1184 \\
\hline 45 & 335227 & 335548 & 335962 & 335579 & 368.47931 \\
\hline 50 & 487962 & 486893 & 487463 & 487439.33 & 534.89282 \\
\hline 55 & 534133 & 532962 & 533308 & 533467.67 & 601.60646 \\
\hline 60 & 560867 & 562692 & 562887 & 562148.67 & 1114.2299 \\
\hline
\end{tabular}




\subsection{APPENDIX 3}

\section{Example of Tranfer Matrix Method (TMM) code written for MATLAB to find the}

\section{total reflectances of layers.}

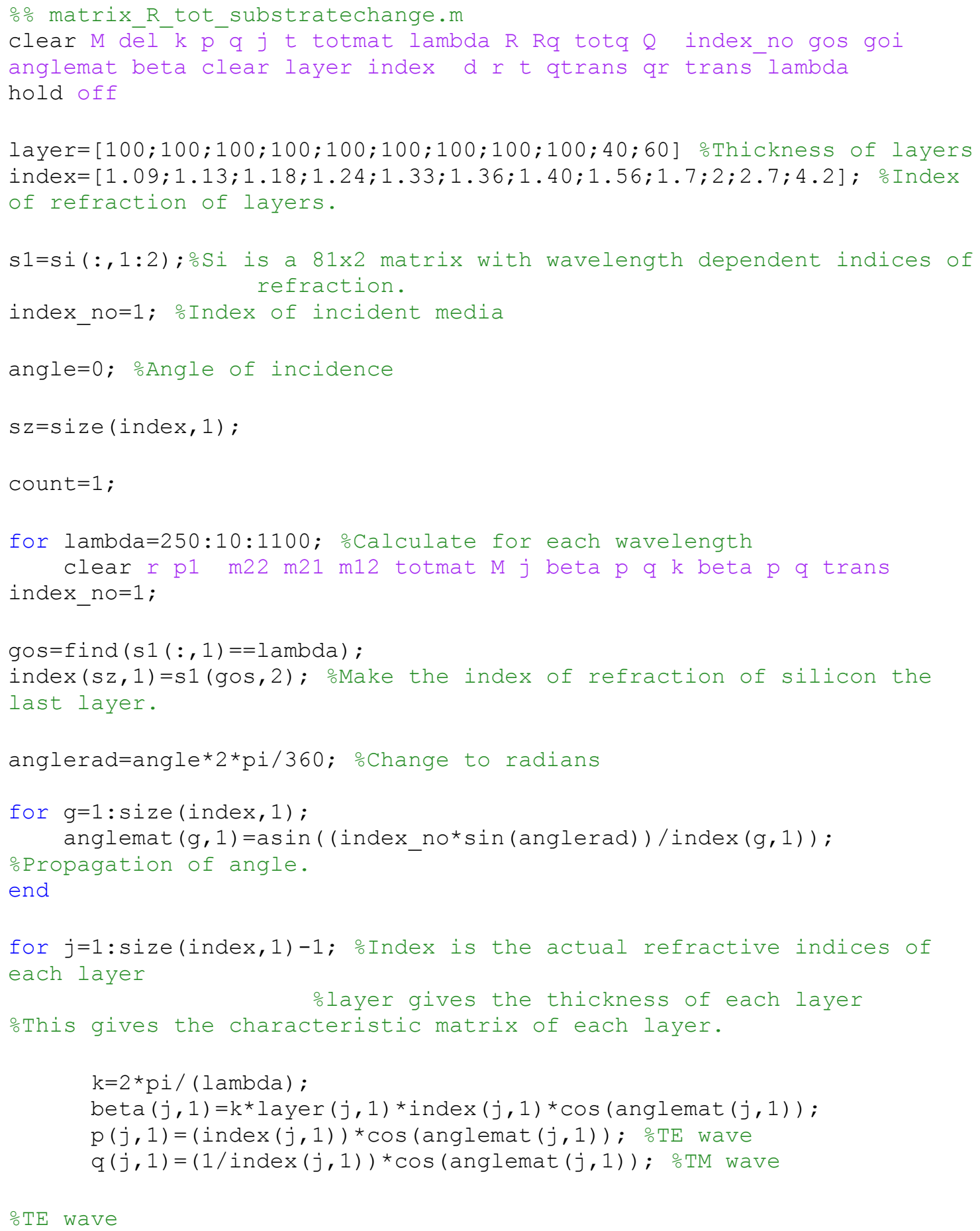




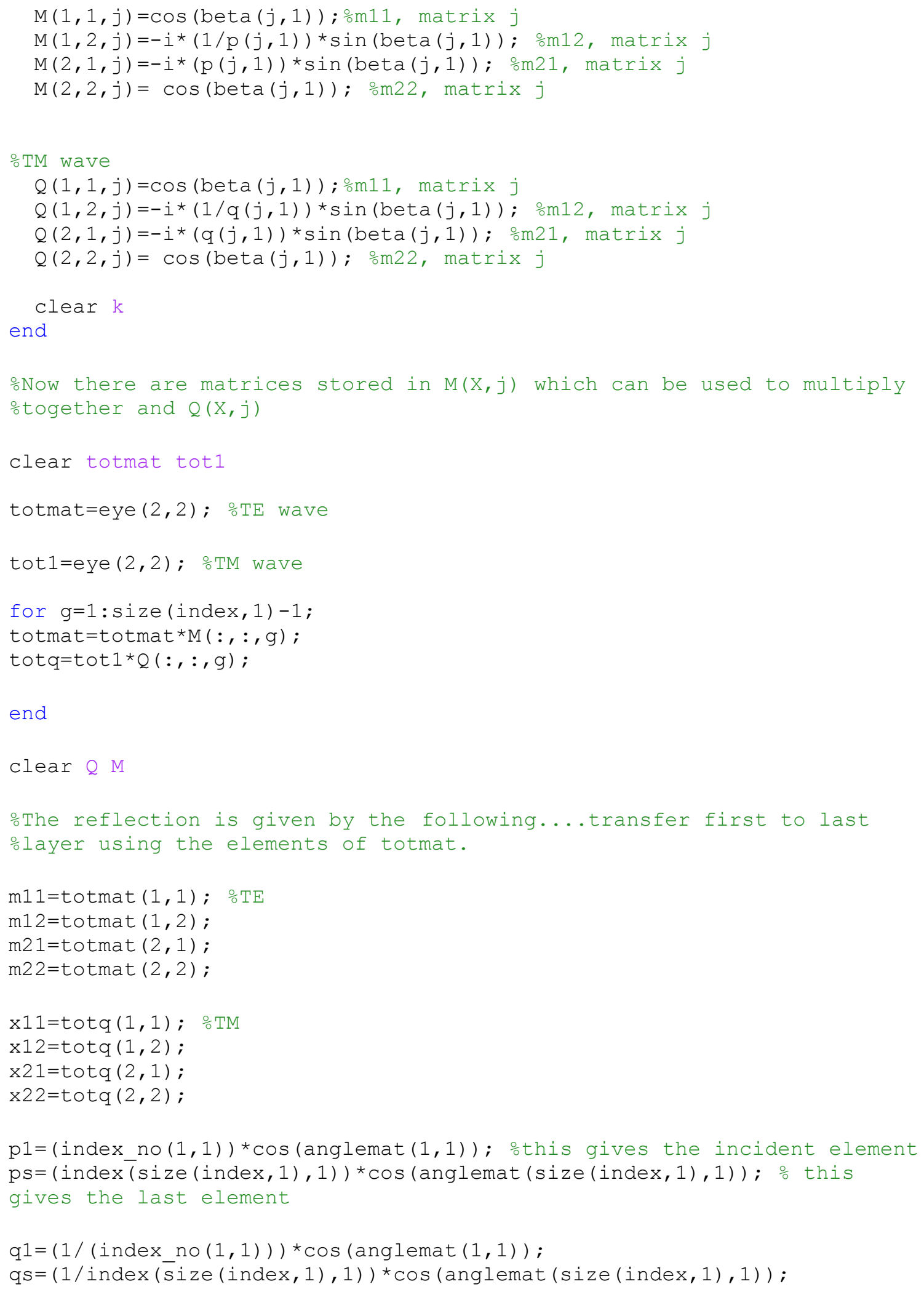




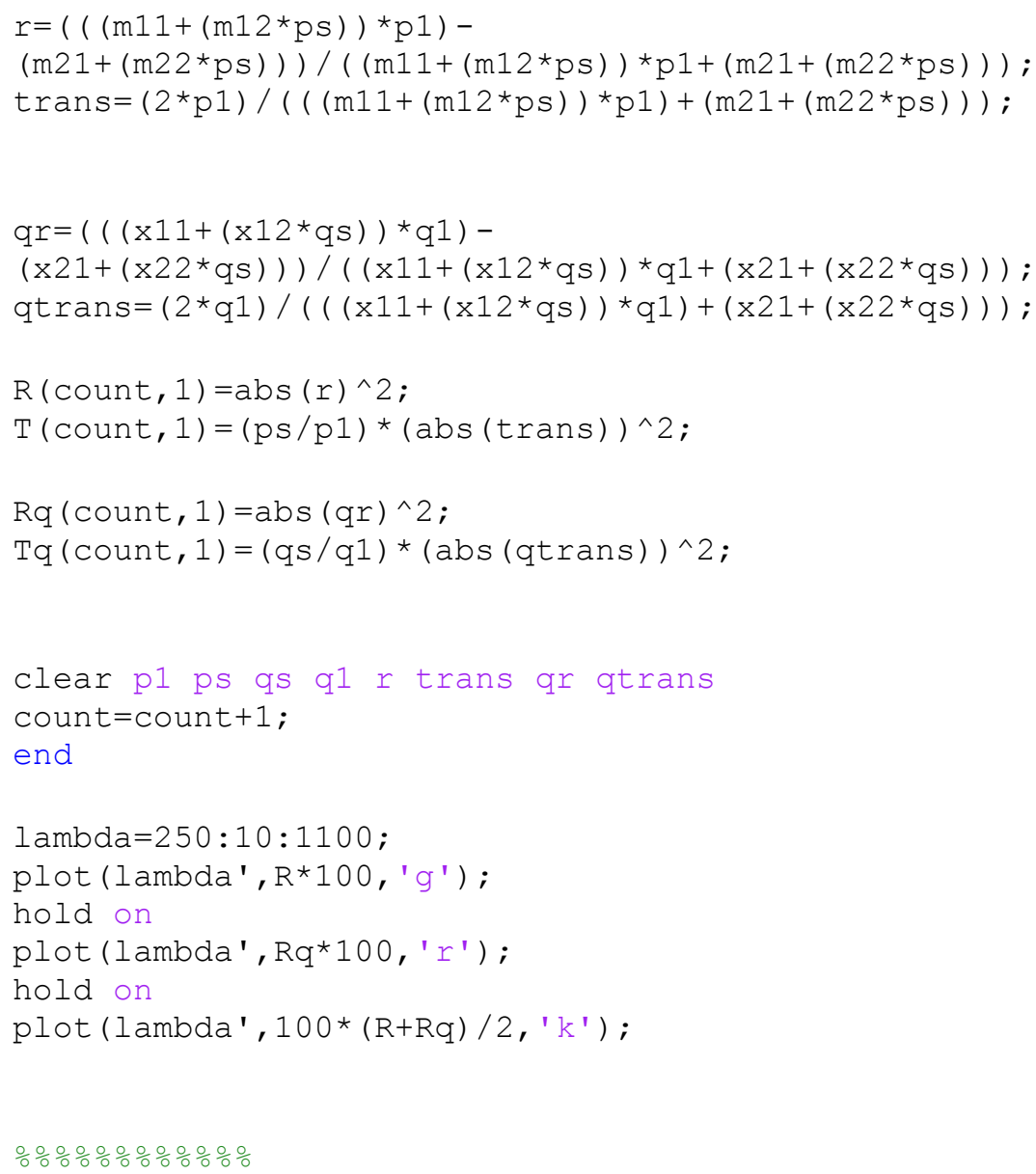

